INSTITUTO DE PESQUISAS ENERGÉTICAS E NUCLEARES

Autarquia associada à Universidade de São Paulo

\title{
AVALIAÇÃO DA ALTERAÇÃO NAS PROPRIEDADES DA PASTA DE CIMENTO EM AMBIENTE DE REPOSITÓRIO
}

EDUARDO GURZONI ALVARES FERREIRA

Dissertação apresentada como parte dos requisitos para obtenção do Grau de Mestre em Ciências na Área de Tecnologia Nuclear - Aplicações

Orientador:

Prof. Dr. Júlio Takehiro Marumo

Versão Corrigida

Versão Original disponível no IPEN

São Paulo

2013 
Dedico este trabalho, que marca o final de um importante ciclo da minha vida, a todos os meus amigos verdadeiros, que irão se identificar aqui, pelo todo apoio e amparo, todas as vezes que fora preciso, por diversos motivos, com dedicação e boa vontade! 


\section{AGRADECIMENTOS}

Ao Prof. Dr. Júlio Takehiro Marumo, pela orientação, dedicação e comprometimento ao longo deste trabalho, além dos ensinamentos e conselhos pessoais e profissionais durante todo o período em que trabalhei sob sua orientação.

Ao Prof. Dr. Roberto Vicente, pela coorientação, pela oportunidade de ingressar na vida acadêmica na iniciação científica, pelas valiosas contribuições neste trabalho e pelos diversos momentos de descontração e aconselhamentos durante todos esses anos juntos nessa jornada.

À Vera Lúcia Keiko Isiki e à Hissae Miyamoto pela grande contribuição durante todo o projeto realizado no IPEN, desde os ensaios preliminares até os ensaios finais, estando sempre à disposição para auxiliar no laboratório.

Ao Laboratório de Materiais de Construção Civil do Instituto de Pesquisas Tecnológicas (IPT), pela infraestrutura e pessoal disponibilizado para a realização das etapas preliminares deste ensaio.

Aos laboratórios e centros de pesquisas (CQMA-IPEN, LAPOC-CNEN, LCTPOLI-USP, LCM-CTMSP e LMM-CCTM-IPEN) que contribuíram com as análises e interpretação de resultados.

Ao Dr. Luciano Gobbo, pelo auxílio na análise e interpretação de alguns dados deste trabalho.

Aos meus pais e irmãos, Eliane, Nuno, Fernando e Juliana, e ao Ricardo, por acreditarem em mim e pelo apoio durante os períodos mais difíceis deste mestrado.

Aos amigos e colegas de GRR, Ana Paula, Bianca, Daiane, Heverton, Isis, Josenílson, Leandro, Maria Eugênia, Marcos, Maurício, Patrícia, Priscila, Rafael, Vanessa e todos aqueles que trabalharam e me ajudaram na GRR, pela amizade, pelos inesquecíveis momentos de descontração e alegria durante todos esses anos.

Ao CNPQ e à AIEA, pelo auxílio financeiro no mestrado e no projeto de pesquisa do GRR. 
"Julgue seu sucesso pelas coisas que você teve que renunciar para conseguir."

Dalai Lama

"Existem muitas hipóteses em ciência que estão erradas. Isso é perfeitamente aceitável, eles são a abertura para achar as que estão

certas."

Carl Sagan 


\section{AVALIAÇÃO DA ALTERAÇÃO NAS PROPRIEDADES DA PASTA DE CIMENTO EM AMBIENTE DE REPOSITÓRIO}

\section{Eduardo Gurzoni Alvares Ferreira}

\section{RESUMO}

Pasta de cimento é um material comum em repositórios para rejeitos radioativos, atuando como material estrutural e de imobilização. Sua utilização como material de preenchimento em um repositório tipo poço tubular profundo para fontes seladas, no entanto, requer um maior tempo de vida útil do material. O conhecimento de seu comportamento em longo prazo é necessário para garantir a segurança da instalação em milhares de anos. O presente trabalho avaliou as alterações na pasta de cimento induzidas por fatores de degradação, como ataque de agentes agressivos, alta temperatura e presença de campo de radiação. Corpos de prova (cps) de pasta de cimento foram submetidos a ensaios acelerados de degradação e os efeitos deletérios foram avaliados por meio de ensaios de resistência mecânica, variação dimensional, lixiviação/penetração de íons, DRX, TGA e MEV. Observou-se que a hidratação dos cps foi beneficiada pela imersão (em água destilada ou em solução salina) e alta temperatura, resultando em uma resistência maior. $\mathrm{O}$ armazenamento à seco prejudicou a hidratação, mantendo a resistência mais baixa. O tempo de imersão e a irradiação não foram capazes de alterar a mineralogia e a resistência da pasta de cimento. 


\title{
ASSESSMENT OF CEMENT PASTE PROPERTIES CHANGES IN REPOSITORY ENVIRONMENT
}

\section{Eduardo Gurzoni Alvares Ferreira}

\begin{abstract}
Cement paste is widely used in repositories for radioactive wastes, acting as structural and immobilization material. However, its use as backfill material in boreholes for sealed sources requires a longer service life of this material. The assessment of the cement paste behavior in long term is needed to improve the confidence that the material will perform as required during the service life of the facility. This research evaluated the changes in cement paste induced by degradation parameters. Portland cement paste specimens (cps) were submitted to accelerated degradation tests and the damage effects was evaluated by mechanical strength, variation of sample mass and volume, leaching/penetration of ions, XRD, TGA and SEM. It was observed that cps hydration was benefited by immersion (in distilled water or salt solution) and high temperatures, resulting in a higher strength. Dry storage, however, influenced the hydration process and maintained strength lower. Time of treatment and irradiation were not able to alter mineralogy and durability of cement paste.
\end{abstract}




\section{SUMÁRIO}

Página

1. INTRODUÇÃ

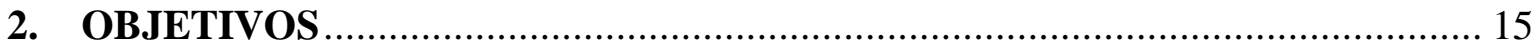

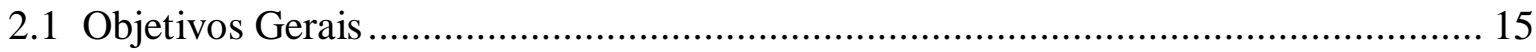

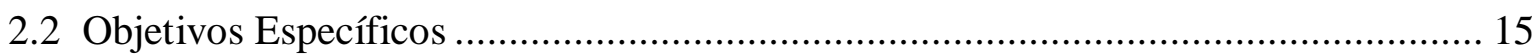

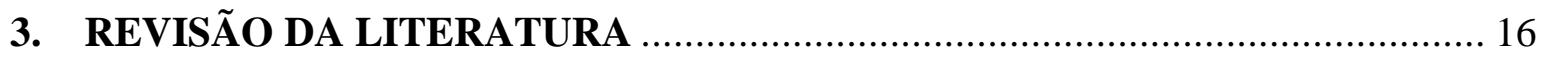

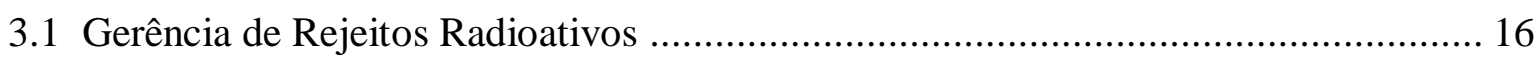

3.2 Deposição de fontes em borehole ...................................................................... 19

3.3 O Cimento Portland e sua utilização ..................................................................... 24

3.4 Principais componentes do Cimento Portland anidro ............................................. 27

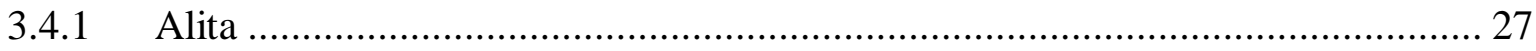

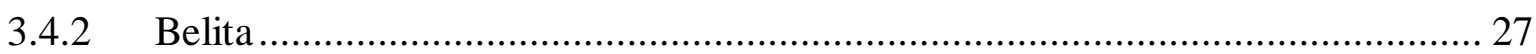

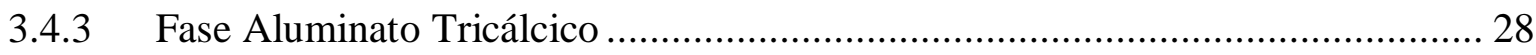

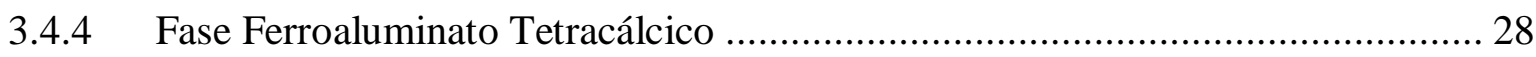

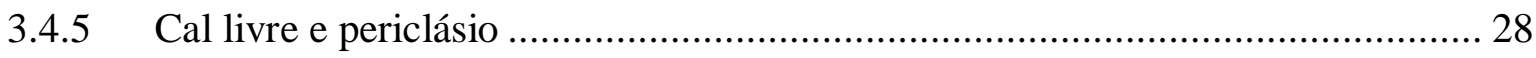

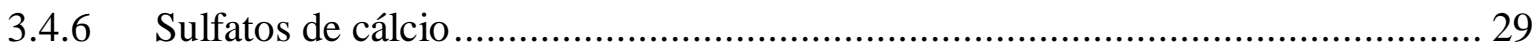

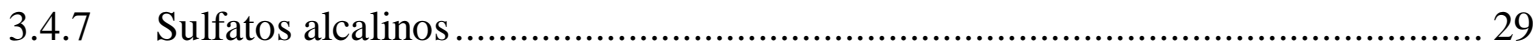

3.4.8 Adições: escória, pozolanas e fíler ................................................................. 29

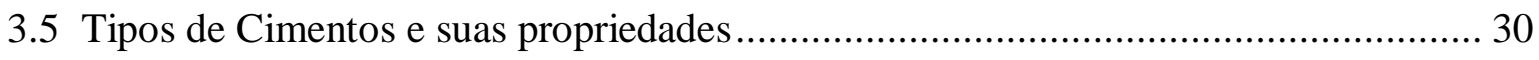

3.6 Propriedades e características importantes do Cimento Portland .............................. 31

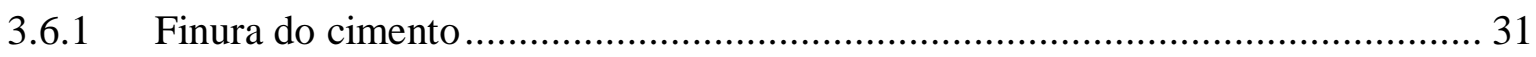

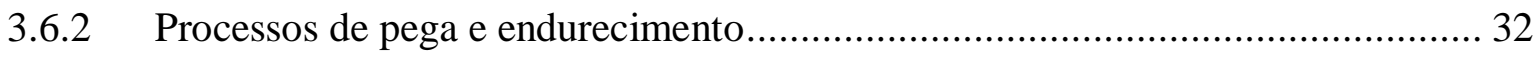

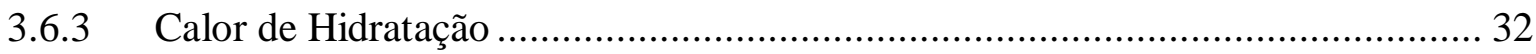

3.7 A hidratação do cimento Portland .............................................................................. 33

3.7.1 A hidratação das fases de silicato de cálcio .................................................... 35

3.7.2 A Hidratação das fases aluminatos ................................................................ 38

3.7.3 Interação entre as fases nos processos de hidratação........................................ 39

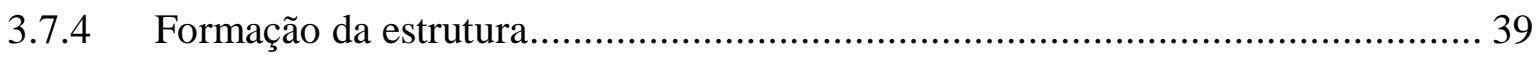

3.7.5 Mecanismos que alteram o processo de hidratação ......................................... 40 
3.8 A durabilidade do cimento Portland .................................................................... 41

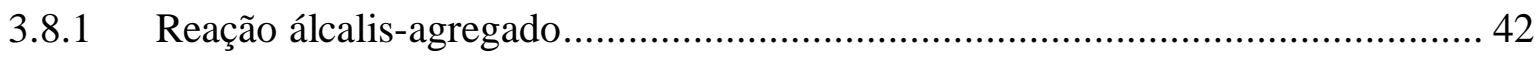

3.8.2 A formação de etringita primária e secundária ............................................... 44

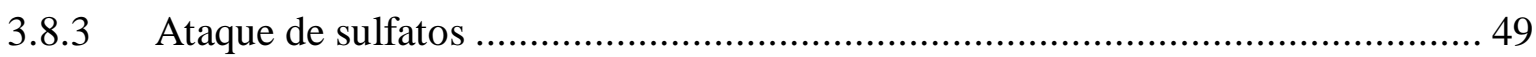

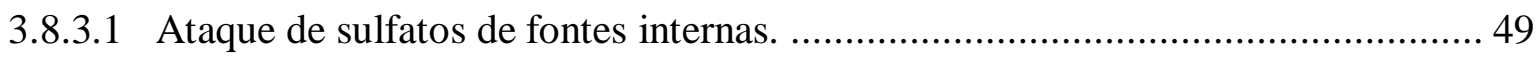

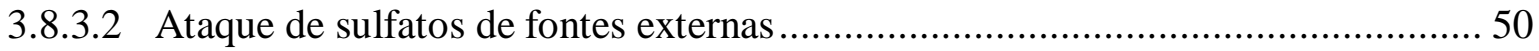

3.8.4 Lixiviação e dissolução de $\mathrm{Ca}(\mathrm{OH})_{2}$ - descalcificação do C-S-H ....................... 52

3.8.5 Diferenças mineralógicas em função da temperatura ...................................... 53

3.8.6 Reação com a formação geológica ................................................................... 54

3.8.7 Comportamento da pasta de cimento sob irradiação ....................................... 54

3.9 Técnicas para análise das propriedades do cimento Portland .................................. 57

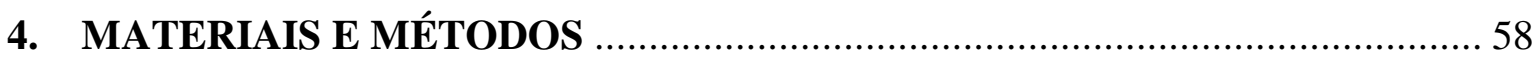

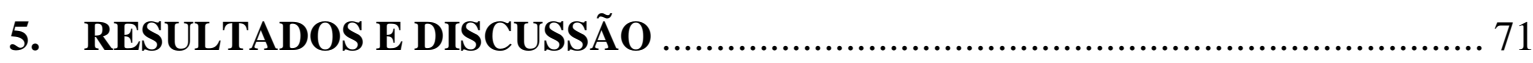

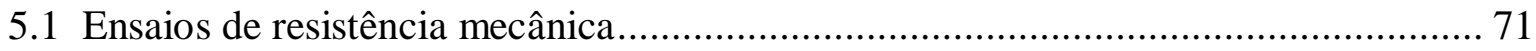

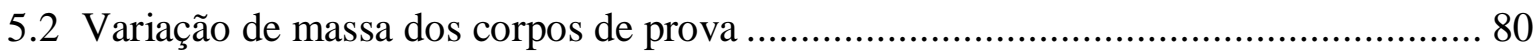

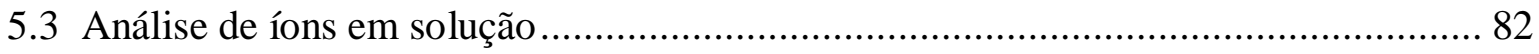

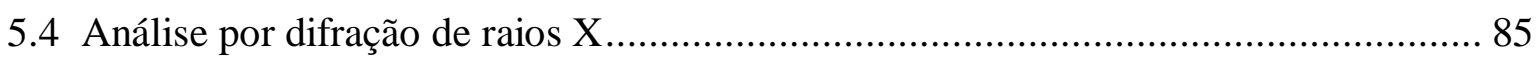

5.5 Análise por microscopia eletrônica de varredura (MEV) …................................. 90

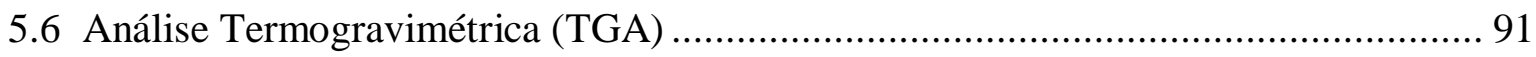

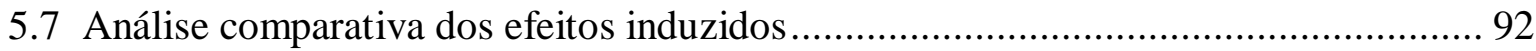

5.7.1 Efeitos da imersão e do armazenamento à seco ............................................... 92

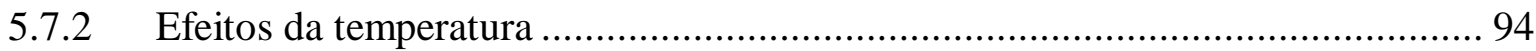

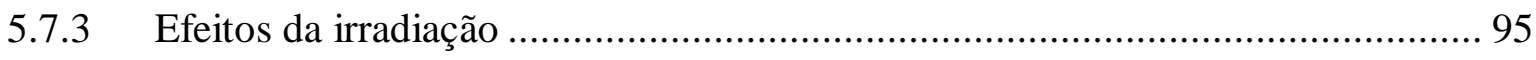

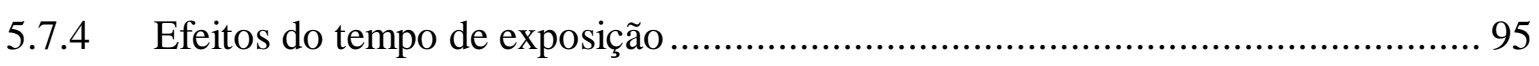

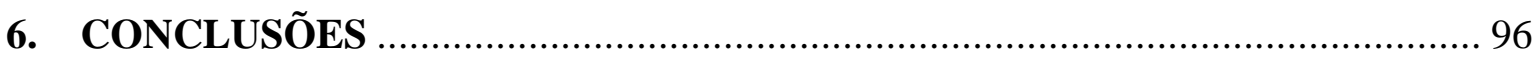

7. SUGESTÃO PARA TRABALHOS FUTUROS ............................................. 98

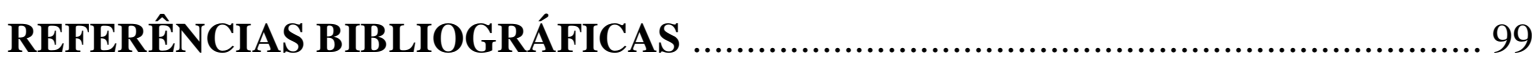




\section{LISTA DE TABELAS}

Página

TABELA 1 - Propriedades dos constituintes principais do cimento Portland (adaptado de SOROKA, 1993)

TABELA 2 - Equivalência entre os Cimentos brasileiros, europeus e americanos e sua composição típica.

TABELA 3 - Composição típica da água subterrânea em meios graníticos (adaptado da literatura). 60

TABELA 4 - Composição da solução salina inicial de imersão das amostras 60

TABELA 5 - Identificação dos lotes e as variáveis dos ensaios acelerados de degradação

TABELA 6 - Condições de coleta dos difratogramas no ensaio por Difração de Raios X 68 TABELA 7 - Valores máximos, médios, medianos, médias e de desvio padrão de cada lote de resistência mecânica dos cps cilíndricos. 72

TABELA 8 - Valores máximos, médios, medianos, médias e de desvio padrão de cada lote de resistência mecânica dos cps cúbicos. 75

TABELA 9 - Análise estatística (teste t) da resistência mecânica de cps submetidos a diferentes tratamentos

TABELA 10 - Identificação das amostras enviadas para análise por difração de raios X. 86

TABELA 11 - Identificação das amostras enviadas para TGA e perda de massa de cada uma nos intervalos de temperatura selecionados. 


\section{LISTA DE FIGURAS}

Página

FIGURA 1 - Fluxograma da gerência de rejeitos radioativos (adaptado de Hiromoto et al, 1999).

FIGURA 2 - O Conceito de repositório profundo para fontes radioativas seladas descartadas. Fonte VICENTE, 2007b 20

FIGURA 3 - Método de encapsulamento das fontes seladas.

FIGURA 4 - Árvore de falhas do cimento em ambiente de repositório (Adaptado de Philipose, 1988)

FIGURA 5 - Taxa de liberação de calor de uma típica pasta de cimento Portland durante as primeiras idades (MEHTA \& MONTEIRO, 2008) 33

FIGURA 6 - Corpos de prova cilíndricos em moldes de plásticos 61

FIGURA 7 - Corpos de prova cilíndricos desmoldados.

FIGURA 8 - Moldes de plásticos utilizados para a confecção dos corpos de prova cúbicos

FIGURA 9 - Corpos de prova cúbicos após a desmoldagem 62

FIGURA 10 - Corpo de prova cilíndrico e o recipiente de imersão 64

FIGURA 11 - Recipientes de imersão dos corpos de prova dentro de banho em alta temperatura

FIGURA 12 - Recipiente de armazenamento seco dos corpos de prova em alta temperatura

FIGURA 13 - Rompimento de corpo de prova cúbico 65

FIGURA 14 - Suporte para o rompimento dos corpos de prova cúbicos..... 66

FIGURA 15 - Máquina de rompimento dos corpos de prova. 66

FIGURA 16 - Corpo de prova cilíndrico após o rompimento 67

FIGURA 17 - Medida do comprimento de corpo de prova cilíndrico 67

FIGURA 18 - Fluxograma da metodologia aplicada neste trabalho 70

FIGURA 19 - Resistência mecânica máxima, mínima e mediana dos cps cilíndricos. ..... 72 FIGURA 20 - Frequência relativa dos cps nos intervalos de pressão de ruptura em diferentes tempos de imersão. 73 
FIGURA 21 - Frequência relativa dos cps nos intervalos de pressão de ruptura em diferentes temperaturas

FIGURA 22 - Frequência relativa dos cps nos intervalos de pressão de ruptura em diferentes doses de irradiação

FIGURA 23 - Frequência relativa dos cps nos intervalos de pressão de ruptura em diferentes meios de imersão. 74

FIGURA 24 - Resistência mecânica máxima, mínima e mediana dos cps cúbicos. 75

FIGURA 25 - Frequência relativa dos cps nos intervalos de pressão de ruptura em diferentes meios de imersão.

FIGURA 26 - Frequência relativa dos cps nos intervalos de pressão de ruptura em diferentes temperaturas.

FIGURA 27 - Frequência relativa dos cps nos intervalos de pressão de ruptura em diferentes tempos de tratamento

FIGURA 28 - Frequência relativa dos cps nos intervalos de pressão de ruptura em diferentes doses de irradiação 78

FIGURA 29 - Variação de massa dos cps cilíndricos antes e após a irradiação. 81

FIGURA 30 - Variação de massa dos cps cúbicos antes e após a irradiação.

FIGURA 31 - Concentração das espécies na água destilada após a imersão dos cps cilíndricos

FIGURA 32 - Razão entre as concentrações finais em relação à inicial das espécies nas soluções salinas após a imersão dos cps cilíndricos 83

FIGURA 33 - Concentração das espécies na água destilada após a imersão dos cps cúbicos

FIGURA 34 - Razão entre as concentrações finais em relação à inicial das espécies nas soluções salinas após a imersão dos cps cúbicos 84

FIGURA 35 - Agrupamento das amostras por semelhanças mineralógicas, obtidas pela análise de cluster de DRX 87

FIGURA 36 - Difratograma de doze amostras de pasta de cimento. 88

FIGURA 37 - Aproximação do difratograma das doze amostras. ................................... 88

FIGURA 38 - Análise semiquantitativa de quatro amostras......................................... 89

FIGURA 39 - Imagem obtida pela MEV do material precipitado na superfície dos cps... 90

FIGURA 40 - Elementos presentes no grão e na agulha do material precipitado.............. 90

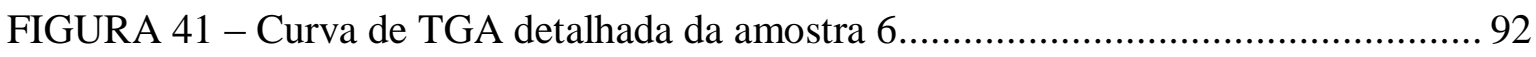




\section{INTRODUÇÃO}

$\mathrm{O}$ advento da tecnologia nuclear trouxe uma série de vantagens para a sociedade e uma diversidade muito grande de aplicações, entre elas está o uso de fontes radioativas seladas na medicina, indústria e pesquisa.

Um dos custos para tais benefícios é a geração de rejeitos radioativos que, assim como os rejeitos comuns, oferecem riscos se não forem gerenciados da forma adequada. Após sua utilização, as fontes são denominadas fontes radioativas seladas descartadas (FRSD). Esse termo é aplicado para fontes que não possam mais ser utilizadas para sua finalidade primária e que não tenham previsão de utilização em nenhuma outra atividade (VICENTE, et al, 2004).

Após serem retiradas de serviço, as FRSD devem ser gerenciadas de forma adequada para garantir a segurança do meio ambiente. A deposição segura e correta de fontes seladas é alvo de preocupações de todos aqueles envolvidos com a gestão de rejeitos radioativos, devido ao uso generalizado, o alto potencial de causar acidentes radiológicos e o grande inventário, na maioria dos países.

No Brasil, os institutos ligados à Comissão Nacional de Energia Nuclear (CNEN) são responsáveis pelo gerenciamento dessas fontes após sua utilização. O inventário brasileiro contava, até 2007, com cerca de 300.000 fontes seladas armazenadas (aguardando decisão sobre a deposição final) ou em uso (fontes que irão se tornar rejeitos no futuro) (VICENTE, 2007a).

As FRSD podem possuir meia-vida de até milhares de anos e atividades, que ultrapassam a ordem de terabecquerel (TBq) (A atividade é medida, no sistema internacional, por becquerel $(\mathrm{Bq})$, que é definido como a quantidade de núcleos radioativos que decai por segundo) (CNEN, 2011). Além disso, seu uso generalizado, o alto potencial de causar acidentes e o grande inventário dessas fontes também são motivos de preocupação no mundo todo. Diversos países estão estudando formas de deposição segura das fontes, porém a maioria ainda realiza o acondicionamento e armazenamento temporário das mesmas, aguardando a decisão sobre sua deposição final (DAYAL, 2004; LEE, et al, 2012; OJOVAN et al, 2003). 
A Gerência de Rejeitos Radioativos (GRR) do IPEN-CNEN/SP está desenvolvendo um conceito de deposição em poço tubular profundo, usualmente chamado borehole na comunidade internacional. Esse repositório deve conter todo o inventário brasileiro e garantir a segurança por milhares de anos, considerando a meia-vida das fontes.

A deposição em poços tubulares possui uma série de vantagens, tanto do ponto de vista tecnológico como de segurança. Algumas vantagens apontadas para a escolha do borehole são seu baixo custo, a facilidade de construção e implementação, proteção radiológica eficaz, segurança a longo prazo, pouco intrusivo no meio ambiente, entre outras (DAYAL, 2004; OJOVAN et al, 2003).

As definições sobre a segurança do repositório são fornecidas pela análise de segurança ou análise de desempenho do repositório. As barreiras artificiais e naturais são consideradas um sistema integrado e elas devem garantir a integridade desse sistema pelo tempo requerido para o decaimento das fontes (VICENTE, 2007b). A durabilidade desses materiais vai depender do comportamento em longo prazo de cada um, submetidos às condições ambientais reinantes no repositório e das interações entre eles (XIE, et al, 2008).

No conceito proposto, o espaço anular entre o tubo e a formação geológica deverá ser preenchido com pasta de cimento Portland para atuar como material estrutural, barreira contra o fluxo de água entre as diferentes camadas do meio geológico, atravessadas pelo poço, e como barreira adicional contra a migração de radionuclídeos para a biosfera, entre outras funções (US-EPA, 1988).

De todas as barreiras do repositório, a pasta de cimento é o material com o menor grau de conhecimento em longo prazo, uma vez que a experiência na utilização desse material é limitada a menos de dois séculos. Além disso, a pasta de cimento é o material mais exposto às condições ambientais severas e sua deterioração nesse ambiente pode levar a falha do sistema. Dessa forma, mais estudos são necessários para melhorar a confiança de que o material terá o desempenho esperado durante toda a vida útil da instalação, prevista para até vários milênios (SCRIVENER \& KIRKPATRICK, 2008; VAN BREUGEL, 2004).

Durante o tempo de vida útil do repositório, de milhares de anos, a pasta de cimento estará exposta a diversos agentes que tendem a degradar e comprometer sua integridade. O comportamento em longo prazo do cimento nessas condições é alvo de pesquisas em diversos países. 
O entendimento das reações químicas que resultam no endurecimento do cimento é fundamental para prever seu desempenho e durabilidade. A análise da durabilidade das estruturas de cimento requer a caracterização e modelagem do comportamento do mesmo em relação à sobrecarga mecânica e degradação química durante a vida útil do repositório.

Em contato prolongado com a água subterrânea, o material cimentício sofre um processo de degradação lento, porém contínuo, que pode comprometer sua integridade durante o período requerido pelo repositório (GALÍNDEZ \& MOLINERO, 2010). Análise da estabilidade dessas estruturas envolve o entendimento do comportamento mecânico e termodinâmico e também da previsão da evolução química do ambiente do repositório, da solução dos poros e das fases do cimento hidratado em idades avançadas (BERNER, 1992; XIE, et al, 2008).

Os mecanismos de degradação podem ser classificados por: a) causas internas, como as reações álcali-agregado, expansão térmica do cimento e agregados, efeitos de deformação e encolhimento, etc; e b) causas externas, como deterioração química por ataques de cloreto, sulfato, lixiviação e dissolução de cálcio (descalcificação, etc) (PHILIPOSE, 1988).

Além de ser o material com o menor grau de conhecimento em longo prazo, a pasta de cimento é o material mais exposto às condições ambientais severas. Dessa forma, é preciso avaliar as alterações que a pasta de cimento sofre no ambiente do repositório para que seja determinado o tempo de vida útil deste material e garantir a segurança da instalação durante o tempo requerido (SCRIVENER \& KIRKPATRICK, 2008). 


\section{OBJETIVOS}

\subsection{Objetivos Gerais}

Avaliar a durabilidade da pasta de cimento no ambiente de repositório profundo para rejeitos radioativos por meio de ensaios acelerados de laboratório e prever o comportamento do material em longo prazo.

\subsection{Objetivos Específicos}

1) Avaliar as alterações nas propriedades de pasta de cimento, induzidas por irradiação, exposição a soluções quimicamente semelhantes às de meios geológicos graníticos e exposição a temperatura esperada na profundidade do repositório.

2) Estabelecer as relações entre o grau de exposição e a intensidade das alterações observadas na resistência à compressão, na composição química e na composição mineralógica da pasta;

3) Avaliar, por meio de ensaios multifatoriais e testes estatísticos apropriados, os efeitos individuais e cruzados dos fatores de degradação;

4) Estabelecer a relação entre a intensidade da exposição e a durabilidade da pasta de cimento. 


\section{REVISÃO DA LITERATURA}

\subsection{Gerência de Rejeitos Radioativos}

$\mathrm{O}$ advento da Tecnologia Nuclear trouxe uma série de vantagens para a sociedade e levou a uma diversidade muito grande de suas aplicações, desde a geração de energia elétrica até o uso de radioisótopos na medicina, agricultura, pesquisa e indústria (MARUMO, 1997).

Uma das aplicações da Tecnologia Nuclear é o uso de fontes radioativas seladas, que são objetos pequenos, de forma cilíndrica e contidas em contêiner de metal. Sua aplicação é corrente em diversas áreas, na medicina, indústria e pesquisa. Na medicina, são usadas em equipamentos de braquiterapia, teleterapia, irradiação de sangue e de tecidos, entre outros. Na indústria, em medidores de espessura, densidade, nível ou de massa, em detectores de fumaça e nos pratos de para-raios radioativos. Na pesquisa em análises físico-químicas, ambientais, agropecuárias e radiológicas (VICENTE, 2002).

$\mathrm{O}$ uso de equipamentos com fontes radioativas vêm crescendo no Brasil nas ultimas décadas. Reis e Heilbron (2000) apontam diversas causas para esse aumento em sua utilização, como: a) o custo competitivo desses equipamentos; b) o crescimento de empresas multinacionais no país (acostumadas com esse tipo de tecnologia em outros países); c) a facilidade de controle e medição que esses equipamentos oferecem; d) a ausência de contato entre o material e o equipamento, evitando problemas de corrosão e abrasão (em medidores de nível ou densidade, por exemplo); e e) a disponibilidade de detectores de alta sensibilidade em pequenos volumes.

O custo para tais benefícios está na geração de rejeitos radioativos que, assim como os rejeitos comuns, oferecem riscos se não forem gerenciados de forma adequada. No Brasil, a Comissão Nacional de Energia Nuclear (CNEN) define rejeito radioativo na norma CNEN-NE-6.05, Gerência de Rejeitos Radioativos em Instalações Radiativas, como qualquer material resultante de atividades humanas que contenha radionuclídeos em quantidades superiores aos limites de isenção e para o qual a reutilização é imprópria ou não prevista (CNEN, 1985).

Após sua utilização, as fontes são denominadas fontes radioativas seladas descartadas (FRSD). As fontes que não podem mais ser utilizadas para sua finalidade 
primária e que não tenham previsão de utilização em nenhuma outra atividade se tornam, dessa forma, rejeitos radioativos (VICENTE, et al, 2004).

O conjunto das atividades realizadas para garantir a destinação correta desses rejeitos é denominado gerência de rejeitos radioativos. Um esquema genérico da gerência de rejeitos está apresentado na FIG. 1 (HIROMOTO et al, 1999). Neste trabalho, apenas a questão da deposição final será abordada.

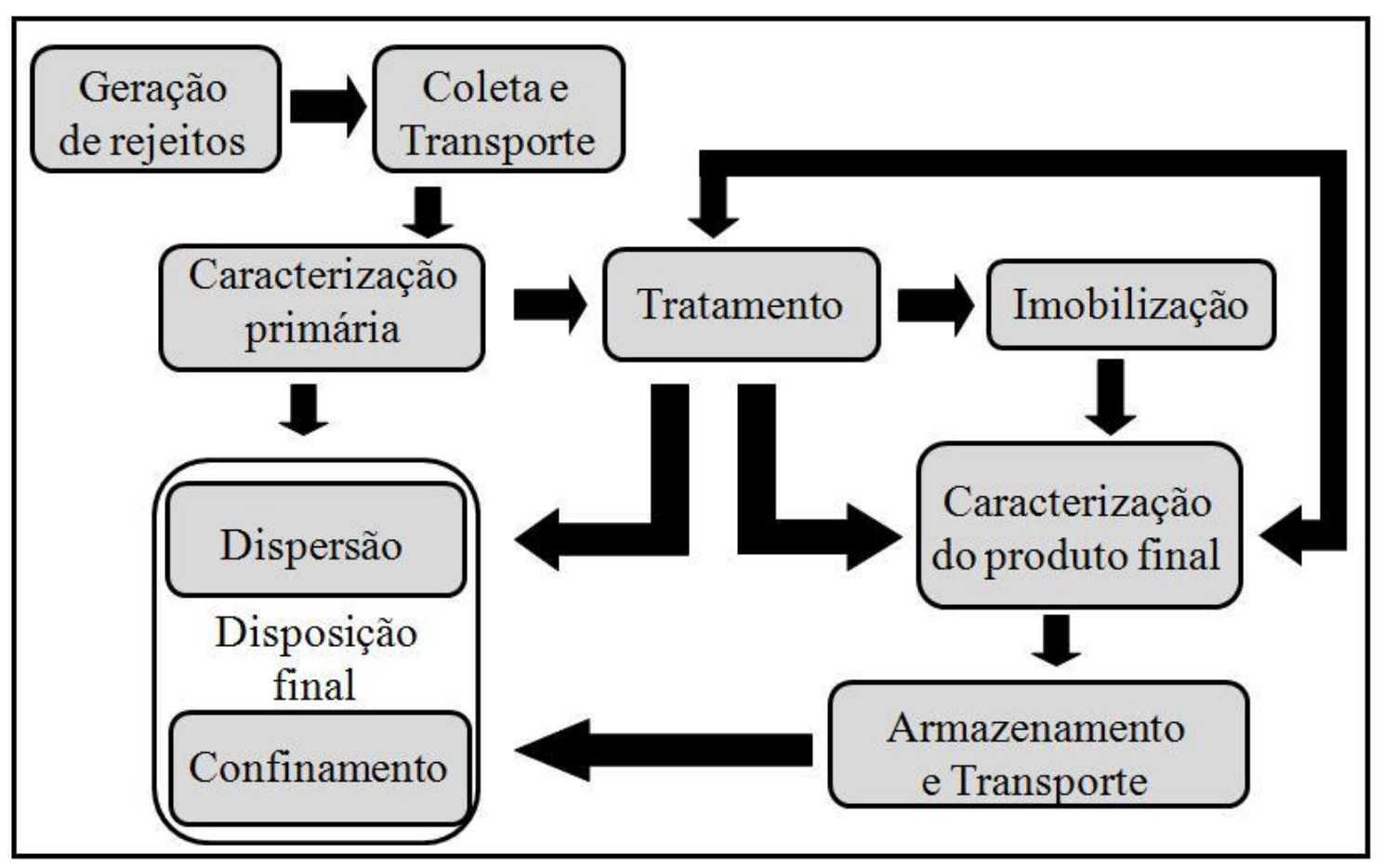

FIGURA 1 - Fluxograma da gerência de rejeitos radioativos (adaptado de Hiromoto et al, 1999).

Após serem retiradas de serviço, as FRSD devem ser gerenciadas de forma adequada. No Brasil, os institutos ligados à CNEN são responsáveis pelo recebimento, armazenamento e acondicionamento dessas fontes. Até 2000, cerca de dez mil fontes já haviam sido coletadas e estavam atualmente armazenadas nesses institutos (REIS \& HEILBRON, 2000).

Na Gerência de Rejeitos Radioativos do IPEN-CNEN/SP, até 2012, já haviam sido coletadas 8.541 fontes utilizadas em equipamentos industriais ou de radioterapia (a maioria de Sr-90, Cs-137, Ra-226 e Am-241), cerca de 70.000 fontes de Am-241 proveniente de para-raios e mais 60.000 fontes provenientes de detectores de fumaça (Marumo, informação verbal). Se for levado em conta as fontes extraídas de para-raios 
radioativos provenientes de instalações comerciais e residenciais em todo o país, esse inventário passa a contar com cerca de trezentas mil fontes (FERREIRA, et al, 2012). Essas fontes estão armazenadas aguardando a decisão sobre deposição final.

A deposição segura e correta de fontes seladas é alvo de preocupações de todos aqueles envolvidos com a gestão de rejeitos radioativos, devido a seu uso generalizado, o alto potencial de causar acidentes radiológicos e o grande inventário, na maioria dos países.

Alguns acidentes com fontes radioativas seladas (como o acidente em Goiânia, em 1987) resultaram em fatalidades e contaminação de grandes áreas urbanas e agrícolas (VICENTE et al, 2004). Além disso, os ataques terroristas em 11/09/2001 nos Estados Unidos da América deixaram algumas preocupações quanto a possíveis ataques terroristas usando as chamadas bombas sujas, fabricadas com alguns tipos de fontes (GRIMM, 2004; McFEE et al, 2006).

As fontes seladas contêm, principalmente, Co-60, Ni-63, Sr-90, Cs-137, Ra226, Pu-238, Am-241, além de outros 30 radioisótopos e podem ser divididas em categorias, divididas pelo tempo de meia-vida dos radioisótopos. As fontes com radioisótopos de meia-vida menor que 100 dias podem ser armazenadas em segurança, nas próprias instalações, até seu decaiamento. Acidentes com esse tipo de fontes ocorrem com alguma freqüência e, por isso, seu armazenamento requer alguns cuidados. (DAYAL, 2004).

As fontes com radioisótopos de meia-vida entre 100 dias e 30 anos podem conter atividades significantes, como fontes de Sr-90, que podem conter atividades superiores a $10 \mathrm{PBq}$ cada uma. Com altos níveis e meia-vida moderada, as FRSD desse tipo devem ser isoladas por centenas ou milhares de anos (DAYAL, 2004). A maioria dessas fontes (exceto com altas atividades) pode ser depositada em repositórios de superfície, como aqueles utilizados para resíduos do ciclo do combustível de baixa e média atividade.

As fontes com radioisótopos de meia-vida superior a 30 anos representam um perigo potencial à saúde por até milhares de anos, algumas com atividades muito altas (DAYAL, 2004; VICENTE, 2007a). As fontes dessa categoria e da anterior com alta atividade não atendem aos critérios de aceitação em repositórios de superfície como rejeito de baixa e média atividade por duas razões principais: a) a meia-vida dos radioisótopos contidos nessas fontes pode variar de alguns anos até milhares de anos; e b) as atividades podem variar da ordem de megabecquerel (MB) até superiores à terabecquerel (TB) 
(DAYAL, 2004; VICENTE, 2007a). Consequentemente, essas fontes deverão ser depositadas definitivamente em repositórios profundos com múltiplas barreiras.

Algumas opções potenciais para a deposição de fontes radioativas estão sendo estudadas no mundo todo, desde repositório de superfície e em minas desativadas até a deposição geológica em alta ou média profundidade. Na França, a Agência Nacional Francesa de Gerenciamento de Rejeitos Radioativos (ANDRA) estuda repositórios geológicos profundos para seus rejeitos radioativos de nível alto e intermediário e de meiavida longa (CODINA, et al, 2008), características das fontes seladas.

Atualmente, os EUA estão reavaliando a política de gerência de rejeitos radioativos de alta atividade e vem estudando sistemas genéricos de deposição no ambiente e de deposição geológica desses rejeitos. A deposição em poços tubulares profundos tipo borehole é uma das opções analisadas nesse estudo (LEE, et al, 2012), cujo objetivo é desenvolver as ferramentas de modelagem necessárias para avaliar e melhorar o entendimento das reações envolvidas no sistema de repositório e dos processos relevantes na deposição em longo prazo desses rejeitos em borehole.

Na Rússia, a agência nacional local iniciou, nos anos 1980, um projeto de deposição das FRSD no qual foi sugerido um isolamento das fontes em uma matriz adicional, para depois serem colocadas em depósitos tipo borehole (OJOVAN et al, 2003).

Outros países da União Europeia, como Áustria, Bélgica, Portugal e Espanha realizam a coleta e o armazenamento temporário das FRSD, até que se tenha uma forma para sua deposição definitiva. Já a Alemanha dispõe de um sítio para deposição final dessas fontes, junto com outros rejeitos radioativos de alta atividade e meia vida longa (ANGUS et al, 2000).

\subsection{Deposição de fontes em borehole}

Diante do problema apresentado, a Gerência de Rejeitos Radioativos (GRR) do IPEN-CNEN/SP está desenvolvendo um conceito de deposição para FRSD em poços tipo borehole.

A deposição em poços tubulares possui uma série de vantagens, tanto do ponto de vista tecnológico como de segurança (DAYAL, 2004; OJOVAN et al, 2003). Algumas vantagens apontadas para a escolha do borehole são o baixo custo; a facilidade de implementação; a proteção radiológica eficaz; a segurança a longo prazo; a segurança operacional; conceitualmente simples; a facilidade de construção; a praticidade de instalação em vários sítios e pouco intrusivo ao meio ambiente. Além disso, outra 
característica de instalações tipo borehole é sua área na superfície, que é muito pequena comparada à outros repositórios, diminuindo os riscos de intrusão humana.

Um esboço do poço proposto pela GRR está apresentado na FIG. 2. O conceito deste repositório procura atender a dois aspectos importantes sobre a deposição desse material: conter todo o inventário do país e garantir a segurança em longo prazo, considerando a meia-vida das fontes.

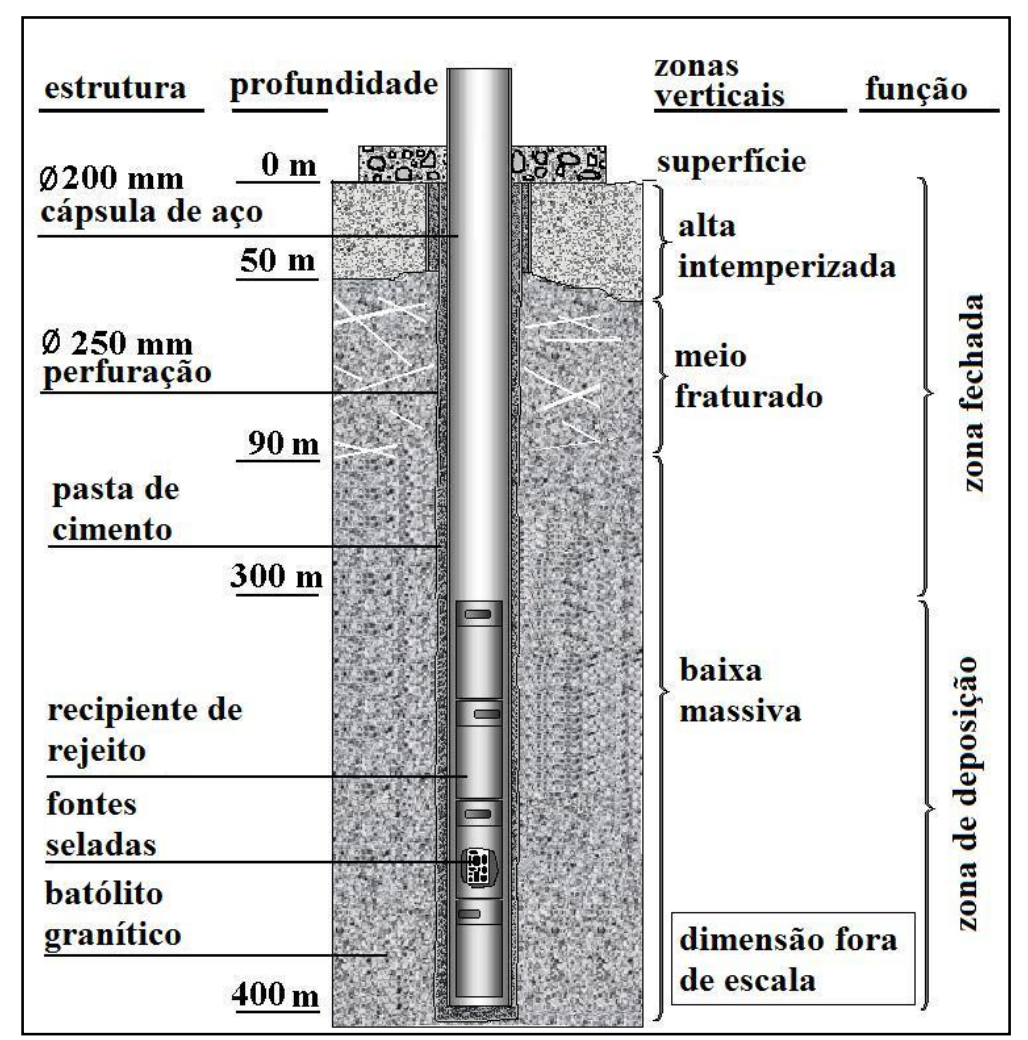

FIGURA 2 - O Conceito de repositório profundo para fontes radioativas seladas descartadas. Fonte VICENTE, 2007b

O repositório está projetado para ser perfurado em uma formação geológica estável, em uma rocha cristalina com extensão e profundidade para acomodar todas as fontes do inventário brasileiro e deixar espaço suficiente, acima da zona de deposição, para isolamento e proteção do ambiente da superfície. A zona de deposição das fontes deverá estar abaixo da zona fraturada da rocha com água circulante (VICENTE et al, 2004).

A análise de segurança ou análise de desempenho do repositório fornece a base para as definições sobre sua segurança. As barreiras artificiais e naturais são consideradas um sistema integrado e elas devem garantir a integridade desse sistema pelo tempo requerido para o decaimento das fontes (VICENTE, 2007b). A durabilidade desses 
materiais vai depender do comportamento em longo prazo de cada um, submetidos às condições ambientais reinantes, e das interações entre os mesmos (XIE, et al, 2008).

Detalhes do encapsulamento das fontes no repositório e do sistema de multibarreiras estão apresentados na FIG. 3. As fontes seladas serão acondicionadas dentro de recipientes de chumbo que, por sua vez, serão depositados no interior do tubo de aço que reveste o poço.

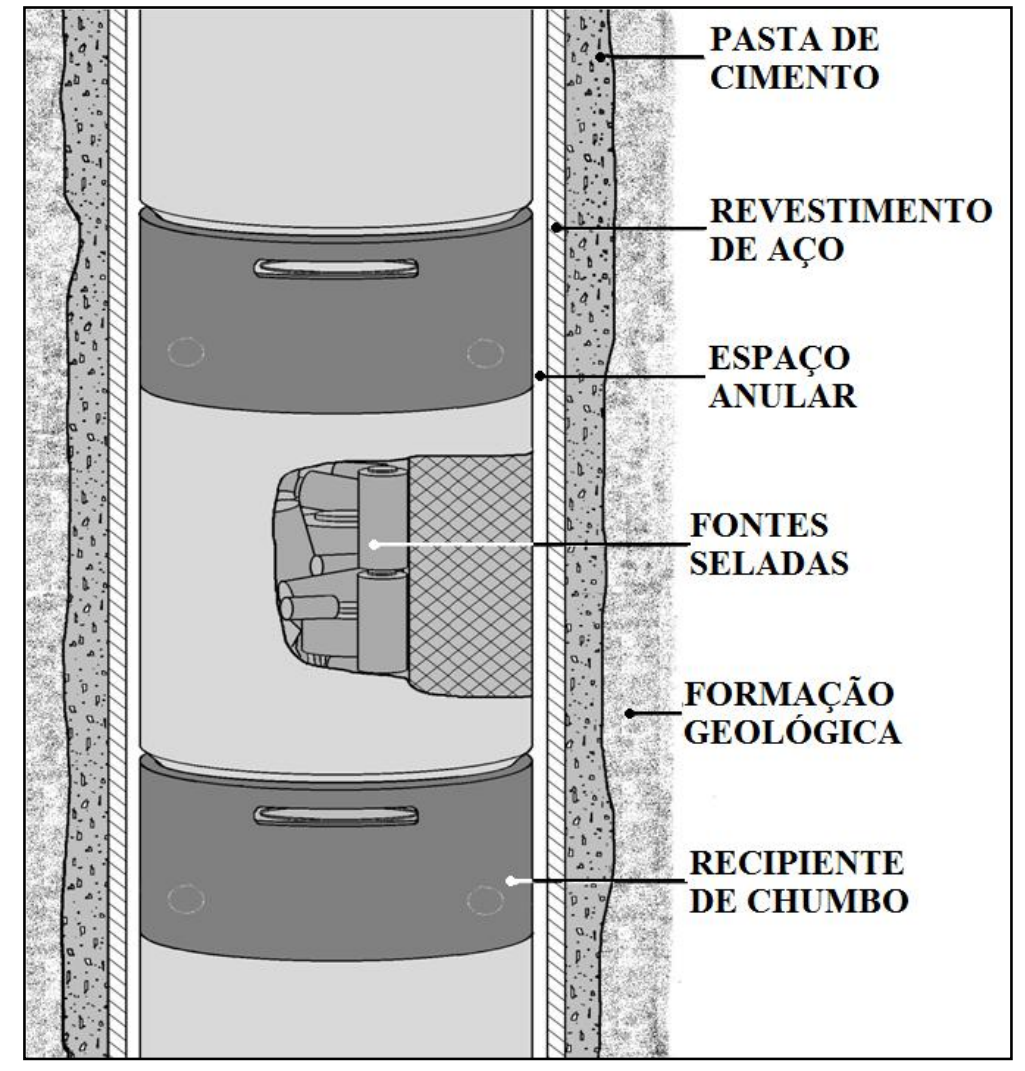

FIGURA 3 - Método de encapsulamento das fontes seladas.

As barreiras artificiais que podem ser utilizadas em um repositório tipo borehole são diversas. Os componentes mais comuns e suas funções principais foram descritas por Dayal (2004) em seu trabalho e estão apresentados abaixo:

- Recipiente original da fonte -É mantido, mesmo que esteja danificado;

- Componentes metálicos e cápsulas para fontes menores - Contenção da atividade. Pode ocorrer corrosão em contato com água;

- Embalagem de metal dos rejeitos (aço carbono ou aço inoxidável) ou recipiente contendo várias capsulas - Contenção da atividade. Pode ocorrer corrosão em contato com água; 
- Preenchimento do recipiente em que as fontes são alocadas (por exemplo, com pasta de cimento ou argamassa) - Controla a taxa de corrosão das cápsulas. Atua como uma matriz de sorção ou barreira à difusão dos radionuclídeos para fora da embalagem;

- Preenchimento dentro borehole em volta da embalagem (ex. cimento/argamassa, solo natural ou materiais argilosos) - Controla o fluxo de água nas embalagens de rejeitos e suas taxas de corrosão. Atua como uma matriz de sorção ou barreira à difusão dos radionuclídeos para fora da embalagem;

- Preenchimento do espaço anular entre as paredes do borehole e a formação geológica (ex. pasta de cimento/argamassa) - Controla o fluxo de água da formação geológica, evitando o contato direto com o material de revestimento do borehole, controlando sua corrosão. Atua como uma matriz de sorção ou barreira à difusão dos radionuclídeos para fora do repositório;

- Revestimento do material das paredes do borehole durante a operação Pode prevenir o acesso de águas subterrâneas à embalagem de rejeito até a corrosão do revestimento ou sua degradação;

- Selamento: tampões de argila ou materiais a base de cimento colocados acima da zona de deposição - Selar a zona de deposição dos rejeitos das partes superiores do sistema.

Esse sistema de barreiras artificiais não deve, necessariamente, conter todos os componentes listados acima. A composição deve ser definida com base nas características especificas das fontes e da formação geológica de cada repositório. Além disso, a profundidade do repositório deve ser grande, visando reduzir a probabilidade de intrusão que poderia resultar em exposição do ambiente a altas doses de radioatividade antes das fontes decaírem (DAYAL, 2004).

Diversos processos físicos e químicos podem comprometer o desempenho do repositório. A radiólise da água, por exemplo, é um processo que ocorre em campos de radiação, como aqueles provenientes das FRSD, e pode gerar acúmulo de gás hidrogênio $\left(\mathrm{H}_{2}\right)$, que é explosivo até em baixas concentrações. A segurança do repositório é reduzida também pelo acúmulo de outros produtos de radiólise (OJOVAN et al, 2003). A penetração de água subterrânea é outro processo que pode comprometer a durabilidade do repositório, comprometendo as barreiras artificiais (BUZZI, et al, 2008). 
No conceito proposto pela GRR, o espaço anular entre o tubo e a formação geológica deverá ser preenchido com pasta de cimento Portland, que possui diversas funções, como atuar como material estrutural, barreira contra o fluxo de água entre as diferentes camadas do meio geológico, atravessadas pelo poço, e como barreira adicional contra a migração de radionuclídeos para a biosfera (US-EPA, 1988).

Entre todas as barreiras do repositório, a pasta de cimento é o material com o menor grau de conhecimento em longo prazo, uma vez que a experiência de engenharia na utilização desse material é limitada a menos de dois séculos. A estabilidade físico-química da pasta de cimento em longos períodos nas condições reinantes no repositório precisa, portanto, ser investigada (Van BREUGEL, 2004).

Além disso, a pasta de cimento é o material mais exposto às condições ambientais severas e sua deterioração nesse ambiente pode levar a falha do sistema. Os estudos da durabilidade dos materiais à base de cimento encontrados na literatura têm como finalidade avaliar as propriedades estruturais em construções com vida útil de décadas ou no máximo de poucos séculos. Assim, mais estudos são necessários para melhorar a confiança de que o material terá o desempenho esperado durante toda a vida útil da instalação, prevista para até vários milênios (SCRIVENER \& KIRKPATRICK, 2008).

Durante o tempo de vida útil do repositório, a pasta de cimento estará exposta a diversos agentes que tendem a degradar e comprometer sua integridade, como pressões e temperaturas elevadas, ação corrosiva de agentes químicos dissolvidos na água subterrânea e a irradiação decorrente do campo de radiação gama e de nêutrons criado pelas fontes (CALVO, et al, 2010; ÇOLAK, et al, 2009; GALÍNDEZ \& MOLINERO, 2010; MEHTA \& MONTEIRO, 2008).

Recentemente, a Agência Internacional de Energia Atômica (IAEA) organizou um Programa Coordenado de Pesquisa sobre o comportamento, em longo prazo, de materiais cimentícios em ambientes de repositórios, que contou com pesquisadores e instituições de vários países (DRACE \& OJOVAN, 2009; IAEA, 2006), indicando que o assunto está em pauta na comunidade internacional.

Philipose (1988) classifica a degradação de argamassas ou concretos a partir de causas internas ou causas externas. Entre as causas internas, as mais importantes para a pasta de cimento são os efeitos de encolhimento e deformação e cristalização da fase silicato de cálcio hidratado (C-S-H). Entre as possíveis causas externas, estão a deterioração química por ataques de íons presentes em águas subterrâneas, corrosão ácida, 
problemas com congelamento/descongelamento (em ambientes de baixa temperaturas), lixiviação e dissolução de compostos de cálcio e ações de microorganismos. Deby et al (2009) e Berner (1992) também retratam esses importantes aspectos da durabilidade da pasta em ambientes de repositório. A FIG. 4 apresenta a árvore de falhas da pasta de cimento no ambiente esperado do repositório para FRSD.

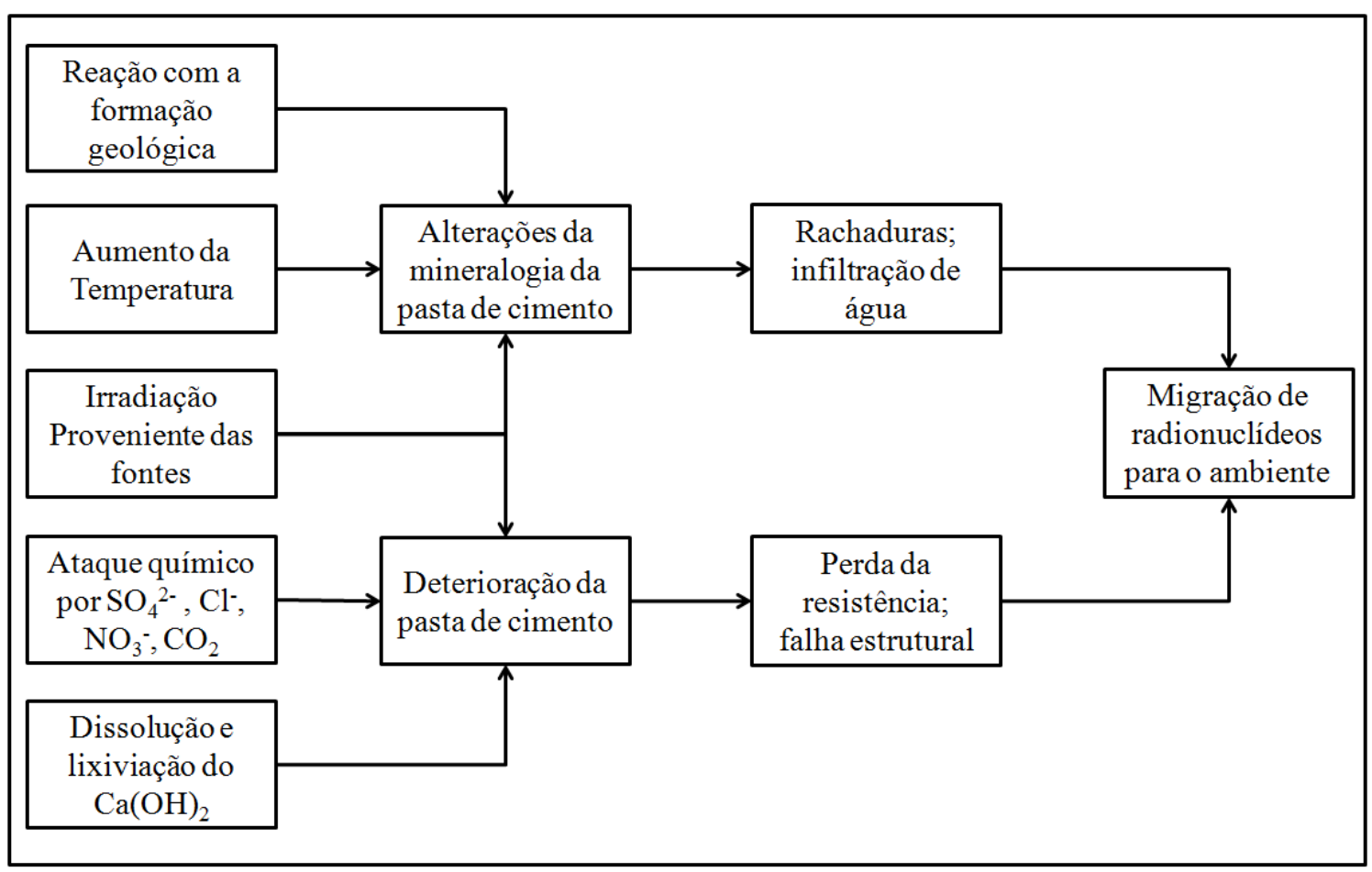

FIGURA 4 - Árvore de falhas do cimento em ambiente de repositório (Adaptado de Philipose, 1988)

\subsection{O Cimento Portland e sua utilização}

Materiais cimentícios são aqueles que endurecem quando reagem com a água. A definição de cimento Portland é, segundo a ASTM C-150, um cimento hidráulico (que forma um produto resistente à água) produzido pela moagem de clínqueres de silicatos de cálcio (ASTM, 1986). O clínquer possui nódulos de 5 a $25 \mathrm{~mm}$ de diâmetro de material e é sinterizado aquecendo-se matérias-primas de composição conhecida em altas temperaturas (MEHTA \& MONTEIRO, 2008).

Os materiais a base de cimento são, em termos de volume, os materiais mais utilizados em todo o mundo. Esse sucesso vem da facilidade em que a mistura de água e um pó se transforma, sendo manipulado com as mãos e em temperatura ambiente, em um sólido rígido e eficaz. Por essa característica, o cimento é considerado um ligante hidráulico. 
Além disso, esses materiais possuem baixo custo e são constituídos de elementos amplamente disponíveis no solo. Nesse cenário, os materiais cimentícios são constantemente inovados, com a incorporação de novos constituintes e materiais suplementares durante a formulação do concreto.

A compreensão dos processos físicos e químicos dos materiais cimentícios requer que a constituição química e seus produtos de hidratação sejam bem conhecidos e estudados. O cimento Portland é a base cimentícia mais utilizada no mundo todo e seus produtos de hidratação são diferentes em diferentes constituições iniciais, inerentes ao local de fabricação dos mesmos.

O cimento Portland é constituído, principalmente, de fases silicato de cálcio, aluminato de cálcio, ferrita e sulfatos (adicionado artificialmente na forma de gipsita). $\mathrm{Na}$ química do cimento, é comum a adoção de uma nomenclatura simplificada para compostos químicos anidros e hidratados do cimento. Essa nomenclatura substitui os óxidos por letra, como segue: $\mathrm{C}=\mathrm{CaO} ; \mathrm{S}=\mathrm{SiO}_{2} ; \mathrm{A}=\mathrm{Al}_{2} \mathrm{O}_{3} ; \mathrm{F}=\mathrm{Fe}_{2} \mathrm{O}_{3} ; \mathrm{N}=\mathrm{Na}_{2} \mathrm{O} ; \mathrm{M}=\mathrm{MgO}, \overline{\mathrm{S}}=\mathrm{SO}_{3} ; \overline{\mathrm{C}}=$ $\mathrm{CO}_{2}$ e $\mathrm{H}=\mathrm{H}_{2} \mathrm{O}$.

Os compostos mais importantes presentes no clínquer do Cimento Portland são as fases $\mathrm{C}_{3} \mathrm{~S}, \mathrm{C}_{2} \mathrm{~S}, \mathrm{C}_{3} \mathrm{~A}$ e $\mathrm{C}_{4} \mathrm{AF}$, chamadas alita, belita, fase aluminato e fase ferrita, respectivamente. As duas primeiras são constituídas basicamente de $\mathrm{SiO}_{2}$ e $\mathrm{CaO}$, enquanto as duas últimas de $\mathrm{CaO}$ e $\mathrm{Al}_{2} \mathrm{O}_{3}$. As fases do cimento contém elementos substituintes, que constituem impurezas do material. A TAB. 1 apresenta os principais compostos químicos presentes no cimento e algumas propriedades dos mesmos (SOROKA, 1993).

TABELA 1 - Propriedades dos constituintes principais do cimento Portland (adaptado de SOROKA, 1993)

\begin{tabular}{|c|c|c|c|c|}
\hline & Alita & Belita & Fase aluminato & Ferrita \\
\hline $\begin{array}{l}\text { Composição } \\
\text { química aproximada }\end{array}$ & 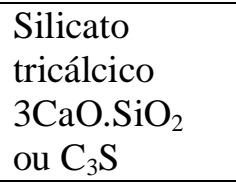 & $\begin{array}{l}\text { silicato } \\
\text { dicálcico } \\
2 \mathrm{CaO} . \mathrm{SiO}_{2} \\
\mathrm{ou}_{2} \mathrm{~S} \\
\end{array}$ & $\begin{array}{l}\text { aluminato } \\
\text { tricálcico } \\
3 \mathrm{CaO} \cdot \mathrm{Al}_{2} \mathrm{O}_{3} \text { ou } \\
\mathrm{C}_{3} \mathrm{~A} \\
\end{array}$ & $\begin{array}{l}\text { ferroaluminato } \\
\text { tetracálcico } \\
4 \mathrm{CaO} \cdot \mathrm{Al}_{2} \mathrm{O}_{3} \cdot \mathrm{Fe}_{2} \mathrm{O}_{3} \\
\text { ou } \mathrm{C}_{4} \mathrm{AF}\end{array}$ \\
\hline Tempo de reação & $\begin{array}{l}\text { Rápido } \\
\text { (horas) }\end{array}$ & $\begin{array}{l}\text { Lento } \\
\text { (dias) }\end{array}$ & Instantâneo & $\begin{array}{l}\text { Muito rápido } \\
\text { (minutos) }\end{array}$ \\
\hline $\begin{array}{l}\text { Desenvolvimento } \\
\text { da resistência }\end{array}$ & $\begin{array}{l}\text { Rápido } \\
\text { (dias) }\end{array}$ & $\begin{array}{l}\text { Lento } \\
\text { (semanas) }\end{array}$ & $\begin{array}{l}\text { Muito rápido } \\
(1 \mathrm{dia})\end{array}$ & $\begin{array}{l}\text { Muito rápido } \\
\text { (1 dia) }\end{array}$ \\
\hline Resistência final & $\begin{array}{l}\text { Alta (dezenas } \\
\text { de MPa) }\end{array}$ & $\begin{array}{l}\text { Alta (dezenas } \\
\text { de MPa) }\end{array}$ & $\begin{array}{l}\text { Baixa (poucos } \\
\text { MPa) }\end{array}$ & Baixa (poucos MPa) \\
\hline Calor de hidratação & $\begin{array}{l}\text { Médio } \\
500 \mathrm{~J} / \mathrm{g}\end{array}$ & $\begin{array}{l}\text { Baixo } \\
250 \mathrm{~J} / \mathrm{g}\end{array}$ & $\begin{array}{l}\text { Muito alto } \\
\sim 850 \mathrm{~J} / \mathrm{g}\end{array}$ & Médio 420J/g \\
\hline $\begin{array}{l}\text { Principais } \\
\text { Elementos } \\
\text { Substituintes }\end{array}$ & $\begin{array}{l}\mathrm{MgO}, \mathrm{Al}_{2} \mathrm{O}_{3} \\
\mathrm{Fe}_{2} \mathrm{O}_{3}\end{array}$ & $\begin{array}{l}\mathrm{Al}_{2} \mathrm{O}_{3}, \mathrm{Fe}_{2} \mathrm{O}_{3}, \\
\mathrm{SO}_{3}, \mathrm{~K}_{2} \mathrm{O} \\
\mathrm{MgO}\end{array}$ & $\begin{array}{l}\mathrm{Na}_{2} \mathrm{O}, \mathrm{Fe}^{3+}, \\
\mathrm{Si}^{4+}, \mathrm{K}_{2} \mathrm{O}\end{array}$ & $\mathrm{MgO}, \mathrm{SiO}_{2}, \mathrm{TiO}_{2}$ \\
\hline
\end{tabular}


Além desses compostos, alguns outros são adicionados ao clínquer ou estão presentes na forma de impurezas. A gipsita (sulfato de cálcio - $\mathrm{CaSO}_{4}$ ou $\mathrm{C} \overline{\mathrm{S}}$ ) é adicionada ao clínquer para retardar a hidratação do $\mathrm{C}_{3} \mathrm{~A}$ e melhorar o tempo de trabalhabilidade do cimento. Outros compostos minoritários são o periclásio (óxido de magnésio - $\mathrm{MgO}$ ou $\mathrm{M}$ ), cal livre (óxido de cálcio - $\mathrm{CaO}$ ou $\mathrm{C}$ ) e sulfatos de sódio e potássio.

Uma série de outros materiais, chamados materiais suplementares ao cimento (MSC), podem ser adicionados à mistura, formando argamassas e concretos de diferentes propriedades. Com exceção da pedra calcária, esses materiais são constituídos principalmente de silício e alumínio, diminuindo a quantidade de cálcio do cimento resultante.

A substituição do cimento por esses materiais suplementares em alta quantidade só é possível com um amplo conhecimento dos seus mecanismos básicos de hidratação. É necessário um melhor entendimento sobre vários aspectos desses materiais, como o desenvolvimento e utilização de novos MSCs e de diferentes tipos de clínquer (SCRIVENER \& NONAT, 2011).

Ultimamente, a utilização de concretos com resistência superior à convencional cresceu em vários setores. A resistência do concreto é função do preenchimento dos espaços entre os grãos do cimento pelos produtos de hidratação e esses espaços são determinados pela quantidade de água adicionada na mistura (a proporção água/cimento). No entanto a redução da quantidade de água é limitada, pois isso diminui a trabalhabilidade do concreto, que é a propriedade do material de ser facilmente preparado e aplicado no local. Nesse conceito, alguns aditivos podem melhorar a fluidez do concreto, como os plastificantes, e melhorar a sua resistência com a diminuição da quantidade de água na mistura (SCRIVENER \& KIRKPATRICK, 2008).

Scrivener \& Kirkpatrickk (2008) descrevem as importantes inovações nos últimos anos no concreto. Entre elas, a introdução dos plastificantes à base de PCE (do inglês polycarboxylate ether, ou éter policarboxilato) merece destaque. Com eles, algumas propriedades importantes do concreto podem ser modificadas, como a trabalhabilidade, retenção de íons, coesão e a taxa do desenvolvimento da resistência. Concreto de alta resistência podem também conter certo teor de sílica ativa, um resíduo oriundo da indústria metalúrgica, que ajuda no preenchimento dos espaços entre os grãos de cimento, devido à presença de partículas de tamanho pequeno (10 a 100 vezes menor que os grãos do cimento), que melhoram a compactação do concreto. 
A necessidade de reduzir o impacto ambiental causado pelos materiais cimentícios é o fator que mais motiva a inovação nesses materiais. O uso de MSC provenientes de processos industriais, como escória de alto-forno, cinza volante, calcário e sílica ativa, necessita de testes extensos para a utilização em larga escala. Dessa forma, a compreensão de todos os processos básicos presentes na hidratação do cimento Portland comum e do concreto com adições de MSCs é crucial no entendimento das propriedades químicas, físicas e mecânicas do produto final. Além disso, a hidratação do cimento na presença desses novos materiais sofrem diversas alterações que devem ser estudadas caso a caso (SCRIVENER \& KIRKPATRICK, 2008).

\subsection{Principais componentes do Cimento Portland anidro}

\subsubsection{Alita}

A alita, um polimorfo do silicato tricálcico, ou $\mathrm{C}_{3} \mathrm{~S}$, constitui cerca de 50-70\% da massa do cimento Portland e tende a dominar a hidratação nos períodos iniciais. É responsável pela resistência inicial do cimento (em idades entre 1 e 28 dias) devido a rápida formação do silicato de cálcio hidratado, C-S-H, o principal produto da hidratação (BATTAGIN, 2011).

Quando o cristal de alita se desenvolve por completo, ele forma um polígono hexagonal. Em um clínquer industrial, nem todas as faces do hexágono são desenvolvidos e os cristais podem se desenvolver em formas variadas. Essa variação gera um material com diferentes diâmetros, que reagem mais lenta (cristais maiores) ou mais rapidamente (cristais menores) na hidratação.

\subsubsection{Belita}

A hidratação da belita também leva à formação de C-S-H e de Portlandita, porém essa reação é muito mais lenta quando comparada às reações que ocorrem com a alita, sendo portanto importante apenas em idades mais avançadas (após 28 dias de cura). A belita, ou $\mathrm{C}_{2} \mathrm{~S}$, é um silicato dicálcico e constitui de $10-20 \%$ da massa do clínquer do cimento Portland. Os cristais de belita possuem formas arredondadas e podem ocorrer dispersos ou agrupados, dependendo das condições do processo de produção do clínquer (BATTAGIN, 2011). 


\subsubsection{Fase Aluminato Tricálcico}

$\mathrm{O}$ aluminato tricálcico, ou $\mathrm{C}_{3} \mathrm{~A}$, é o responsável pela pega do cimento, uma vez que sua reação com a água é muito rápida. Com o intuito de retardar a pega, é adicionado ao clínquer gipsita para melhorar a trabalhabilidade do cimento. A hidratação dessa fase gera os compostos hidroaluminatos de cálcio contendo ou não ferro, denominados fases AFm, e compostos do tipo etringita, denominados fases AFt (VICHOT \& OLLIVIER, 2008). Além desses produtos, a hidratação na presença de óxido de magnésio gera hidrotalcita $\left(\left(\mathrm{Mg}_{6} \mathrm{Al}_{2}(\mathrm{OH})_{16} \mathrm{CO}_{3} \cdot 4 \mathrm{H}_{2} \mathrm{O}\right)\right.$.

A fase de cristalização do $\mathrm{C}_{3} \mathrm{~A}$ é importante, uma vez que a presença desse material na forma ortorrômbica aumenta muito a reatividade e se faz necessária adição de maior quantidade de sulfato de cálcio para retardar a pega. Um cimento com alto teor de $\mathrm{C}_{3} \mathrm{~A}$ cúbico evita o início de pega acelerado e a consequente diminuição da trabalhabilidade na pasta de cimento (VICHOT \& OLLIVIER, 2008).

\subsubsection{Fase Ferroaluminato Tetracálcico}

A hidratação da fase ferroaluminato tetracálcio leva aos mesmos produtos da hidratação do $\mathrm{C}_{3} \mathrm{~A}$. A presença desse material inibi a reação do $\mathrm{C}_{3} \mathrm{~A}$, permitindo um maior tempo de pega do material. Esse material possui papel importante papel ao aumentar a resistência do cimento a agentes químicos, em especial ao ataque de sulfatos em cimento. As fases $\mathrm{C}_{3} \mathrm{~A}$ e $\mathrm{C}_{4} \mathrm{AF}$ correspondem a cerca de 15 a 20\% do clínquer (BATTAGIN, 2011).

\subsubsection{Cal livre e periclásio}

A cal livre $(\mathrm{CaO})$ é formada pela descarbonatação do $\mathrm{CaCO}_{3}$ e é indesejável em quantidades superiores a $2 \%$ no clínquer. Teores elevados desse material indicam que o processo de formação do clínquer não foi completo. Além disso, a presença de cal livre leva a expansão da pasta de cimento no processo de hidratação pela formação de de Portlandita $\left[\mathrm{Ca}(\mathrm{OH})_{2}\right]$, cerca de $97 \%$ superior em volume (CENTURIONE, 1993). O periclásio, ou óxido de magnésio, é indesejado em quantidades superiores a $5 \%$ no clínquer. Teores de $\mathrm{MgO}$ acima de $2 \%$ levam a cristalização de periclásio, que durante a hidratação pode formar brucita $\left(\mathrm{Mg}(\mathrm{OH})_{2}\right)$, causando expansão da pasta de cimento (BATTAGIN, 2011). 


\subsubsection{Sulfatos de cálcio}

Adicionada ao clínquer, a gipsita $\left(\mathrm{CaSO}_{4} \cdot 2 \mathrm{H}_{2} \mathrm{O}\right)$ é utilizada retardar a pega da pasta de cimento. Se não fosse adicionado, a pega do cimento seria praticamente instantânea (menos de 10 minutos), inviabilizando a utilização do concreto na prática. A perda de moléculas de água da gipsita pode levar a formação de bassanita $\left(\mathrm{CaSO}_{4} \cdot 0,5 \mathrm{H}_{2} \mathrm{O}\right)$ ou anidrita $\left(\mathrm{CaSO}_{4}\right)$, levando a diferentes comportamentos durante o início da hidratação da pasta (VICHOT \& OLLIVIER, 2008).

\subsubsection{Sulfatos alcalinos}

Os sulfatos alcalinos são formados devido à presença de álcalis no clínquer e possuem papel importante em reações álcalis-agregados e na própria cinética de hidratação do cimento. Os sulfatos alcalinos são facilmente solubilizáveis na água de amassamento do cimento enquanto que os álcalis contidos nos aluminatos e nos silicatos serão liberados mais lentamente durante o processo de hidratação (BATTAGIN, 2011). Os sulfatos alcalinos mais conhecidos no clínquer são arcanita, langbeinita e aftitalita. Durante o processo de hidratação, aceleram o início da pega e diminuem a resistência da pasta de cimento à idades mais tardias (VICHOT \& OLLIVIER, 2008).

\subsubsection{Adições: escória, pozolanas e fíler}

A escória de alto forno é subproduto da fabricação de ferro gusa e é constituída de aluminossilicatos cálcicos, com sulfetos de cálcio e manganês e óxidos de ferro e manganês como impurezas. A escória é o material mais utilizado pela indústria cimentícia como adição devido à sua alta disponibilidade (BATTAGIN, 2011).

Os materiais pozolânicos são silicosos ou sílico-aluminosos que, quando finamente moídos e na presença de água e $\mathrm{Ca}(\mathrm{OH})_{2}$, reagem e formam compostos aglomerantes (MONTANHEIRO, 2003). As pozolanas podem ser de origem vulcânica ou de subprodutos de diversas atividades industriais. O fíler calcário é retirado da moagem de rocha calcária e, quando adicionados ao cimento Portland, produz uma pasta de cimento mais trabalhável. A sua adição causa efeitos químicos e físicos durante a hidratação do cimento, como a formação de carboaluminatos e a incorporação de $\mathrm{CaCO}_{3}$ na estrutura do C-S-H. O efeito físico é o preenchimento dos poros do cimento (BATTAGIN, 2011). 


\subsection{Tipos de Cimentos e suas propriedades}

Os tipos de cimentos fabricados no Brasil são definidos pela ABNT (Associação Brasileira de Normas Técnicas) e são equivalentes ao modelo europeu, que é normalizado pelo Comitê Europeu de Normalização (CEN - do francês Comité Européen de Normalisation), de acordo com a norma EN 197-1 - Composição, especificação e critérios de conformidade para cimentos comuns (CEN, 2000). O cimento Portland comum (CP I), embora praticamente ausente no mercado por questões econômicas e ambientais, segue como referência para as propriedades dos demais (BATTAGIN, 2011). Os tipos de cimento normalizados disponíveis no mercado brasileiro são:

- Cimento Portland Comum (CP I)

- $\quad$ CP I - Cimento Portland Comum

- $\quad$ CP I-S - Cimento Portland Comum com Adição

- Cimento Portland Composto (CP II)

- $\quad$ CP II-E - Cimento Portland Composto com Escória

- $\quad$ CP II-Z - Cimento Portland Composto com Pozolana

- $\quad$ CP II-F - Cimento Portland Composto com Fíler

- Cimento Portland de Alto Forno (CP III)

- Cimento Portland Pozolânico (CP IV)

- Cimento Portland de Alta Resistência Inicial (CP V-ARI)

- Cimento Portland Resistente a Sulfatos (RS)

- Cimento Portland de Baixo Calor de Hidratação (BC)

- Cimento Portland Branco (CPB)

- Cimento Portland classe G (CPP-G)

Esses tipos diferenciam-se pela proporção de clínquer e gipsita e pela presença de adições, como escórias, pozolanas e fíler calcário. Podem também diferenciar-se por propriedades físicas, caso do CP V-ARI, com área superficial maior e, por isso, taxa de reação de hidratação maior.

A TAB. 2 apresenta os principais cimentos brasileiros e o correspondente nas normas americanas e europeias, além da composição típica dos mesmos (SKALNY et al, 2002). 
TABELA 2 - Equivalência entre os Cimentos brasileiros, europeus e americanos e sua composição típica.

\begin{tabular}{cccccccc}
\hline Cimento & Tipo I & Tipo II & Tipo III & Tipo IV & Tipo V & Tipo IS & Tipo IP \\
Americano & C150- & C150- & C150- & C150- & C150- & C595- & C595- \\
Norma ASTM & $86^{1}$ & $86^{1}$ & $86^{1}$ & $86^{1}$ & $86^{1}$ & $09^{2}$ & $09^{2}$ \\
\hline Cimento & CEM I & CEM II & CEM I & - & - & CEM III & CEM IV \\
Europeu & EN 197- & EN 197- & EN 197- & & & EN 197- & EN 197- \\
Norma & $1^{3}$ & 1 & 1 & - & - & 1 & 1 \\
\hline Cimento & CP I & CP II & CP V - & BC & RS & CP III & CP IV \\
Brasileiro & NBR & NBR & NBR & NBR & NBR & NBR & NBR \\
Norma ABNT & $5732^{4}$ & $11578^{5}$ & $5733^{6}$ & $13116^{7}$ & $5737^{8}$ & $5735^{9}$ & $5736^{10}$ \\
\hline $\mathrm{C}_{3} \mathrm{~S}(\%)$ & $42-65$ & $35-60$ & $45-70$ & $20-30$ & $40-60$ & & \\
$\mathrm{C}_{2} \mathrm{~S}(\%)$ & $10-30$ & $15-35$ & $10-30$ & $50-55$ & $15-40$ & & \\
$\mathrm{C}_{3} \mathrm{~A}(\%)$ & $0-17$ & $0-8$ & $0-15$ & $3-6$ & $0-5$ & & \\
$\mathrm{C}_{4} \mathrm{AF}(\%)$ & $6-18$ & $6-18$ & $6-18$ & $8-15$ & $10-18$ & & \\
Área Superficial & $300-400$ & $280-380$ & $450-600$ & $280-320$ & $290-350$ & & \\
Específica $\left(\mathrm{m}^{2} / \mathrm{kg}\right)$ & & & & & & \\
\hline
\end{tabular}

(1 - ASTM, 1986; 2 - ASTM, 2009; 3 - CEN, 2000; 4 - ABNT,1991b; 5 - ABNT,1991a; 6 ABNT,1991c; 7 - ABNT,1994; 8 - ABNT,1992; 9 - ABNT,1991d; 10 - ABNT,1991e)

\subsection{Propriedades e características importantes do Cimento Portland}

As propriedades do cimento Portland dependem de uma série de fatores, como a escolha dos compostos (tipo de cimento, agregados, etc), do tipo de processamento (mistura, colocação, cura, etc), da natureza química e física do sistema (produtos de hidratação, estrutura dos poros, etc) e do ambiente de utilização (temperatura, umidade, presença de espécies químicas agressivas, etc) (SKALNY et al, 2002). A performance mecânica e a durabilidade também dependem desses fatores.

Diversas características são importantes para determinarmos a melhor escolha do material à utilização proposta. Entre elas, estão a finura, os processos de pega e endurecimento, a hidratação do cimento e o calor de hidratação. Essas características serão abordadas nas próximas seções.

\subsubsection{Finura do cimento}

A finura do cimento afeta sua reatividade com água, uma vez que quanto mais fino o cimento, mais rápida será sua reação. A taxa de reatividade e, consequentemente o desenvolvimento da resistência são intensificados pela moagem mais fina do cimento. Esse processo é o que dá origem ao cimento Portland tipo V de alta resistência inicial (CP VARI) (MEHTA \& MONTEIRO, 2008). 


\subsubsection{Processos de pega e endurecimento}

$\mathrm{O}$ endurecimento se inicia quando o cimento perde sua plasticidade devido ao consumo de água livre. A perda de água livre é resultado da formação de produtos de hidratação e da adsorção superficial por produtos como a etringita e o C-S-H e a evaporação.

De acordo com Mehta e Monteiro (2008), o termo pega se refere à solidificação da pasta plástica de cimento. O início da solidificação, chamado início de pega, marca o ponto em que a pasta se torna não trabalhável. Já o tempo que leva para se solidificar completamente se chama final de pega. O tempo final de pega representa o início do período de hidratação do $\mathrm{C}_{3} \mathrm{~S}$, reação que continua por várias semanas. Apenas ao longo dessas semanas a pasta de cimento começa a adquirir resistência.

Com o passar do tempo, o preenchimento dos espaços vazios da pasta com os produtos de reação de hidratação reduz sua porosidade e permeabilidade, aumentando a sua resistência. Esse ganho de resistência é chamado endurecimento (MEHTA \& MONTEIRO, 2008).

\subsubsection{Calor de Hidratação}

Os compostos do cimento Portland possuem alta energia química acumulada e, quando hidratados, reagem com a água para formar produtos em estado mais estáveis de baixa energia, liberando calor. A quantidade de calor liberada e as taxas de liberação de calor de hidratação são usadas como índices de suas reatividades. A FIG. 5 apresenta a taxa de liberação de calor de uma pasta de cimento durante o tempo de pega e endurecimento. Os períodos identificados como A, B, C e D podem ser chamados de a) reação inicial; b) período de indução; c) período de aceleração e d) período de desaceleração. Ao se misturar cimento com água, observa-se uma rápida evolução de calor, resultante da dissolução de aluminatos e sulfatos (período A). Esse período termina rapidamente e se inicia um período de baixo calor de reação (período B). Após algumas horas, a evolução do calor apresenta outro pico, correspondente ao calor de formação da etringita (C). Após a formação da etringita, observa-se uma diminuição do calor de reação no período de desaceleração (D). Para um cimento Portland comum, cerca de $50 \%$ do calor potencial é liberado nos três primeiros dias e $70 \%$ nos sete primeiros dias de hidratação. 


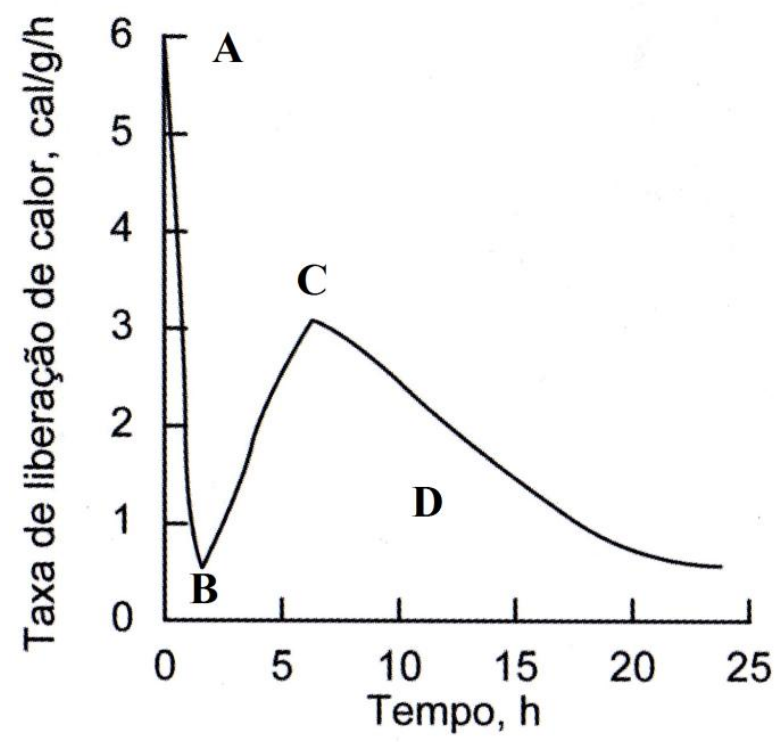

FIGURA 5 - Taxa de liberação de calor de uma típica pasta de cimento Portland durante as primeiras idades (MEHTA \& MONTEIRO, 2008)

A hidratação do cimento é o fenômeno em que uma suspensão, em temperatura ambiente, se transforma em um sólido rígido. A hidratação é caracterizada pelas reações de cada fase presente no clínquer ou adicionada ao cimento Portland com a água. Os fenômenos químicos e microestruturais que caracterizam a hidratação desses materiais são complexos e interdependentes.

\subsection{A hidratação do cimento Portland}

A hidratação do cimento envolve as reações de seus compostos anidros com a água, resultando em produtos que possuem características de pega e endurecimento. Esse fenômeno envolve vários processos químicos, cada um com uma diferente taxa de reação e cinética. O conhecimento avançado sobre os mecanismos de hidratação envolve questões fundamentais nesse processo que dão origem aos diversos períodos observados.

Scrivener \& Nonat (2011) descrevem a hidratação como um processo de dissolução e precipitação. A fase anidra não pode se transformar na fase hidratada sem a passagem de íons pela solução. O transporte dos componentes da solução pelos poros da pasta de cimento ou sua adsorção na superfície dos sólidos é chamado processo de difusão. A fase de crescimento envolve a ligação e a incorporação de moléculas na superfície de um sólido, produzindo material suficiente na solução para a aparição da fase menos solúvel, o precipitado. O processo de nucleação, descrito por esses autores, é responsável pelo inicio da precipitação dos sólidos de forma heterogênea. De acordo com a teoria clássica de 
nucleação, o período de indução necessário para estabelecer núcleos aptos para crescer depende da supersaturação e da energia interfacial dos cristais. A complexação é descrita como a etapa em que ocorrem reações entre íons simples para formar íons complexos ou adsorvidos na superfície dos sólidos formados. O processo de adsorção é a acumulação de íons ou outras moléculas na superfície do sólido.

O pico principal da hidratação é caracterizado por um período de aceleração, seguido de um período de desaceleração (FIG. 5). Em vários estudos, a parte de aceleração do pico pode ser modelada pelo processo de nucleação e crescimento do C-S-H. O mecanismo responsável pela desaceleração após cerca de 10 horas é mais difícil de identificar, mas algumas propriedades são apontadas como responsáveis, como a formação de uma camada de produtos de hidratação que desacelera a reação, a redução da área superficial disponível para reagir e mudanças locais de concentração na superfície dos grãos. Em pastas de cimento, o preenchimento dos espaços também tem um papel importante. (SCRIVENER \& NONAT, 2011).

Cimentos com diferentes fases de clínquer irão reagir a taxas diferentes. As fases alita e aluminato são as mais reativas, com graus de reação entre 40 e $60 \%$ para alita e 20-80\% para o aluminato em um dia. Já a belita apresenta uma reação muito lenta (menor que $20 \%$ entre 7 e 10 dias). Isso ocorre pois as concentrações dos produtos de hidratação da alita inibem a dissolução da belita (MEHTA \& MONTEIRO, 2008).

A química macroscópica do cimento Portland hidratado é definido como um sistema contendo $\mathrm{CaO}, \mathrm{Al}_{2} \mathrm{O}_{3}, \mathrm{Fe}_{2} \mathrm{O}_{3}, \mathrm{SiO}_{2}$, e $\mathrm{H}_{2} \mathrm{O}$. A soma de C-S-H e de Portlandita compreendem cerca de $70 \%$ do cimento hidratado.Em geral, a pasta de cimento hidratada consiste, em peso, de (MEHTA \& MONTEIRO, 2008):

- $40-50 \%$ de gel de C-S-H

- $20-25 \%$ da fase Portlandita $\left[\mathrm{Ca}(\mathrm{OH})_{2}\right]$

- 10 - $20 \%$ das fases AFm, AFt e ferrita

- $10-20 \%$ solução intersticial

- $0-5 \%$ componentes menores $\left(\mathrm{NaOH}, \mathrm{KOH}, \mathrm{Mg}(\mathrm{OH})_{2}, \ldots\right)$

A resistência a longo prazo e as propriedades de transporte de cimentos com adições de MSC é normalmente superior às propriedades do cimento Portland. Isso é explicado pelo refinamento da estrutura porosa. 


\subsubsection{A hidratação das fases de silicato de cálcio}

A hidratação inicial das fases de silicato de cálcio é caracterizada pela rápida reação do $\mathrm{C}_{3} \mathrm{~S}$ com a água. Ao entrar em contato com a água, o $\mathrm{C}_{3} \mathrm{~S}$ se dissolve segundo a equação abaixo, que possui um amplo sinal exotérmico (VICHOT \& OLLIVIER, 2008).

$$
\mathrm{C}_{3} \mathrm{~S}+3 \mathrm{H}_{2} \mathrm{O} \leftrightarrows 3 \mathrm{Ca}^{2+}+\mathrm{H}_{2} \mathrm{SiO}_{4}{ }^{2-}+4 \mathrm{OH}^{-}
$$

Os produtos desta reação formam o silicato de cálcio hidratado (xCaO.SiO $\mathrm{SiH}_{2} \mathrm{y}$ ou C-S-H), segundo a equação abaixo. A formação do C-S-H deixa a solução supersaturada em relação a este produto.

$$
\mathrm{x} \mathrm{Ca}{ }^{2+}+\mathrm{H}_{2} \mathrm{SiO}_{4}{ }^{2-}+2(\mathrm{x}-1) \mathrm{OH}^{-}+\mathrm{yH}_{2} \mathrm{O} \leftrightarrows \mathrm{xCaO} \cdot \mathrm{SiO}_{2} \cdot \mathrm{yH}_{2} \mathrm{O}
$$

O C-S-H não é um composto bem definido e sua estequiometria é definida pela relação molar $\mathrm{CaO} / \mathrm{SiO}_{2}$ (ou $\mathrm{C} / \mathrm{S}$ ). A sua relação $\mathrm{C} / \mathrm{S}$ varia entre 1,5 a 2,0 e o conteúdo de água varia ainda mais (MEHTA \& MONTEIRO, 2008). A liberação de cálcio pela alita torna a solução supersaturada em relação a esse íon, o que resulta na precipitação de hidróxido de cálcio, ou Portlandita (VICHOT \& OLLIVIER, 2008).

$$
\mathrm{Ca}^{2+}+2 \mathrm{OH}^{-} \leftrightarrows \mathrm{Ca}(\mathrm{OH})_{2}
$$

A hidratação da belita também leva à formação de C-S-H e de Portlandita, porém essa reação é muito mais lenta quando comparada às reações que ocorrem com a alita.

A hidratação da alita pode ser dividida em quatro etapas: a) reação inicial; b) período de baixa reação; c) período de aceleração e d) período de desaceleração.

O primeiro processo pode ser classificado como um processo de dissolução/dissociação, em que as moléculas da superfície do sólido se separam quando entram em contato com a água. Durante a dissolução, a superfície de contato total diminui enquanto o material constituinte do cimento é consumido, para depois aumentar durante a precipitação, quando ocorre a formação dos produtos. Por isso a taxa de reação nessa fase varia constantemente com o desenvolvimento da mesma (BULLARD, et al, 2011; SCRIVENER \& NONAT, 2011). Tão $\log$ o o $\mathrm{C}_{3} \mathrm{~S}$ entra em contato com a água ele dissolve e as concentrações de cálcio, silicato e de hidróxido aumentam na solução, diminuindo o 
grau de saturação e a taxa de dissolução. Porém, nem todos os detalhes desse processo são claros.

O período de baixa reação ou período de indução é tema de muito debate. Dois mecanismos principais são propostos para explicar a diminuição rápida da taxa de reação: a hipótese da barreira metaestável e a hipótese da etapa lenta de dissolução.

Por um longo tempo, a teoria mais aceita sobre esse tema foi a de que a adição de água leva a formação de uma camada contínua e fina de silicato de cálcio hidratado metaestável (C-S-H(m)), que isola as camadas mais profundas da alita da solução e inibe a reação. Essa teoria, chamada de hipótese da barreira metaestável, tem alguns problemas, uma vez que o primeiro precipitado é um hidrato do silicato de cálcio, que possui estrutura radicalmente diferente do $\mathrm{C}_{3} \mathrm{~S}$ e é muito difícil que esse material forme uma barreira impermeável na superfície (SCRIVENER \& NONAT, 2011). Bullard et al (2011) relatou que não é possível observar a presença dessa camada contínua nas últimas pesquisas sobre o assunto, mesmo com métodos de análise da superfície mais modernos.

Quanto à hipótese da etapa lenta de dissolução, Bullard et al (2011) relatou que algumas pesquisas apontam que a dissolução do $\mathrm{C}_{3} \mathrm{~S}$ diminui rapidamente devido à formação de uma camada superficial hidroxilada na superfície do $\mathrm{C}_{3} \mathrm{~S}$ em contato com a água e, por isso, a dissolução de íons desta camada ocorre muito lentamente. A taxa de dissolução diminui com o aumento da concentração de hidróxido de cálcio.

O crescimento do C-S-H causa a diminuição da concentração de silicato e a proporção molar $\mathrm{Ca} / \mathrm{Si}$ aumenta. Em alguns minutos, a solução torna-se saturada em $\mathrm{C}$-S$\mathrm{H}$, porém não saturada em respeito ao $\mathrm{C}_{3} \mathrm{~S}$. A dissolução é um mecanismo de controle da taxa de reação e fornece uma maneira satisfatória de relacionar a diminuição da taxa de dissolução da alita com soluções não saturadas no período inicial de reação.

O período de aceleração é normalmente relacionado aos mecanismos de nucleação e crescimento. O controle da taxa de hidratação nessa etapa é relacionado à nucleação e ao crescimento heterogêneo do C-S-H na superfície da alita.

O mecanismo que causa o início do período de aceleração da reação de hidratação é ainda alvo de pesquisas. Isso porque dois eventos ocorrem quase que simultaneamente nesse ponto para a hidratação do $\mathrm{C}_{3} \mathrm{~S}$ em uma pequena quantidade de solução: a) precipitação do hidróxido de cálcio (portlandita); e b) crescimento acelerado do C-S-H. Algumas hipóteses ou mecanismos para o surgimento da etapa de aceleração foram propostos por Bullard et al (2011) e estão apresentados abaixo: 
- Nucleação e crescimento do C-S-H: Acontece no final do período de reação lenta e o controle da taxa ocorre pela camada protetora do C-S-H metaestável que se torna quimicamente instável e expõe o $\mathrm{C}_{3} \mathrm{~S}$, altamente solúvel.

- Crescimento do C-S-H estável: núcleos de C-S-H estáveis, já formados durante a reação inicial, crescem em uma taxa exponencial. Não ocorreria a formação de barreira de hidratos metaestáveis.

- Ruptura da barreia inicial: A camada da barreira de C-S-H metaestável seria semipermeável. A solução dentro é fechada e a saturação de $\mathrm{C}_{3} \mathrm{~S}$ causa uma pressão osmótica e sua ruptura.

- Nucleação da Portlandita: A nucleação e o crescimento da portlandita começam a ocorrer em taxas controladas e, indiretamente, controlaria a taxa de crescimento do C-S-H.

Bullard et al (2011) descrevem que, desde 1989, a hipótese da nucleação da portlandita se tornou contraditória com alguns experimentos, porém alguns experimentos mais recentes mostram que essa hipótese pode ser conciliada com o início da nucleação e crescimento.

Quanto ao período de indução, sua duração pode estar relacionada à presença de alumínio na solução, proveniente da dissolução da alita e das fases aluminato. Íons Al podem prejudicar o crescimento dos núcleos de C-S-H formados inicialmente. O C-S-H continua a se formar, porém não crescem como o esperado enquanto íons $\mathrm{Al}$ estiverem disponíveis na solução. Uma vez que todos os íons Al forem adsorvidos no núcleo do C-S$\mathrm{H}$, outros núcleos livres de $\mathrm{Al}$ começam a crescer e a hidratação acelera da mesma forma que um cimento de puro $\mathrm{C}_{3} \mathrm{~S}$.

Em idades avançadas, o processo de hidratação é controlado pelo processo de difusão, porém outros processos são também importantes, como o consumo de partículas menores, restando apenas as maiores para reagir, a falta de espaço no cimento e a falta de água, uma vez que o volume do produto hidratado é menor que o volume combinado do reagente do cimento + água (cerca de 5 a 10\%). Dessa forma, a diminuição no volume leva à formação de poros e uma diminuição na umidade relativa. 


\subsubsection{A Hidratação das fases aluminatos}

O processo de hidrólise e dissolução do aluminato de cálcio, quando entra em contato com a água, conduzem à reação abaixo representada e a formação das fases Afm e Aft.

$$
\mathrm{Ca}_{3} \mathrm{Al}_{2} \mathrm{O}_{6}+6 \mathrm{H}_{2} \mathrm{O} \leftrightarrows 3 \mathrm{Ca}^{2+}+2 \mathrm{Al}^{3+}+12 \mathrm{OH}^{-}
$$

O primeiro produto de hidratação é a fase AFm, um monossulfoaluminato de baixa cristalização que pode ser descrita como $\mathrm{C}_{2} \mathrm{AH}_{8}$ e $\mathrm{C}_{4} \mathrm{AH}_{13}$. Com o tempo, essa fase metaestável se transforma em hidrogranadas, $\mathrm{C}_{3} \mathrm{AH}_{6}$. Essa reação ocorre naturalmente em aproximadamente 25 minutos e a taxa aumenta conforme a temperatura aumenta. Essa rapidez, porém, é indesejada, pois diminui o período de trabalho do cimento antes do seu uso. A adição de gipsita abranda a reação e o período de trabalho do cimento é restituído (SCRIVENER \& NONAT, 2011; BULLARD, et al, 2011).

Ao contrário da alita, a reação dos aluminatos não mostra um período de baixa reatividade e ocorre quase instantaneamente na ausência de sulfato de cálcio (gipsita), liberando uma grande quantidade de calor de hidratação. (MEHTA \& MONTEIRO, 2008).

$\mathrm{O}$ sulfato de cálcio é adicionado na forma de gipsita $\left(\mathrm{CaSO}_{4} \cdot 2 \mathrm{H}_{2} \mathrm{O}\right)$, mas anidrita $\left(\mathrm{CaSO}_{4}\right)$ e hemidrato $\left(\mathrm{CaSO}_{4} \cdot 0,5 \mathrm{H}_{2} \mathrm{O}\right)$ também estão presentes como impurezas. Com a adição de sulfato, o produto de formação principal da hidratação é a etringita $\left(\mathrm{C}_{3} \mathrm{~A} \cdot 3 \mathrm{CaSO}_{4} \cdot 32 \mathrm{H}_{2} \mathrm{O}\right)$. Quando todo o sulfato de cálcio adicionado é consumido, a taxa de reação volta a subir, ocorrendo a formação de monossulfoaluminato (BULLARD, et al, 2011; MEHTA \& MONTEIRO, 2008; SCRIVENER \& NONAT, 2011).

A questão mais importante referente à hidratação do $\mathrm{C}_{3} \mathrm{~A}$ é sobre a diminuição da taxa de reação. Algumas possíveis explicações para esse fenômeno podem ser: a) a formação de etringita diminui a reação por formar uma barreira de difusão na superfície do $\mathrm{C}_{3} \mathrm{~A}$; b) outras fases, como AFm, diminui a reação da mesma forma; e c) a reação é diminuída diretamente pela adsorção de algumas espécies provenientes da dissolução do sulfato de cálcio.

O padrão para a reação do $\mathrm{C}_{3} \mathrm{~A}$, em presença de gipsita, é semelhante ao do $\mathrm{C}_{3} \mathrm{~S}$, com uma reação inicial rápida seguida de um período de baixa reação antes da taxa de reação aumentar novamente.

Bullard et al (2011), em seu trabalho, atribuem a desaceleração ao processo de adsorção dos íons sulfato na superfície do $\mathrm{C}_{3} \mathrm{~A}$, uma vez que a morfologia da etringita dificilmente fornece uma barreira substancial ao transporte de íons. Além disso, foi 
observada uma formação mais acentuada da fase $\mathrm{AFm}$ quando o $\mathrm{C}_{3} \mathrm{~A}$ é hidratado com gipsita do que quando é hidratado com hemidrato, apesar da desaceleração com hemidrato ser mais rápida.

A formação de etringita e o consumo de sulfato durante o período estão relacionados com a dissolução do $\mathrm{C}_{3} \mathrm{~A}$. Dessa forma, a redução na taxa seria devido a mudanças na dissolução do $\mathrm{C}_{3} \mathrm{~A}$ e não devido a uma barreira.

\subsubsection{Interação entre as fases nos processos de hidratação}

A interação entre as duas fases descritas anteriormente altera a hidratação da pasta de cimento e é claramente observada a influência de um processo no outro. Vários trabalhos estão sendo realizados como intuito de investigar as diferenças nas reações de hidratação de cada fase quando a hidratação ocorre em sistemas puros ou multifásicos para identificar os efeitos das interações entre elas (BULLARD, et al, 2011; QUENNOZ, et al, 2011; SCRIVENER \& NONAT, 2011).

Esses processos podem ocorrer em série, em paralelo ou em uma combinação mais complexa. Quando em série, produtos de um tornam-se reagentes em outro processo e, se um processo tiver uma taxa de reação muito lenta, este se torna limitante da reação, o chamado processo de controle da taxa da reação. A dificuldade em isolar os processos químicos para estudos mais detalhados torna muito difícil a análise de um sistema complexo, como o de hidratação do cimento Portland.

Quennoz et al (2011) desenvolveu um trabalho para investigar as diferenças entre as reações das fases do cimento individualmente quando a hidratação ocorre em sistemas puros ou multifásicos para identificar os efeitos da interação entre elas. Foi demonstrado que os íons alumínio, provenientes do aluminato, podem prejudicar a reação da alita, que ocorre em menor proporção na presença desses íons. Na presença de sulfato, no entanto, a reação da alita é acelerada e a reação do aluminato é retardada.

\subsubsection{Formação da estrutura}

Soroka (2003) aponta em seu livro texto que os produtos de hidratação são formados e depositados na superfície, formando uma densa camada que causa o encapsulamento dos grãos do cimento. Com o andamento da hidratação, essa camada se torna mais espessa e a taxa de hidratação diminui, dependendo da taxa de difusão da água por essa camada. Quanto maior a espessura da camada, mais lenta será a taxa de reação e isso explica o declínio na taxa de hidratação com o tempo. Espera-se que, com o aumento 
da espessura da camada após algum tempo, o processo de hidratação pare mesmo na presença de água em quantidade suficiente, o que implica na presença de núcleos de material não hidratado dentro dos grãos do cimento com diâmetros muito grande.

\subsubsection{Mecanismos que alteram o processo de hidratação}

A hidratação do cimento pode ser alterada também por vários processos. Aumento de temperatura, de pressão e a presença de agentes químicos agressivos durante a cura do cimento pode ocasionar mudanças nos produtos formados e nas taxas de reação.

Quanto à hidratação da alita, o aumento da temperatura, pode diminuir o período de reação lenta e aumentar a taxa de penetração de hidrogênio na superfície. Isso ocorre porque a cinética das reações é maior conforme aumenta a temperatura do ambiente. Em aplicações de cimentação de poços de petróleo, a dependência da pressão também se torna importante.

Soroka (2003) discute que a composição dos produtos de hidratação muda com o aumento da temperatura de cura. A proporção $\mathrm{Ca} / \mathrm{Si}$ do cimento aumenta e a proporção de água/ $\mathrm{SiO}_{2}$ diminui nessas condições. Ainda de acordo com este autor, a temperatura acelera a taxa de hidratação e, dessa forma, acelera a formação do C-S-H. Observa-se que a porosidade diminui de acordo com essa aceleração. Conforme a hidratação progride, no entanto, esse efeito torna-se menos evidente e o efeito da temperatura em longo prazo é menor. Por outro lado, esse autor argumenta que o aumento da temperatura durante o período de pega do cimento afeta o tamanho dos poros. Embora a porosidade em uma pasta curada a $60^{\circ} \mathrm{C}$ seja menor, o volume dos poros é maior. Um volume de poros maior resulta em maior permeabilidade da pasta de cimento e, por isso, a temperatura possui um efeito deletério na resistência em longo prazo.

A hidratação de materiais cimentícios com diferentes adições leva à formação de novos produtos. Melhorar ou desenvolver novos produtos à base de cimento requer o conhecimento prévio de quais compostos são formados, em qual taxa os produtos são formados ou como os produtos formados podem preencher os espaços entre os grãos anidros. Isso é obtido pela termodinâmica, pela cinética da reação, pelas propriedades do material anidro e hidratado e pela microestrutura final e suas propriedades.

A redução da permeabilidade pode aumentar a resistência do concreto à ataques químicos (reduzindo a difusão) e diminuir a lixiviação do hidróxido de cálcio para a água subterrânea. A adição de materiais suplementares como escória de alto forno, cinza 
volante e sílica ativa ao cimento têm sido reportado como um importante redutor da permeabilidade do concreto (PHILIPOSE, 1988).

\subsection{A durabilidade do cimento Portland}

$\mathrm{O}$ entendimento das reações químicas que conduzem o endurecimento do cimento é fundamental para prever seu desempenho e durabilidade. A análise da durabilidade das estruturas de cimento nas condições prevalecentes no ambiente do repositório é necessária para avaliar a viabilidade de armazenar rejeitos radioativos em formações geológicas. Isto requer a caracterização e modelagem do comportamento em longo prazo do cimento em relação à sobrecarga mecânica e degradação química.

Para suportar a vida útil estabelecida para o repositório, o concreto deve sofrer uma deterioração muito pequena durante este período. A durabilidade será influenciada por três principais aspectos : a) ambiente no qual o concreto estará exposto; b) qualidade dos materiais selecionados para a formulação, suas proporções no concreto e sua composição química; e c) tensões internas provocadas por sobrecarga normal do cimento e em eventos como terremotos, etc (PHILIPOSE, 1988).

Em contato prolongado com a água subterrânea, o material cimentício sofre um processo de degradação lento, porém contínuo, que pode comprometer sua integridade em longo prazo (GALÍNDEZ \& MOLINERO, 2010).

Análise da estabilidade dessas estruturas requer o entendimento do comportamento mecânico, da química do ponto de vista termodinâmico e prever e evolução química em longo prazo do ambiente do repositório, da solução dos poros e das fases do cimento hidratado (BERNER, 1992; XIE, et al, 2008).

O comportamento mecânico de materiais a base de cimento é caracterizado por deformações plásticas (por dois mecanismos principais: cisalhamento em baixas pressões de confinamento e colapso dos poros em altas pressões de confinamento) e danos causados pelo crescimento de microfraturas. Em muitas ocasiões esses materiais são submetidos à sobrecarga mecânica e à degradação química quando em contato com ambiente agressivo como chuva, água do mar ou fluidos ácidos (XIE, et al, 2008).

Vários fatores podem contribuir para a degradação química do cimento. Os mecanismos de degradação podem ser classificados por: a) causas internas, como as reações álcali-agregado, expansão térmica do cimento e agregados, estresse interno causado por sobrecarga externa, efeitos de deformação e encolhimento, cristalização do gel; e b) causas externas, como deterioração química por ataques de cloreto, sulfato, 
corrosão por ácido carbônico, corrosão ácida por ácidos orgânicos, escala de congelamento/descongelamento (em ambientes de baixas temperaturas), lixiviação e dissolução de cálcio (descalcificação) e ações de microorganismos. Outros fatores são perda do equilíbrio químico, o processo de dissolução por fenômenos de difusão, cinética da degradação etc. (PHILIPOSE, 1988; XIE, et al, 2008).

A porosidade da pasta de cimento, por exemplo, pode ser significantemente aumentada pelo processo de dissolução do cálcio, ou descalcificação, que promove o esgotamento da portlandita (de 36\% em materiais de boa qualidade para $60 \%$ em materiais degradados) (DEBY, et al, 2009; GALÍNDEZ \& MOLINERO, 2010). O encolhimento da pasta de cimento é também muito maior em materiais degradados devido ao colapso sofrido pelos poros quando a porosidade se torna muito grande.

Outros processos podem modificar a porosidade do material, como a formação de calcita, que causa o bloqueio dos poros e a redução da permeabilidade, podendo aumentar a vida útil do material. Em seu estudo, Galíndez e Molinero (2010) mostram que a degradação em ambientes com água subterrânea que apresente baixo teor de bicarbonato pode ser muito acelerado em relação a um ambiente normal e que essa degradação está relacionada à ausência do processo de precipitação de calcita.

A fase silicato de cálcio hidratado (C-S-H), que domina a química da solução intersticial do cimento hidratado, mostra um comportamento não trivial e modelar suas propriedades termodinâmicas é parte central deste problema (BERNER, 1992).

\subsubsection{Reação álcalis-agregado}

Das reações internas que ocorrem no concreto, as reações entre o cimento e os agregados e suas compatibilidades durante expansão térmica é uma questão importante. A resistência de um concreto é dependente da distribuição espacial dos poros e das microfissuras na interface dos agregados.

A reação álcali agregados ocorre entre determinados minerais presentes na pasta e íons hidroxila associados aos álcalis, essencialmente óxido de sódio $\left(\mathrm{Na}_{2} \mathrm{O}\right)$ e óxido de potássio $\left(\mathrm{K}_{2} \mathrm{O}\right)$. As reações desse tipo podem ser classificadas em três tipos: a) reação sílica-álcali; b) reação álcali-silicato; e c) reação álcali-carbonato.

Embora seja mais importante em concretos devido à presença de agregados, essas reações podem ocorrer no ambiente do repositório, uma vez que compostos minerais presentes na água subterrânea penetram na pasta de cimento, podendo atuar como tal. 
As reações sílica-álcali (RSA) são extremamente complexas e influenciadas pela estrutura molecular, pela mudança constante do ambiente (química) e pela heterogeneidade da mistura. Nessa reação, são formados produtos expansivos na superfície dos sítios de reação, o que causa rachaduras na superfície de concretos, alterando a durabilidade da estrutura.

Os dois efeitos estruturais mais importantes causados pelas RSA são: a) a formação, ou o aumento, de microfissuras existentes na matriz do concreto, levando a uma resistência final menor do que a esperada e, em algumas circunstâncias, uma real redução da resistência com o tempo; e b) a expansão do concreto, levando a geração de forças de imobilização tanto no interior de zonas não reativas quanto no reforço ou elementos estruturais (COURTIER, 1990). No geral, o efeito das RSA é maior no núcleo do que na superfície.

Há duas considerações importantes na avaliação final das RSA: a) a interação entre os membros devido à expansão total; e b) interação entre a expansão no interior e a superfície do concreto.

O principal problema associado à RSA é, sem dúvida, as microfissuras causadas na superfície, que podem levar à corrosão e à instabilidade da superfície. Normalmente, a corrosão é agravada pela carbonatação nas fissuras.

Foi observado que o tamanho das partículas pode influenciar na cinética e na expansão total observada nas RSA. Frações muito finas não causam expansão. No entanto, partículas maiores causam diminuição da expansão em idades precoces, enquanto aumenta em idades mais avançadas (DUNANT \& SCRIVENER, 2012; MULTON, et al, 2010).

Multon et al (2010) demonstrou que para diferentes tamanhos de agregados reativos e diferentes quantidades de álcalis, a expansão aumenta linearmente com o conteúdo de álcalis e não linearmente com o diâmetro do agregado. Os autores descrevem que o aumento da expansão por RSA com o tamanho das partículas pode ser explicado pelo efeito das conexões dos poros com o agregado reativo. Além disso, esse autor demonstra que a expansão diminui na medida em que se aumenta a quantidade de partículas reativas menores. Esse efeito pode ser explicado pelo consumo de álcalis pelas partículas pequenas. Quando os grãos do agregado são dispersos na pasta de cimento, eles liberam sílica, abaixando a proporção $\mathrm{Ca} / \mathrm{Si}$ do $\mathrm{C}-\mathrm{S}-\mathrm{H}$, aumentando sua habilidade de fixar os álcalis. A falta de álcalis livres reduz o pH da solução dos poros e, consequentemente, reduz o ataque dos agregados reativos. Dessa forma, a expansão é reduzida ou não ocorre (MULTON, et al, 2010). 
A reação álcali-silicato ocorre em um processo semelhante ao do item anterior, porém ela é mais lenta devido ao fato de os materiais estarem presentes na matriz do cimento. Nesse tipo de reação, os íons hidroxila reagem com silicatos, formando um gel expansivo. Também pode causar defeitos estruturais no material e causar sua corrosão e instabilidade.

A reação álcali-carbonato ocorre em entre o hidróxido de magnésio e os álcalis do cimento. Isso gera o enfraquecimento da zona entre os agregados e a pasta de cimento e provoca fissuras.

\subsubsection{A formação de etringita primária e secundária}

Existem duas maneiras da etringita se formar no cimento: a formação da etringita primária e a formação de etringita secundária. A etringita primária é formada imediatamente (poucas horas ou dias) após a cura do cimento e de forma homogênea. A expansão a partir desse tipo de etringita, se ocorrer, não causa nenhum efeito deletério no material (COLLEPARDI, 2003; LOTHENBACH, et al, 2010).

A formação de etringita primária é um processo natural e ocorre a partir da reação entre a gipsita (adicionada ao clínquer do cimento) e o aluminato de cálcio $\left(\mathrm{C}_{3} \mathrm{~A}\right)$. Nesse caso, ocorre um aumento da resistência mecânica do cimento/concreto associada a este fenômeno. Depois de um tempo, ela é substituída pelo monossulfato. Em vários cimentos, porém, ela persiste indefinidamente (KATSIOTI, et al, 2011).

Pequenos cristais de etringita são mais susceptíveis à degradação do que os maiores (devido à grande área superficial). Por isso os cristais menores tendem a se recristalizar em espaços vazios ou fraturas existentes no material. A presença de cristais grandes de etringita nesses lugares não representa necessariamente perigo ao material, apenas indica que o cimento expandiu e é, normalmente, uma consequência das fraturas, não uma causa delas (TAYLOR, et al, 2001).

A formação da etringita secundária ocorre após o período de cura do cimento (após vários meses ou anos) e seu endurecimento. Dessa forma, a expansão é heterogênea e produz fissuras e fragmentação no cimento/concreto. O efeito deve-se à expansão localizada e não uniforme apenas na área do concreto onde a etringita é formada. Este tipo de formação é responsável pelos danos em ataques de sulfatos ao concreto. Por isso, para efeitos de durabilidade e avaliação de segurança do cimento, a etringita secundária se mostra muito mais importante e sua formação deve ser evitada (KATSIOTI, et al, 2011). 
A formação de etringita secundária ocorre em materiais submetidos à cura em temperaturas acima de $70^{\circ} \mathrm{C}$. Danos em estruturas de concreto, principalmente pré moldados, submetidos à cura em alta temperatura, são atribuídos à formação de etringita. $\mathrm{Na}$ maioria dos casos de danos em concreto, a dimensão se torna maior devido à ocorrência da reação sílica álcali (RSA) (TAYLOR, et al, 2001).

A formação de etringita secundária em materiais não submetidos a altas temperaturas é atribuído ao excesso de $\mathrm{SO}_{3}$ no clínquer, em diferentes fases, onde ocorre a liberação lenta de sulfato, como a anidrita e fases de silicato. Porém não há dados experimentais nem cálculos normativos que provem que o excesso de $\mathrm{SO}_{3}$ no clínquer é uma causa provável de danos por formação de etringita secundária (TAYLOR, et al, 2001).

A temperatura e o aquecimento permanente ou intermitente do material são dois fatores importantes para a formação da etringita secundária. A cura em temperatura entre $80-100^{\circ} \mathrm{C}$ e em água causa maior expansão e mais rápida do que quando o material é armazenado em ambiente com umidade elevada apenas (ADAMOPOULOU et al, 2011).

A expansão é influenciada pelo tamanho dos agregados (lento com calcário e em pasta pura e rápida em quartzo) e é favorecida por fraquezas pré-existentes na matriz do cimento, como as deixadas pelas reações sílica álcali (RSA). A RSA normalmente ocorre antes e pode causar danos que são evidenciados pela formação de etringita secundária depois.

A fase C-S-H e a solução intersticial dos poros competem com a etringita pelo sulfato. Essa tendência faz com que o pH da solução intersticial aumente. Cada fase produz as seguintes espécies que reagem para formar a etringita (TAYLOR, et al, 2001):

$$
\begin{array}{ll}
\text { C-S-H: } & \mathrm{Ca}^{2+} ; \mathrm{SO}_{4}{ }^{2-} ; \mathrm{OH}^{-} ; \mathrm{H}_{2} \mathrm{O} \\
\text { Monossulfato: } & \mathrm{Ca}^{2+} ; \mathrm{SO}_{4}{ }^{2-} ; \mathrm{OH}^{-} ; \mathrm{Al}(\mathrm{OH})_{4}{ }^{-} ; \mathrm{H}_{2} \mathrm{O} \\
\text { Solução intersticial: } & \mathrm{SO}_{4}{ }^{2-} ; \mathrm{H}_{2} \mathrm{O} \\
6 \mathrm{Ca}^{2+}+2 \mathrm{Al}(\mathrm{OH})_{4}{ }^{-}+4 \mathrm{OH}^{-}+3 \mathrm{SO}_{4}{ }^{2-}+26 \mathrm{H}_{2} \mathrm{O} \rightarrow \mathrm{Ca}_{6}\left[\mathrm{Al}(\mathrm{OH})_{6}\right]_{2} \cdot\left(\mathrm{SO}_{4}\right)_{2} \cdot 26 \mathrm{H}_{2} \mathrm{O}
\end{array}
$$

São facilmente observadas fissuras em volta das partículas dos agregados que contenham etringita. Essas fissuras são de tamanho proporcional ao tamanho das próprias partículas, pois elas se formam nos arredores dos agregados. A etringita também pode estar presente em fissuras formadas na pasta (TAYLOR, et al, 2001).

A supersaturação em relação aos íons citados fornece a força que conduz o crescimento do cristal e a pressão que o cristal precisa para crescer aumenta com o grau de saturação. O dano causado pela sua formação depende da pressão, da geometria do cristal e 
das redondezas dele. O cristal formado não exerce pressão se pode ser depositado em um lugar onde não é necessária a pressão. Danos causados por crescimento em um único poro são improváveis devido ao volume afetado ser muito pequeno. A resistência de cimentos/argamassas é controlada por falhas, algumas centenas, e os danos devem ocorrer em várias regiões diferentes, que devem estar próximas para causar danos (COLLEPARDI, 2003; TAYLOR, et al, 2001).

A região mais próxima ao produto interno têm seus espaços mais preenchidos (grau de supersaturação maior) e o monossulfato formado ali, ao se transformar em etringita, causará maior pressão e dano. A etringita formada nas fraturas mais distantes não gera pressão de expansão significativa. Se o material é reaquecido e depois armazenado, ocorrerá novamente expansão e fissuras. Nessa situação, a etringita é depositada nas fissuras na interface dos agregados e em outros lugares durante o primeiro período de estocagem. Durante o segundo aquecimento, esses locais são preenchidos com monossulfato e a pressão pode aumentar quando a etringita for formada novamente (COLLEPARDI, 2003; LEE, et al, 2005; LOTHENBACH, et al, 2010)

Três tipos de fatores podem governar a expansão: a) química, que determina a quantidade de etringita formada; b) microestrutura da pasta, que determina o estresse que pode resultar dessa formação e; c) microestrutura do concreto ou argamassa, que determina como o material responde a esse estresse (TAYLOR, et al, 2001)

O processo de expansão está diretamente associado a quantidade de etringita formada, porém a quantidade formada é dificilmente prevista, pois nem todo $\mathrm{SO}_{3}$ ou $\mathrm{Al}_{2} \mathrm{O}_{3}$ presente na matriz de cimento estará disponível para formação de etringita. A maioria do $\mathrm{Al}_{2} \mathrm{O}_{3}$, por exemplo, estará na fase $\mathrm{C}-\mathrm{S}-\mathrm{H}$, na ferrita não reagida ou nos produtos de hidratação da ferrita. O C-S-H também contém uma parte do $\mathrm{SO}_{3}$ (TAYLOR, et al, 2001).

$\mathrm{Na}$ ausência de $\mathrm{SO}_{3}$, não ocorre formação de etringita. Se está em excesso, a etringita estará presente no final do tratamento quente, ou seja, forma-se etringita primária, e não monossulfato. $\mathrm{Na}$ ausência de $\mathrm{Al}_{2} \mathrm{O}_{3}$, novamente não ocorre formação de etringita. Porém em excesso, a etringita não se forma e sim o monossulfato.

Em cimentos com alta concentração de $\mathrm{Al}_{2} \mathrm{O}_{3}$, qualquer coisa que se ligue a ele aumenta a tendência à formação de etringita. As variáveis que afetam a quantidade de $\mathrm{Al}_{2} \mathrm{O}_{3}$ disponível para a formação das fases sulfoaluminatos são (TAYLOR, et al, 2001):

- Quantidade de $\mathrm{MgO}$ : Liga-se ao $\mathrm{Al}_{2} \mathrm{O}_{3}$ e pode explicar a tendência de expansão do cimento com o aumento de sua quantidade 
- Proporção de $\mathrm{Al}_{2} \mathrm{O}_{3} / \mathrm{Fe}_{2} \mathrm{O}_{3}$ : A expansão proveniente de formação de etringita secundária em cimentos resistentes a sulfatos é insignificante. Isso pode ocorrer porque muito do $\mathrm{Al}_{2} \mathrm{O}_{3} / \mathrm{Fe}_{2} \mathrm{O}_{3}$ estão nas hidrogranadas ou nas fases tipo hidrotalcita na hidratação.

- Temperatura e tempo de cura: A expansão aumenta em temperaturas de cura acima de $100^{\circ} \mathrm{C}$ e em tempos de cura acima de 3 dias. Ao mesmo tempo, é diminuída ou praticamente eliminada se o tempo de cura se estende entre 7 ou 10 dias.

- Adição de escória ou cinza volante: Essas adições podem causar diminuição da expansão. Isso pode ocorrer devido, em parte, ao aumento da quantidade de $\mathrm{Al}_{2} \mathrm{O}_{3}$ para a formação de sulfoaluminatos (formação de monossulfato e não etringita)

- $\mathrm{CO}_{2}$ : Liga-se ao $\mathrm{Al}_{2} \mathrm{O}_{3}$ formando fases carboaluminatos. Carbonatação é considerada como ter um importante papel na formação de etringita secundária, mas falta evidencias de que é um requisito para isso.

A expansão associada à formação de certa quantidade de etringita é influenciada pela microestrutura do material em que ela é depositada. Algumas considerações podem ser feitas em relação à expansão (TAYLOR, et al, 2001):

1. A expansão é diminuída ou eliminada se o material é plástico e facilmente deformado. Isso explica porque a etringita formada nas primeiras horas da hidratação não causa danos.

2. A expansão é afetada pelo espaço disponível nos poros. Uma parte da etringita produzida se deposita nos espaços livres e não contribui para a expansão. Por essa razão, a expansão não depende simplesmente da quantidade de etringita produzida.

3. A expansão depende também da característica do espaço do poro. A etringita irá produzir mais expansão se os poros em que ela depositar forem pequenos e fracamente conectados do que se eles forem largos e amplamente conectados.

Espera-se, dessa forma, que a formação de etringita secundária seja maior conforme aumenta o grau de hidratação do cimento, uma vez que ocorre a diminuição do volume, do tamanho e da conectividade dos poros capilares. Foi observado que o aumento da quantidade de alita, da finura ou uma diminuição da proporção água/cimento tendem a aumentar a expansão, assim como o aumento no tempo de cura ou na temperatura (acima de limites normais) (TAYLOR, et al, 2001). 
$\mathrm{O}$ andamento da hidratação diminui a permeabilidade da pasta. Isso pode explicar porque, embora a expansão seja maior em materiais com baixa proporção água/cimento, a taxa de expansão nesses materiais pode ser muito baixa. A microestrutura do material determina como ele responde ao estresse causado pela formação da etringita. Expansão por etringita em uma pasta pura e sem danos é muito baixa. O material é forte o suficiente para resistir ao estresse, retardar a reação e a expansão resultante. Isso limita a extensão em que a reação ocorre. Material com calcário tem um comportamento parecido, devido à força da ligação entre a pasta e o agregado. A ligação entre quartzo e pasta é bem mais baixa, sendo portanto um cimento que propicia que a reação e a expansão ocorram mais rapidamente (COLLEPARDI, 2004; TAYLOR, et al, 2001)

Qualquer coisa que enfraqueça o material diminui sua habilidade de resistir à expansão. Concretos curados à alta temperatura ou submetidos a aquecimento/resfriamento podem ter microfraturas, propiciando vários tipos de danos, entre eles a formação de etringita secundária.

A expansão causada pela formação de etringita secundária é mais baixa para armazenamento no ar do que para armazenamento em água. Além disso, se armazenado em soluções de hidróxido de álcalis, a expansão é retardada ou eliminada. O álcali inibi a formação de etringita, deixando o sulfato no C-S-H, no monossulfato ou na solução do poro. Quando ocorre armazenamento do cimento em água, o pH da solução intersticial diminui devido à lixiviação do sulfato do C-S-H e a consequente substituição do monossulfato por etringita. A reação sílica álcali (RSA) diminui o $\mathrm{pH}$ da solução do poro, favorecendo a formação de etringita pelo aumento da quantidade de íons $\mathrm{Ca}^{2+}$. (TAYLOR et al, 2001)

Para cimentos com alto teor de $\mathrm{SO}_{3}$, a expansão é favorecida com o aumento do conteúdo de álcalis. Em cimentos com baixo teor de $\mathrm{SO}_{3}$, o teor de álcali não tem efeito significante (LEE et al, 2005, LOTHENBACH, et al, 2010).

O efeito é o oposto com o que ocorre com álcalis durante o armazenamento e o conteúdo de álcali na mistura inicial é perdido por lixiviação durante o armazenamento. Dessa forma, algum efeito do álcali na mistura inicial deve-se a algo que ocorre durante a cura à quente. Dois mecanismos podem explicar essas observações (TAYLOR, et al, 2001):

1. Quando a etringita está presente no tratamento a quente, se o conteúdo de $\mathrm{SO}_{3}$ está acima de determinado limite, o alto $\mathrm{pH}$ favorece a formação de monossulfato do 
em detrimento da etringita, estando o sulfato na fase C-S-H e na solução dos poros. Se essa situação existe durante o armazenamento, a expansão é inibida. Se isso ocorre durante a cura a quente, o baixo teor de etringita aumenta a quantidade que pode ser formada durante o armazenamento, aumentando a possibilidade de expansão.

2. O aumento do teor de álcali com alto teor de $\mathrm{SO}_{3}$ tende a aumentar a taxa de hidratação da alita em idades primárias. Isso pode aumentar a expansão produzida pela formação de etringita durante o armazenamento.

\subsubsection{Ataque de sulfatos}

Ataque de sulfato pode ser definido pela reação entre íons sulfato e os produtos de hidratação do cimento. Esse ataque pode causar danos e é uma ameaça real para a durabilidade de concreto em ambientes agressivos.

$\mathrm{O}$ principal dano causado por ataque de sulfatos em estruturas à base de cimento é a formação de etringita secundária, que pode levar à expansão e fissura. A formação de etringita secundária pode ocorrer por duas vias principais: a) ataque de sulfato proveniente de fontes internas; e b) ataque de sulfato proveniente de fontes externas.

A reação desses íons com os produtos do cimento leva à formação de gipsita, etringita e/ou taumasita e pode causar fissuras, fragmentação, amolecimento, expansão, perda de resistência e outros danos. Fatores físicos e químicos, tais como o pH da solução e a sua concentração, o cátion associado, o tipo de ligante, a proporção água/ligante e as condições de cura podem influenciar o ataque (EL-HACHEM, et al, 2012).

\subsubsection{Ataque de sulfatos de fontes internas.}

Em seu trabalho, Collepardi (2003) classificou os danos por ataque de sulfato interno na pasta de cimento. Segundo o autor, esses danos podem ocorrer por meio de dois diferentes mecanismos: a) decomposição térmica e reformação de etringita em ambiente saturado em temperatura ambiente; e b) abordagem holística baseada em microfissuras, tardia liberação de sulfato e exposição à água. Na ausência de qualquer um desses elementos, não ocorre a formação da etringita secundária.

De acordo com o mecanismo de decomposição térmica, a etringita primária é decomposta quando o cimento é curado em altas temperaturas $\left(>70^{\circ} \mathrm{C}\right)$ e se forma novamente em concreto/cimento exposto à água, causando expansão e fissuras. Fissuras já existentes (como as ocasionadas em reações sílica álcali) serviriam de depósito para a 
etringita secundária. Collepardi (2003), no entanto, levantou algumas dúvidas sobre essa teoria, como a ocorrência aleatória em concretos curados em temperaturas acima de $70^{\circ} \mathrm{C}$, ou a formação de etringita secundária em concretos com cura em temperaturas comuns, por exemplo. Esse autor acredita que a decomposição térmica só pode ocorrer em concreto que tenha sido curado em altas temperaturas $\left(80-90^{\circ} \mathrm{C}\right)$. A expansão e a reformação de etringita são favorecidas pela pré-existência de fraturas, com clínquer de alto teor de enxofre e em cimento Portland com alto teor de sulfatos.

De acordo com o mecanismo de abordagem holística, Collepardi (2003) cita três fatores necessários para a formação da etringita secundária:

1. O surgimento de micro fissuras: As microfissuras, necessárias para a formação e deposição da etringita na pasta de cimento, podem ser causadas por vários motivos, entre eles: a) a ocorrência de reações sílica álcali (RSA); b) Cura da pasta de cimento em altas temperaturas, excessiva taxa de aquecimento/resfriamento ou cura preliminar muito curta à baixa temperatura; c) efeitos de clima, como alterações de umidade/secagem ou aquecimento/resfriamento; d) cargas na pasta de cimento em serviço; e) retração plástica em estruturas com cura incompleta; f) ciclos de congelamento/descongelamento; e g) grande esforço localizado em estruturas;

2. A liberação posterior de sulfato: A liberação tardia de sulfato pode ocorrer de três modos diferentes: a) a partir de agregados contaminados com gipsita, com partículas de sulfato de cálcio muito grossas, que não são disponibilizadas imediatamente para a formação da etringita primária e podem alimentar a formação da etringita secundária; b) decomposição térmica da etringita primária em concretos com superaquecimento; e c) íons sulfato adsorvidos na fase C-S-H são liberados lentamente em concretos curados em altas temperaturas; e

3. A exposição à água. A exposição à água é um fator importante na formação da etringita secundária, pois ela transporta, através dos poros, os íons sulfato, aluminato e cálcio para as microfissuras onde se deposita a etringita. Estruturas expostas à chuva ou sol são mais vulneráveis ao ataque interno de sulfato, uma vez que a temperatura de super saturação do meio é alterada, favorecendo a deposição da etringita.

\subsubsection{Ataque de sulfatos de fontes externas}

Os íons sulfato estão presentes na água subterrânea, água do mar, solos e em águas residuais. No ataque externo de sulfato, duas fases podem ser identificadas: a 
primeira fase é um período de dormência, onde nenhuma ou pouca expansão é observada e, em seguida, ocorre uma fase de expansão significativa (MEHTA \& MONTEIRO, 2008).

A duração da primeira fase pode exceder vários anos, por isso a dificuldade, nos ensaios de laboratório, de identificar os mecanismos de expansão e de degradação e de avaliar da durabilidade do cimento. Por outro lado, pode-se observar que a penetração de sulfato ocorre principalmente por meio de difusão. O inicio da expansão é diretamente relacionado à difusão dos íons sulfato. Um aumento na concentração de sulfato leva ao aumento na lixiviação de hidróxido de cálcio para fora da matriz de cimento. A lixiviação segue a reação abaixo (EL-HACHEM, et al, 2012):

$$
\mathrm{Ca}(\mathrm{OH})_{2}+2 \mathrm{H}_{3} \mathrm{O}^{+} \rightarrow \mathrm{Ca}^{2+}+4 \mathrm{H}_{2} \mathrm{O} \quad \text { Equação 3-6 }
$$

El-Hachem et al (2012) relatam ainda que, em concentrações muito altas de sulfato, a proporção de lixiviação muda, pois além da lixiviação da portlandita, uma quantidade adicional de íons cálcio é liberada, pela dissolução da gipsita, de acordo com a equação abaixo:

$$
\mathrm{CaSO}_{4} \cdot 2 \mathrm{H}_{2} \mathrm{O} \rightarrow \mathrm{SO}_{4}{ }^{2-}+\mathrm{Ca}^{2+}+2 \mathrm{H}_{2} \mathrm{O}
$$

Durante a fase de dormência, a lixiviação é o fenômeno predominante e que explica a diminuição da massa. Na segunda fase, a formação de produtos expansivos induzem a expansão e o aumento da massa. Estudos mostraram que a ocorrência do ataque externo de sulfato pode ser diferente em diferentes valores de $\mathrm{pH}$ da solução.

Os danos por ataque de sulfato de fonte externa ocorrem quando há interação entre solo ou água rico em sulfatos e a pasta de cimento. Para ocorrer, é necessário que algumas condições sejam preenchidas: a) alta permeabilidade do cimento/concreto; b) cimento com alta quantidade de $\mathrm{C}_{3} \mathrm{~A}$; c) alta proporção água/cimento; d) ambiente rico em sulfato; e e) presença de água (COLLEPARDI, 2003; EL-HACHEM, et al, 2012).

$\mathrm{O}$ ataque de sulfatos por fatores externos pode se manifestar de diversas formas, dependendo de qual processo químico é predominante. $\mathrm{O}$ ataque de sulfato na portlandita $(\mathrm{CH})$ ou no gel de C-S-H forma gipsita. Esse processo pode causar expansão e fragmentação, além da descalcificação do C-S-H (responsável pela capacidade de ligação da pasta de cimento), ocasionando em perda de resistência e adesão da pasta de cimento. 
$\mathrm{O}$ ataque de sulfato nos hidratos de aluminatos de cálcio (C-A-H) e monossulfatos forma a etringita. Esse processo é o principal responsável pelas fissuras e fragmentação do cimento por formação de etringita secundária.

$\mathrm{O}$ ataque de sulfato na Portlandita $(\mathrm{CH})$ ou no gel de C-S-H na presença de íons carbonato forma um composto chamado taumasita. A formação de taumasita é acompanhada de perda muito grande de resistência e adesão, pois é capaz de transformar concreto endurecido em uma pasta, uma vez que parte significante do $\mathrm{C}-\mathrm{S}-\mathrm{H}$ pode ser destruído pela reação. Esse processo pode ocorrer com qualquer tipo de sulfato em ambientes úmidos e com baixa temperatura $\left(<10^{\circ} \mathrm{C}\right)$.

Por último, o ataque de sulfatos de magnésio no C-S-H, pode levar à formação de gipsita, brucita e sílica gel. Esse tipo de ataque pode diminuir a resistência e aderência devido à descalcificação do C-S-H.

\subsubsection{Lixiviação e dissolução de $\mathrm{Ca}(\mathrm{OH})_{2}$ - descalcificação do C-S-H}

Se o repositório for construído em uma formação granítica, é esperado um fluxo de água subterrânea em direção ao cimento ou concreto. Dessa forma, o concreto é suscetível à lixiviação, o que pode comprometer o confinamento em longo prazo do repositório. A redução da resistência do concreto em até $50 \%$ é considerada como uma falha na barreira artificial. A resistência do concreto é diminuída em aproximadamente $1,5 \%$ para cada $1 \%$ de perda total de cálcio, ou seja, a lixiviação de $33 \%$ da portlandita $\left[\mathrm{Ca}(\mathrm{OH})_{2}\right]$ livre pela água subterrânea pode reduzir sua resistência para 50\% (PHILIPOSE, 1988).

A dissolução de cálcio pela água leva a dissolução do conteúdo de Portlandita $\left[\mathrm{Ca}(\mathrm{OH})_{2}\right]$ e a descalcificação da fase C-S-H com consequente diminuição da proporção $\mathrm{Ca} / \mathrm{Si}(\mathrm{C} / \mathrm{S})$. A cinética da degradação é influenciada pela microestrutura (composição) do material, pela natureza química e pela temperatura da solução agressiva, assim como pelo gradiente do fluido intersticial. A degradação química leva ao aumento da porosidade do material e afeta o comportamento elástico e as propriedades de transporte (difusão e permeabilidade) (BUZZI, et al, 2008).

$\mathrm{O}$ aumento rápido do $\mathrm{pH}$ verificado na pasta de cimento se deve à dissolução rápida dos cristais de Portlandita. Por outro lado, a perda de massa das amostras de cimento continua a aumentar com o tempo durante o processo de lixiviação. A porosidade da pasta de cimento é muito maior quando ocorre o processo de dissolução do cálcio (de $36 \%$ em materiais sem a degradação para $60 \%$ em materiais degradados). O encolhimento 
do material também é muito maior em materiais degradados do que aqueles em bom estado (XIE, et al, 2008).

A formação de água com pH muito alcalino é devida à lixiviação de hidróxido de sódio e potássio em idades iniciais de hidratação. À medida que o material está em um grau de hidratação mais avançado e esses álcalis já foram liberados, a dissolução da portlandita controla o pH da solução intersticial, mantendo o valor de $\mathrm{pH}$ em cerca de 12 . Depois, com pH entre 12,6 e 10, ocorre a dissolução de cálcio proveniente do gel de C-S-H (CALVO, et al, 2010).

O processo de descalcificação do gel de C-S-H gera uma proporção muito baixa de $\mathrm{C} / \mathrm{S}$, entre 0,25 e 0,6, nessa região e em seguida ocorre a inclusão de $\mathrm{Mg}$ e $\mathrm{Cl}$ na fase sólida, para compensar o defeito de carga causado pela descalcificação (CALVO, et al, 2010; CODINA, et al, 2008).

\subsubsection{Diferenças mineralógicas em função da temperatura}

Com o aumento da temperatura, surgem no concreto algumas rachaduras (microfissuras) devido à incompatibilidade térmica entre os agregados e a pasta endurecida. Geralmente em altas temperaturas, a pasta de cimento pode se contrair devido à desidratação e/ou decomposição dos hidratos, enquanto os agregados normalmente se expandem após a sua desintegração. A pasta de cimento expande quando a temperatura aumenta da ambiente até $150^{\circ} \mathrm{C}$. Entre $150^{\circ} \mathrm{C}$ e $300^{\circ} \mathrm{C}$ começa a contração e quando chega a $800^{\circ} \mathrm{C}$ a contração chega a quase $2 \%$. Assim, o estresse térmico e rachaduras ocorrem em exposição a altas temperaturas (XU, et al, 2003).

Quando o concreto é aquecido em uma taxa muito alta, um gradiente de temperatura pode se formar entre as camadas externas e internas e causar rachaduras. Outra causa de rachaduras pode ser a criação de uma pressão de vapor muito alta nos poros e causar um tipo de rachadura chamada fragmentação térmica do concreto (XU, et al, 2003).

As rachaduras são visíveis em volta dos cristais de Portlandita e depois avançam para as áreas próximas aos grãos não hidratados de cimento. Essas rachaduras são microscópicas e, por isso, são indicadas como micro fissuras. As fissuras aumentam significantemente em temperaturas acima de $300^{\circ} \mathrm{C}$. Quando a temperatura máxima fica abaixo de $300^{\circ} \mathrm{C}$, os danos no concreto são apenas algumas fissuras localizadas na ligação entre os agregados e a pasta de cimento (XU, et al, 2003).

Durante o resfriamento, a re-hidratação da $\mathrm{CaO}$ dissociada pode prorrogar uma fissura já existente ou desenvolver uma nova fissura pois ocorre aumento significante do 
volume nesse processo. Portanto, a redução na quantidade de hidróxido de cálcio na pasta de cimento, adicionando cinza volante, por exemplo, pode ajudar a reduzir as fraturas devido ao resfriamento (XU, et al, 2003).

As micro fissuras no concreto começam a ser significantes somente quando a temperatura de exposição é acima de $450^{\circ} \mathrm{C}$. No repositório, é esperado uma temperatura nas camadas mais profundas de, no máximo, $60^{\circ} \mathrm{C}$.

\subsubsection{Reação com a formação geológica}

A interação entre a pasta de cimento e a barreira geológica deve ser estudada com cuidado. A barreira geológica deve possuir baixa permeabilidade, levando a um fluxo de água baixo, e estabilidade em escala geológica. Dessa forma, a rocha escolhida deve ser livre de falhas geológicas, que é uma descontinuidade que se forma pela fratura das rochas por ação de forças tectônicas. Essas falhas causam um grande fluxo de água subterrânea, o que causaria degradação maior e mais rápida na pasta de cimento (LEINZ, 1998).

$\mathrm{O}$ cimento fornece à água subterrânea próxima ao repositório um alto pH que pode alterar as propriedades da formação geológica pela de dissolução dos minerais presentes na rocha.

Além disso, a rocha não pode, em longo prazo, sofrer grandes alterações que causem sua degradação. A degradação da rocha por fatores ambientais é um processo longo e contínuo e que pode, ao liberar íons e componentes químicos na água subterrânea, prejudicar o desempenho do repositório e da pasta de cimento.

Nas condições do clima brasileiro, as rochas tendem a se decompor, alterando física e quimicamente seus minerais, graças à ação de agentes atmosféricos e biológicos. Esse processo é chamado intemperismo e os principais processos relacionados são a degradação física (ligada à variações de temperatura), degradação química e degradação química-biológica (LEINZ, 1998).

\subsubsection{Comportamento da pasta de cimento sob irradiação}

O encapsulamento e a retenção de radionuclídeos são duas das razões de se utilizar materiais a base de cimento em imobilização, estruturas e como material para preenchimento dos espaços em repositórios. A retenção dos radionuclídeos na matriz de cimento pode ser modelada pelo comportamento dos radionuclídeos em vários períodos, inclusive após a suposta degradação do cimento. A lixiviação desses radionuclídeos depende exclusivamente das propriedades dos mesmos (BERNER, 1992). 
Além disso, a água residual dos poros do cimento é afetada pela decomposição (radiólise) em campos de radiação ionizante, cuja intensidade é função de muitos fatores: dose de radiação, tipo de radiação e composição química inicial da água. Esse problema é comum nos repositórios por causa dos campos de radiação provenientes das FRSD e pode gerar acúmulo de gás hidrogênio $\left(\mathrm{H}_{2}\right)$, que é explosivo, até em baixas concentrações. (BOUNIOL, 2010; BOUNIOL \& BJERGBAKKE, 2008; OJOVAN et al, 2003).

A segurança do repositório é reduzida também pelo acúmulo de outros produtos de radiólise. Os principais produtos da radiólise são os gases óxidos de nitrogênio e ozônio. O ozônio possui propriedades oxidativas, o que pode oxidar os óxidos de nitrogênio para $\mathrm{NO}_{2}$ que, na presença água, pode produzir ácido nítrico, em alguns casos, concentrado. A formação de ácido nítrico pode aumentar a corrosão do revestimento das fontes. Dessa forma, o aumento da concentração de ozônio em solução aquosa também acelera o processo de corrosão (OJOVAN et al, 2003).

Para analisar a segurança da instalação, é necessária uma avaliação precisa das fontes de $\mathrm{H}_{2}$ e a descrição completa da radiólise a seus fenômenos. Bouniol e Bjergbakke (2008) relatam que em cerca de $10^{-7}$ a $10^{-6}$ segundos após a radiação gama atravessar o material, a decomposição da água já ocorre e leva à formação de oito espécies primárias (quatro moléculas: $\mathrm{H}_{2}, \mathrm{H}_{2} \mathrm{O}_{2}, \mathrm{OH}^{-}$e $\mathrm{H}_{3} \mathrm{O}^{+}$e quatro radicais: $\mathrm{e}_{\mathrm{aq}}^{-}, \mathrm{H}^{\cdot}, \mathrm{OH}^{\cdot}$ e $\mathrm{HO}_{2}{ }^{-}$), uniformemente distribuídos na solução (etapa homogênea)

Em pH entre 12 e 14, predominante no cimento, os produtos radicais apresentam um aumento em sua concentração enquanto os produtos moleculares apresentam diminuição moderada.

Após a primeira etapa da reação, as espécies podem reagir com a água, com íons hidroxila $\left(\mathrm{OH}^{-}\right)$ou entre elas, através de pelo menos sete reações de equilíbrio ácidobase e cerca de sessenta reações diferentes. Essas reações são correspondentes à decomposição da água em meio alcalino desprovido de outro soluto reagente, e levam à formação tanto de produtos secundários (moléculas ou radicais) iguais aos produtos primários ou novos, como $\mathrm{O}_{2}, \mathrm{O}_{3}$, etc (BOUNIOL \& BJERGBAKKE, 2008).

Segundo Bouniol e Bjergbakke (2008), todas as espécies primárias são convertidas, principalmente, para seus equivalentes básicos, de acordo com as equações abaixos:

$$
\begin{aligned}
& \mathrm{H}^{\cdot}+\mathrm{OH}^{-} \leftrightarrows \mathrm{e}_{\mathrm{aq}}^{-} \\
& \mathrm{OH}^{-}+\mathrm{OH}^{-} \leftrightarrows \mathrm{O}^{--}+\mathrm{H}_{2} \mathrm{O}
\end{aligned}
$$




$$
\begin{aligned}
& \mathrm{HO}_{2}{ }^{-}+\mathrm{OH}^{-} \leftrightarrows \mathrm{O}_{2}{ }^{--}+\mathrm{H}_{2} \mathrm{O} \\
& \mathrm{H}_{2} \mathrm{O}_{2}+\mathrm{OH}^{-} \leftrightarrows \mathrm{HO}_{2}{ }^{-}+\mathrm{H}_{2} \mathrm{O} \\
& \mathrm{HO}_{2}{ }^{-}+\mathrm{OH}^{-} \leftrightarrows \mathrm{O}_{2}{ }^{2-}+\mathrm{H}_{2} \mathrm{O}
\end{aligned}
$$

As novas espécies possuem reatividade mais forte do que o radical $\mathrm{e}_{\mathrm{aq}}{ }^{-} \mathrm{e}$ mais fraca do que espécies desprotonadas de oxigênio, como o radical superóxido $\mathrm{O}_{2}{ }^{-}$que é muito mais reativo do que o homologo $\mathrm{HO}_{2}$.

$\mathrm{O}$ comportamento da pasta de cimento Portland exposta à longos períodos de radiação gama é função de três parâmetros essenciais: a taxa de dose, o grau de saturação dos poros e a quantidade inicial de $\mathrm{H}_{2}$.

Nesse sistema, a produção de gases de radiólise é uniforme no interior dos poros e cria uma variação global de pressão sem um gradiente de transporte. Isso leva a um estado de equilíbrio progressivo em cerca de um ano, após um aumento significante da quantidade de $\mathrm{H}_{2}, \mathrm{HO}_{2}{ }^{-}$e $\mathrm{O}_{2}{ }^{-}$. É observado um aumento na quantidade de $\mathrm{O}_{2}$ em proporções mais moderadas, limitada permanentemente pelo radical $\mathrm{e}_{\mathrm{aq}}$. Antagonicamente com o $\mathrm{H}_{2}$, o radical $\mathrm{O}^{--}$diminui quando o meio enriquece em $\mathrm{H}_{2}$. $\mathrm{O}$ alto nível de $\mathrm{O}_{2}{ }^{-}$ alcançados confirma o status de que o radical oxigenado é menos reativo. Não foi observado mudança de $\mathrm{pH}$ durante a radiólise, com concentrações de $\mathrm{H}_{3} \mathrm{O}^{+}$constantes nos trabalhos de Bouniol e Bjergbakke (2008).

Em termos de pressão total, o aumento do volume de fases é responsável pelo estado de equilíbrio adiantado, enquanto a supressão desse volume é seguido por um rápido estado de equilíbrio. A pressão obtida através da Lei de Henry é significantemente menor em alta saturação em relação à uma porosidade insaturada. Na ausência de um deposito de gases tampão, isso ocorre devido ao fato de que quando todo o $\mathrm{H}_{2}$ disponível está na fase aquosa, a taxa de ataque pelo radical $\mathrm{O}^{-}$é máxima.

O estado estável da radiólise procede tanto a partir de uma lei de ação das massas no sistema reacionário na solução como a partir da ativação especifica da cadeia de reações, ou então do controle mineralógico da solução intersticial pelo $\mathrm{CaO}_{2} \cdot 8 \mathrm{H}_{2} \mathrm{O}$.

Como conclusão, a matriz cimentícia exposta à irradiação tipo gama em um sistema fechado apresenta diferentes mecanismos de regulação capazes de limitar os efeitos da radiólise ou até mesmo torna-la não perigosa (não há pressurização importante no material). Esse comportamento não pode ser extrapolado para sistemas abertos ou submetidos à irradiações tipo alfa (BOUNIOL \& BJERGBAKKE, 2008). 


\subsection{Técnicas para análise das propriedades do cimento Portland}

Algumas técnicas para análise da hidratação da pasta de cimento são: a) calorimetria isotérmica; b) monitoramento contínuo da contração química; c) Análise quantitativa in-situ por difração de raios X; d) Análise semi-contínua da composição da solução dos poros; e) espectroscopia de ressonância magnética nuclear (NMR); f) espalhamento de nêutrons quasi-elásticos (QENS); e g) espalhamento de nêutrons a baixo ângulo (SANS).

A comparação dos diferentes métodos podem trazer percepções no processo de hidratação que não poderiam ser obtidas analisando apenas por um método. Uma das maneiras de se avaliar os efeitos deletérios na pasta de cimento é analisar as mudanças químicas e mineralógicas de seus constituintes e correlacionar essas mudanças com suas propriedades (SCRIVENER, et al, 2004). 


\section{MATERIAIS E MÉTODOS}

A durabilidade de materiais a base de cimento foi investigada por meio de testes acelerados de laboratório, cujos resultados foram usados para estimar a vida útil de pasta de cimento, sob as condições de exposição ao ambiente no entorno de um repositório profundo para rejeitos radioativos. Em ensaios acelerados, amostras do material a ser estudado são confeccionadas e sua degradação é acelerada de forma intencional em relação ao tempo esperado de serviço, presumindo que os efeitos nas condições de laboratório possam prever os efeitos nas condições ambientais reais do repositório.

Experimentos multifatoriais foram utilizados de modo a estimar os efeitos dos fatores individuais e sinergéticos sobre o comportamento do material. Corpos de prova (cps) foram submetidos às condições esperadas no repositório, que incluem: a) alta temperatura e pressão; b) ataque de agentes agressivos proveniente da água subterrânea e c) altas doses de radiação ionizante proveniente das fontes. $\mathrm{O}$ tempo em que os cps foram submetidos a essas condições e os níveis de exposição seguiram a metodologia recomendada pela ASTM E632 - "Norma para o desenvolvimento de ensaios acelerados para auxiliar a predição do tempo de vida útil de componentes e materiais de construção" (ASTM, 1996).

A temperatura no local mais profundo do repositório tende a acelerar a degradação da pasta de cimento e a perda de água dos poros. A temperatura de ensaio corresponde ao limite superior esperado na profundidade de 400 metros, considerando um grau geotérmico de $1^{\circ} \mathrm{C}$ a cada 30 metros de profundidade. Duas temperaturas foram escolhidas neste trabalho, considerando $20^{\circ} \mathrm{C}$ como temperatura ambiente e $60^{\circ} \mathrm{C}$ como a maior temperatura esperada nessa profundidade.

Durante o período de funcionamento da instalação, a pasta de cimento sofre degradação como consequência de reações químicas com os íons presentes na água subterrânea. Para avaliar esse efeito, as amostras foram imersas em solução salina (SS) contendo os principais cátions e ânions encontrados em uma água subterrânea típica de rochas graníticas, de acordo com levantamento bibliográfico prévio. Os dados do levantamento e das concentrações de cada íon na solução de imersão inicial do trabalho estão apresentados nas TAB. 3 e 4, respectivamente. Além disso, outras amostras foram imersas em água destilada (AD) com o intuito de avaliar a lixiviação de íons da pasta de 
cimento para a solução, enquanto outras foram armazenadas a seco (AS), para controle experimental.

O tempo de exposição em que as amostras ficaram imersas ou armazenadas, a diferentes temperaturas, foi de 30 dias e 60 dias, com o intuito de verificar a evolução dos níveis de degradação com o tempo.

Após esses ensaios, as amostras foram irradiadas em irradiador de ${ }^{60} \mathrm{Co}$ com $3.408 \mathrm{TBq}$, com a taxa de dose máxima de 4kGy/h, no Centro de Aceleradores Ciclotron (CAC), do IPEN-CNEN/SP. A irradiação simulou o campo de radiação no ambiente do repositório, até acumular a dose de radiação correspondente àquela depositada pelas fontes radioativas seladas mais intensas e relevantes do inventário brasileiro, ou seja, ${ }^{137} \mathrm{Cs},{ }^{226} \mathrm{Ra}$ $\mathrm{e}^{241} \mathrm{Am}-\mathrm{Be}$. As amostras foram irradiadas por 100 horas, até acumular a dose de 400kGy.

Os ensaios acelerados de degradação seguiram os protocolos estabelecidos em testes preliminares (Vicente et al, 2008), com a confecção de cps de pasta de cimento na GRR-IPEN. A pasta de cimento usada nesse trabalho foi composta apenas de água e cimento. A mistura foi preparada com relações água/cimento (A/C) de 0,35 , ou seja, seguiu a relação $\mathrm{A}=0,35 \mathrm{C}$, em que $\mathrm{A}$ é a massa de água e $\mathrm{C}$ é a massa de cimento anidro.

Dessa forma, cps de pasta de cimento foram confeccionados com a composição utilizada em trabalhos de cimentação de poços de extração de água e da indústria do petróleo e gás, considerando a disponibilidade e viabilidade econômica do tipo de cimento empregado. A pasta de cimento foi utilizada por ser o material cimentício mais simples e eficaz para a utilização prevista, evitando assim que outros compostos (ex. areia, pedra, etc) possam interagir com o ambiente do repositório.

Neste trabalho, foi empregado o Cimento Portland Tipo V, que segue especificações da norma da ABNT NBR - 5733 - Cimento Portland com Alta Resistência Inicial (ABNT, 1991c) e é equivalente ao Cimento Portland Tipo III-HES da norma ASTM C-150 - "Especificações Técnicas para Cimento Portland" (ASTM, 1986). Por não haver norma brasileira específica para confecção de cp's de pasta de cimento, adaptou-se a ABNT NBR - 5738 - Concreto - Procedimento para moldagem e cura de corpos de prova (ABNT, 2003) para esse fim. As dimensões dos cp's foram menores que o recomendado nessa norma para possibilitar a irradiação homogênea.

Os ensaios acelerados foram conduzidos com cps cilíndricos e cúbicos. Os cilíndricos, com dimensões de 2,5 cm x $5 \mathrm{~cm}$ (diâmetro x altura), foram confeccionados em moldes plásticos e mantidos selados por sete dias, tempo necessário para sua cura (FIG. 6 e 7). 
TABELA 3 - Composição típica da água subterrânea em meios graníticos (adaptado da literatura)

\begin{tabular}{|c|c|c|c|c|c|c|c|c|c|c|c|c|c|}
\hline \multirow{2}{*}{ Meios } & \multicolumn{13}{|c|}{ Espécie Iônica } \\
\hline & $\mathrm{Ca}$ & $\mathrm{Na}$ & $\mathrm{K}$ & $\mathrm{Mg}$ & $\mathrm{Cl}$ & $\mathrm{F}$ & $\mathrm{HCO}_{3}$ & $\mathrm{SO}_{4}$ & $\mathrm{Si}$ & $\mathrm{Fe}$ & $\mathrm{Cu}$ & $\mathrm{NO}_{3}$ & $\mathrm{pH}$ \\
\hline $01^{*}$ & $1,89 \cdot 10^{0}$ & $2,10.10^{0}$ & $8,00 \cdot 10^{-3}$ & $1,73 \cdot 10^{-3}$ & $6,34.10^{0}$ & - & $1,00 \cdot 10^{-2}$ & $5,60 \cdot 10^{-1}$ & $5,60 \cdot 10^{-1}$ & $2,41.10^{-4}$ & $6,40 \cdot 10^{-8}$ & - & 7,7 \\
\hline $02^{\dagger}$ & $5,00 \cdot 10^{-3}$ & $7,00 \cdot 10^{-3}$ & - & $2,00 \cdot 10^{-3}$ & $2,00 \cdot 10^{-3}$ & $1,00 \cdot 10^{-4}$ & $3,40 \cdot 10^{-2}$ & $2,00 \cdot 10^{-3}$ & - & $2,00 \cdot 10^{-4}$ & - & $9,00 \cdot 10^{-4}$ & 6,5 \\
\hline $03^{\ddagger}$ & $4,40 \cdot 10^{-2}$ & $1,50 \cdot 10^{-2}$ & $1,09 \cdot 10^{-3}$ & $9,84 \cdot 10^{-3}$ & $1,19 \cdot 10^{-2}$ & $1,79 \cdot 10^{-4}$ & $1,46.10^{-1}$ & $1,34 \cdot 10^{-2}$ & $9,24 \cdot 10^{-3}$ & - & - & - & 8,3 \\
\hline $04^{\ddagger}$ & $6,00 \cdot 10^{-3}$ & $9,89 \cdot 10^{-2}$ & $2,09 \cdot 10^{-3}$ & $3,84 \cdot 10^{-3}$ & $1,38 \cdot 10^{-2}$ & $3,29 \cdot 10^{-4}$ & $3,09 \cdot 10^{-1}$ & $9,98 \cdot 10^{-4}$ & $9,97 \cdot 10^{-3}$ & - & - & - & 7,9 \\
\hline $05^{\ddagger}$ & $1,68 \cdot 10^{0}$ & $2,10 \cdot 10^{0}$ & $8,00 \cdot 10^{-3}$ & $4,15 \cdot 10^{-2}$ & $6,34 \cdot 10^{0}$ & $1,50 \cdot 10^{-3}$ & $1,00 \cdot 10^{-2}$ & $5,60 \cdot 10^{-1}$ & $4,09 \cdot 10^{-3}$ & - & - & - & 7,7 \\
\hline $06^{\ddagger}$ & $8,28 \cdot 10^{-2}$ & $4,85 \cdot 10^{-1}$ & $6,28 \cdot 10^{-3}$ & $1,58 \cdot 10^{-2}$ & $8,86 \cdot 10^{-1}$ & $5,19 \cdot 10^{-4}$ & $2,35 \cdot 10^{-2}$ & $5,49 \cdot 10^{-2}$ & $2,97 \cdot 10^{-3}$ & - & - & - & 8,4 \\
\hline $07^{\ddagger}$ & $5,48 \cdot 10^{-3}$ & $1,58 \cdot 10^{-2}$ & $1,56 \cdot 10^{-4}$ & $1,92 \cdot 10^{-5}$ & $5,43 \cdot 10^{-3}$ & $6,27 \cdot 10^{-3}$ & $2,56 \cdot 10^{-2}$ & $5,95 \cdot 10^{-3}$ & $5,60 \cdot 10^{-3}$ & - & - & - & 9,7 \\
\hline $08^{a}$ & $4,00 \cdot 10^{-3}$ & $1,11.10^{-1}$ & $2,11.10^{-3}$ & $2,95 \cdot 10^{-3}$ & $1,73.10^{-2}$ & $3,23 \cdot 10^{-4}$ & $2,83 \cdot 10^{-1}$ & $1,63 \cdot 10^{-3}$ & $9,32 \cdot 10^{-3}$ & $5,60 \cdot 10^{-5}$ & - & - & - \\
\hline $09^{\S}$ & $2,70 \cdot 10^{-2}$ & $9,50 \cdot 10^{-3}$ & $1,40 \cdot 10^{-3}$ & $6,20 \cdot 10^{-3}$ & $5,20.10^{-3}$ & - & $9,30 \cdot 10^{-2}$ & $3,20.10^{-2}$ & $3,90 \cdot 10^{-2}$ & $1,60 \cdot 10^{-3}$ & - & - & 6,6 \\
\hline $10^{\S}$ & $7,00 \cdot 10^{-3}$ & $1,80 \cdot 10^{-2}$ & - & $2,00 \cdot 10^{-3}$ & $1,70 \cdot 10^{-2}$ & - & - & $4,00 \cdot 10^{-3}$ & $1,30 \cdot 10^{-2}$ & - & - & $1,10.10^{-3}$ & - \\
\hline $11^{\S}$ & $1,40 \cdot 10^{-3}$ & $1,70 \cdot 10^{-2}$ & $1,20.10^{-3}$ & - & $2,20.10^{-2}$ & - & - & $1,10.10^{-2}$ & $1,50 \cdot 10^{-2}$ & - & - & - & - \\
\hline $12^{\S}$ & $1,10 \cdot 10^{-3}$ & $1,00 \cdot 10^{-3}$ & - & - & $1,89 \cdot 10^{-2}$ & - & - & - & - & - & - & - & - \\
\hline $13^{\S}$ & $6,50 \cdot 10^{-3}$ & $5,90 \cdot 10^{-3}$ & $8,00 \cdot 10^{-4}$ & $2,60 \cdot 10^{-3}$ & $5,00 \cdot 10^{-3}$ & - & $3,80 \cdot 10^{-2}$ & $9,00 \cdot 10^{-4}$ & $2,00 \cdot 10^{-2}$ & $1,90 \cdot 10^{-4}$ & - & $1,50 \cdot 10^{-3}$ & 7,6 \\
\hline $14^{\S}$ & $4,00 \cdot 10^{-2}$ & $1,89 \cdot 10^{-1}$ & $2,51 \cdot 10^{-2}$ & $7,34 \cdot 10^{-2}$ & $1,76.10^{-1}$ & - & & $2,00 \cdot 10^{-1}$ & - & - & - & $8,00 \cdot 10^{-4}$ & 7,1 \\
\hline
\end{tabular}

TABELA 4 - Composição da solução salina inicial de imersão das amostras

\begin{tabular}{|c|c|c|c|c|c|c|c|c|c|c|}
\hline & \multicolumn{10}{|c|}{ Espécie Iônica } \\
\hline & $\mathrm{Ca}$ & $\mathrm{Na}$ & K & Mg & $\mathrm{Cl}$ & $\mathrm{HCO}_{3}$ & $\mathrm{SO}_{4}$ & $\mathrm{Si}$ & $\mathrm{Fe}$ & $\mathrm{NO}_{3}$ \\
\hline Solução Salina Inicial & $1,79.10^{0}$ & $1,3.10^{0}$ & $3,3 \cdot 10^{-1}$ & $5,59 \cdot 10^{-2}$ & $4,9.10^{0}$ & $6,40 \cdot 10^{-2}$ & $5,50 \cdot 10^{-1}$ & $1,00 \cdot 10^{-4}$ & $1,31.10^{-4}$ & $1,72.10^{0}$ \\
\hline
\end{tabular}




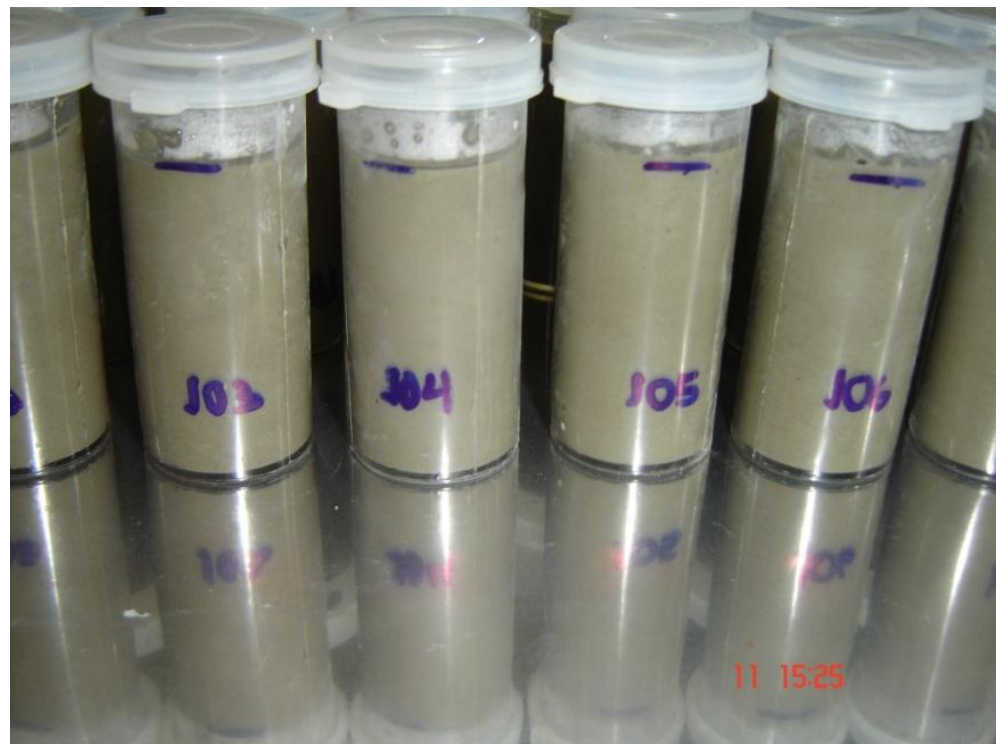

FIGURA 6 - Corpos de prova cilíndricos em moldes de plásticos

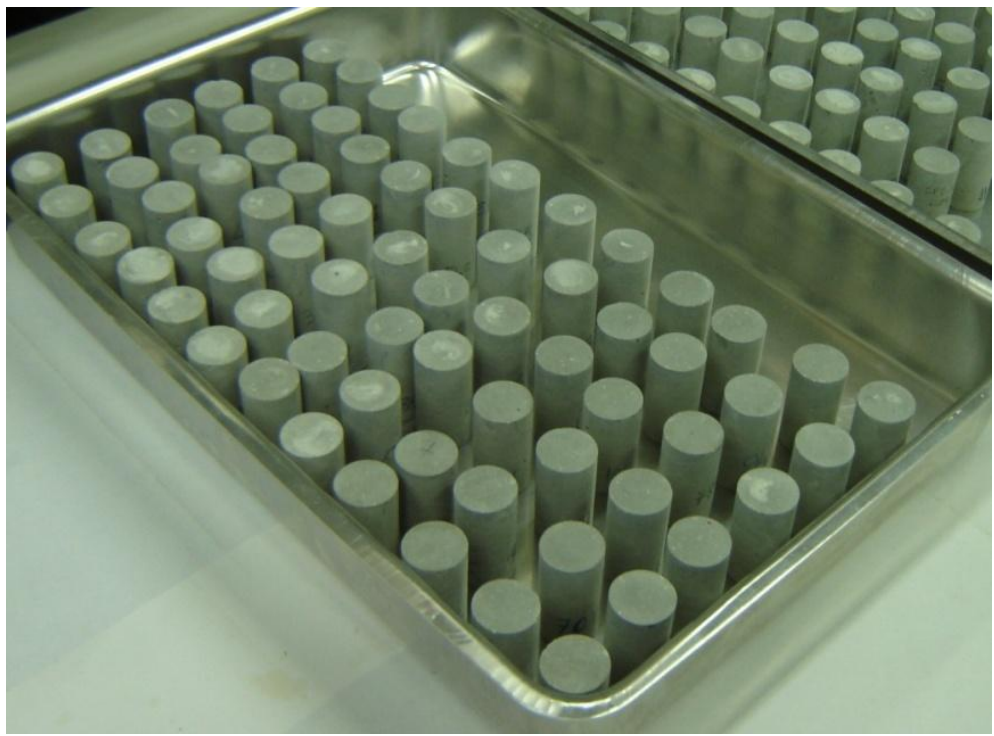

FIGURA 7 - Corpos de prova cilíndricos desmoldados

Os cps cúbicos, com dimensões de $2 \mathrm{~cm} \times 2 \mathrm{~cm} \times 2 \mathrm{~cm}$, foram confeccionados em moldes maleáveis de resina e desmoldados após um dia. Em seguida, foram armazenados em uma câmara úmida contendo solução de água de cal saturada, com o intuito de promover melhor hidratação (FIG. 8 e 9). 


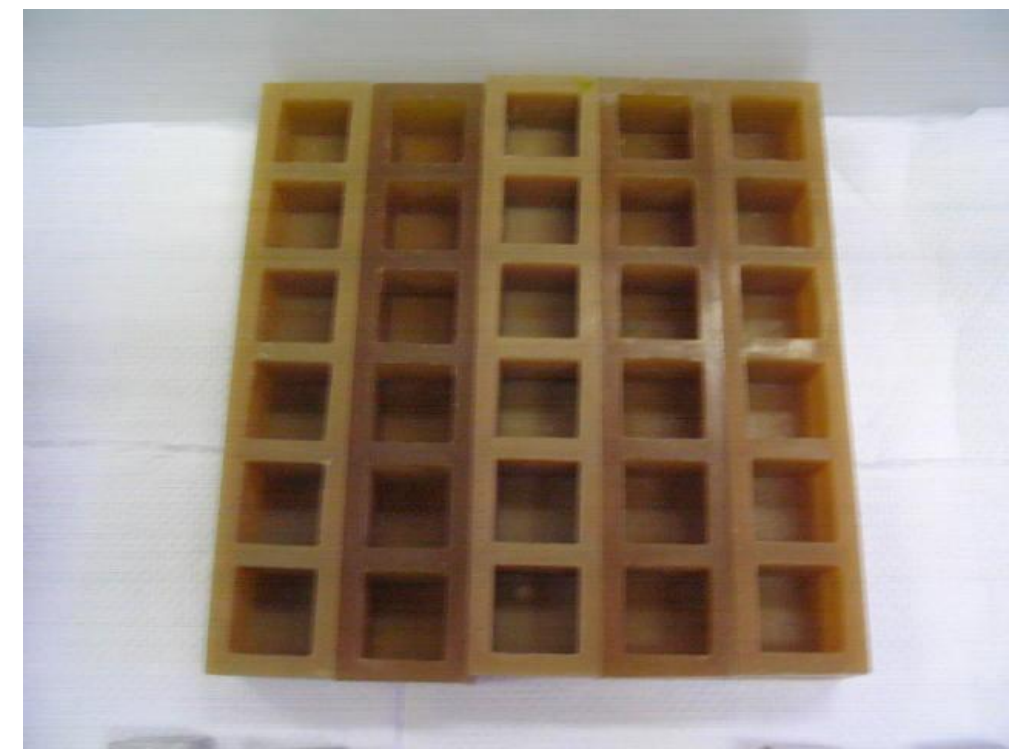

FIGURA 8 - Moldes de plásticos utilizados para a confecção dos corpos de prova cúbicos

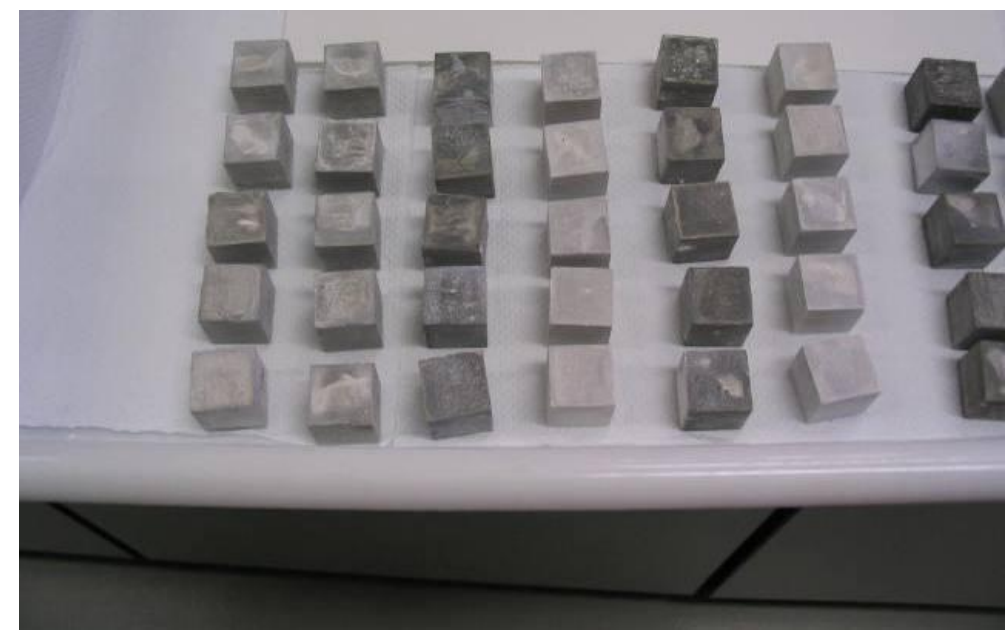

FIGURA 9 - Corpos de prova cúbicos após a desmoldagem

Os corpos de prova foram divididos em lotes e submetidos às seguintes condições:

a) imersão em solução salina (SS), água destilada (AD) ou armazenamento $\operatorname{seco}(\mathrm{AS})$;

b) temperatura ambiente $\left(20^{\circ} \mathrm{C}\right)$ e temperatura elevada $\left(60^{\circ} \mathrm{C}\right)$;

c) tempo de imersão de 30 dias (30D) ou de 60 dias (60D);

d) irradiado ou não irradiado.

Na TAB. 5 são apresentadas as condições a que cada lote foi exposto. 
TABELA 5 - Identificação dos lotes e as variáveis dos ensaios acelerados de degradação

\begin{tabular}{|c|c|c|c|c|c|c|c|c|c|}
\hline \multirow[t]{2}{*}{ Lote } & \multicolumn{3}{|c|}{ Imersão } & \multicolumn{2}{|c|}{ Temperatura } & \multicolumn{2}{|c|}{ Tempo de Imersão } & \multicolumn{2}{|c|}{ Irradiação } \\
\hline & $\mathrm{AD}$ & $\mathrm{SS}$ & AS & $20^{\circ} \mathrm{C}$ & $60^{\circ} \mathrm{C}$ & $30 \mathrm{D}$ & $60 \mathrm{D}$ & $0 \mathrm{kGy}$ & $400 \mathrm{kGy}$ \\
\hline A & $\mathrm{X}$ & & & $X$ & & $\mathrm{X}$ & & $\mathrm{X}$ & \\
\hline B & X & & & $\mathrm{X}$ & & & $\mathrm{X}$ & $X$ & \\
\hline $\mathrm{C}$ & & $\mathrm{X}$ & & $X$ & & $X$ & & $X$ & \\
\hline D & & $X$ & & $X$ & & & $\mathrm{X}$ & $\mathrm{X}$ & \\
\hline $\mathrm{E}$ & $X$ & & & & $X$ & $X$ & & $X$ & \\
\hline $\mathrm{F}$ & X & & & & $X$ & & $X$ & $X$ & \\
\hline G & & $X$ & & & $X$ & $X$ & & $X$ & \\
\hline $\mathrm{H}$ & & $X$ & & & $X$ & & $\mathrm{X}$ & $X$ & \\
\hline I & $\mathrm{X}$ & & & $\mathrm{X}$ & & $\mathrm{X}$ & & & $\mathrm{X}$ \\
\hline $\mathrm{J}$ & $X$ & & & $\mathrm{X}$ & & & $\mathrm{X}$ & & $\mathrm{X}$ \\
\hline $\mathrm{K}$ & & $\mathrm{X}$ & & $\mathrm{X}$ & & $\mathrm{X}$ & & & $\mathrm{X}$ \\
\hline $\mathrm{L}$ & & $\mathrm{X}$ & & $X$ & & & $\mathrm{X}$ & & $\mathrm{X}$ \\
\hline $\mathrm{M}$ & $X$ & & & & $\mathrm{X}$ & $\mathrm{X}$ & & & $X$ \\
\hline $\mathrm{N}$ & $X$ & & & & $\mathrm{X}$ & & $X$ & & $\mathrm{X}$ \\
\hline $\mathrm{O}$ & & $\mathrm{X}$ & & & $\mathrm{X}$ & $\mathrm{X}$ & & & $X$ \\
\hline $\mathrm{P}$ & & $\mathrm{X}$ & & & $\mathrm{X}$ & & $\mathrm{X}$ & & $\mathrm{X}$ \\
\hline $\mathrm{Q}$ & & & $\mathrm{X}$ & $\mathrm{X}$ & & & $X$ & $\mathrm{X}$ & \\
\hline $\mathrm{R}$ & & & $\mathrm{X}$ & $\mathrm{X}$ & & & $\mathrm{X}$ & $\mathrm{X}$ & \\
\hline $\mathrm{S}$ & & & $\mathrm{X}$ & & $X$ & $X$ & & $X$ & \\
\hline $\mathrm{T}$ & & & $X$ & & X & & $\mathrm{X}$ & $X$ & \\
\hline $\mathrm{U}$ & & & $\mathrm{X}$ & $\mathrm{X}$ & & & $\mathrm{X}$ & & $\mathrm{X}$ \\
\hline $\mathrm{V}$ & & & $\mathrm{X}$ & $X$ & & & $\mathrm{X}$ & & $\mathrm{X}$ \\
\hline W & & & $\mathrm{X}$ & & $X$ & $\mathrm{X}$ & & & $\mathrm{X}$ \\
\hline$X$ & & & $X$ & & $\mathrm{X}$ & & $\mathrm{X}$ & & $\mathrm{X}$ \\
\hline
\end{tabular}

Foram confeccionados seis cp's cilíndricos e cinco cúbicos para cada lote. Cada lote foi projetado para determinar a importância de um processo na deterioração do cimento. A exceção são os lotes $\mathrm{Q}, \mathrm{R}, \mathrm{U}$ e $\mathrm{V}$ que ficaram armazenados a seco, em temperatura ambiente, tempo de exposição de 60 dias sendo que os lotes $\mathrm{Q}$ e $\mathrm{R}$ foram irradiados e os lotes U e V não foram irradiados.

Neste trabalho, as propriedades avaliadas para detectar as alterações na composição dos cps após a exposição aos fatores citados foram: a) perda de resistência mecânica; b) contração dos cps; c) variação de massa; d) penetração e/ou lixiviação dos íons; e e) composição mineralógica dos cps após os ensaios.

Nas FIG. 10-12 são apresentadas a condição de imersão e de armazenamento seco dos corpos de prova cilíndricos. 


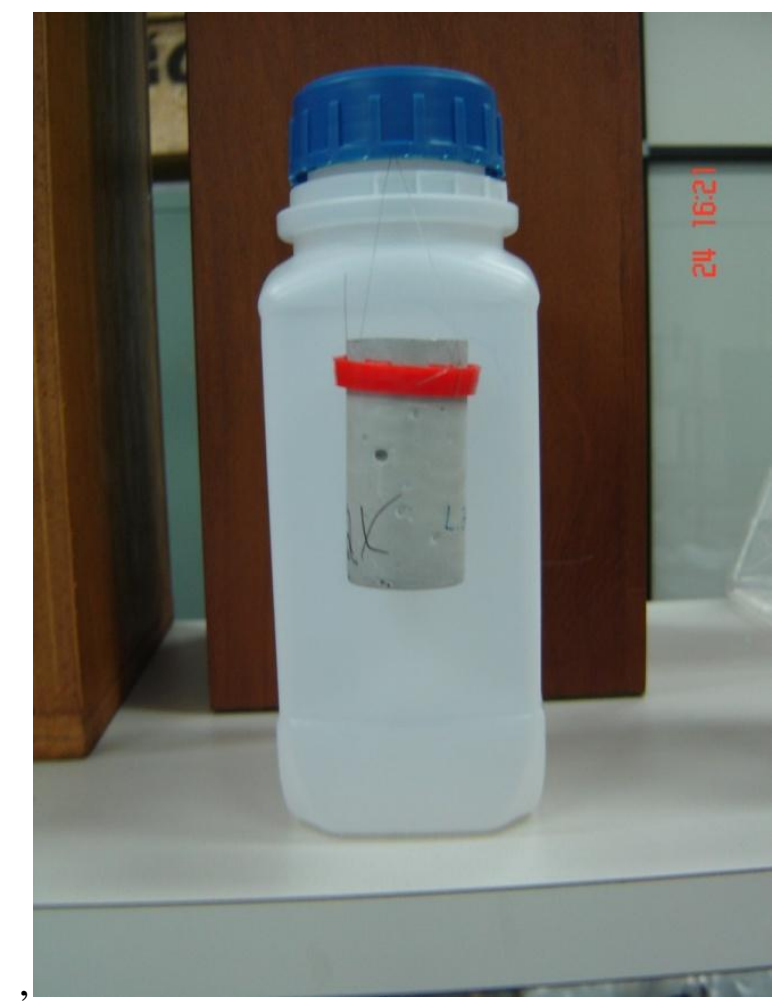

FIGURA 10 - Corpo de prova cilíndrico e o recipiente de imersão

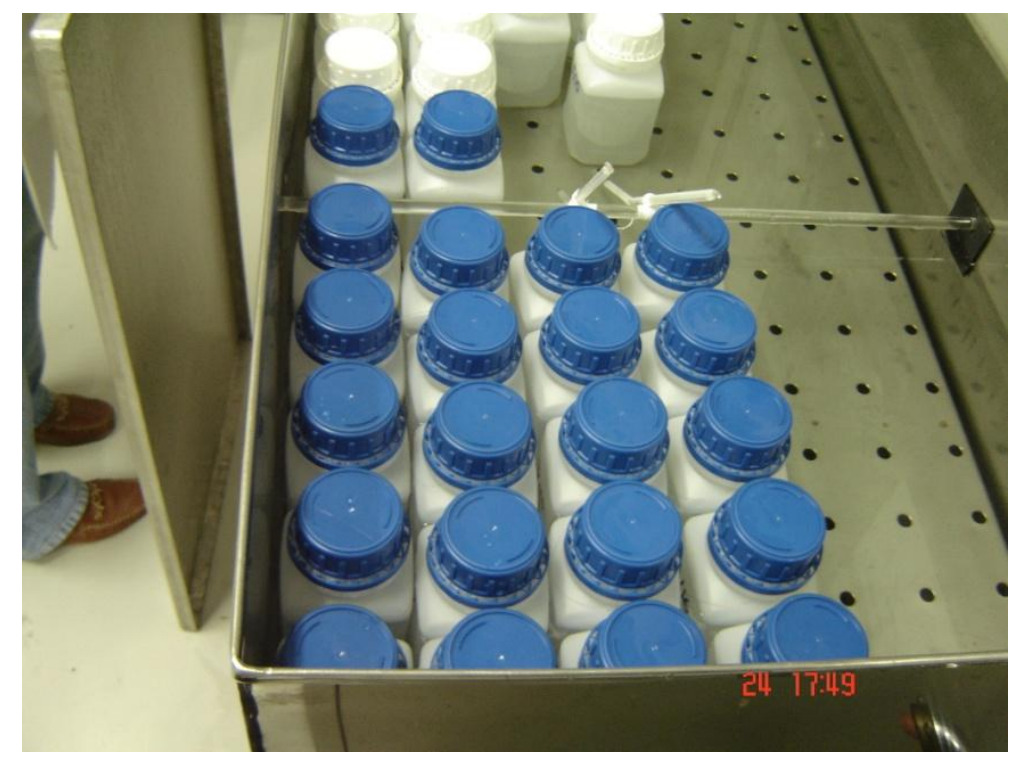

FIGURA 11 - Recipientes de imersão dos corpos de prova dentro de banho em alta temperatura 


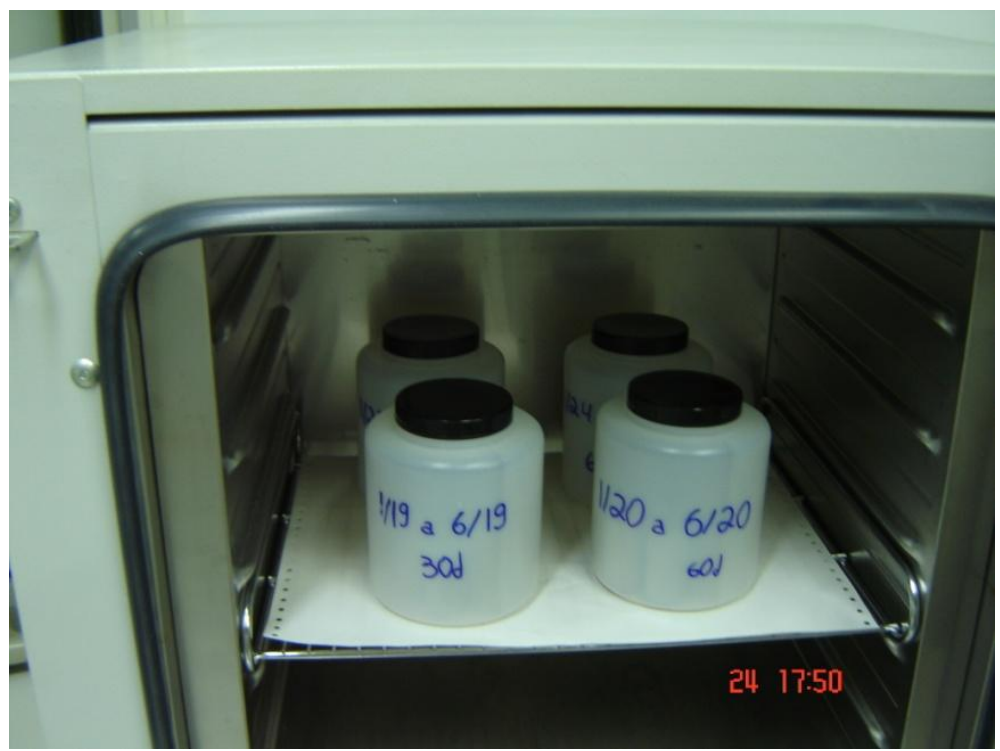

FIGURA 12 - Recipiente de armazenamento seco dos corpos de prova em alta temperatura

A resistência mecânica foi avaliada a partir de ensaios de resistência à compressão, adaptado da norma ABNT NBR - 7215 Cimento Portland - Determinação da resistência à compressão (ABNT, 1996). A ruptura ocorreu no laboratório da GRR-IPEN, na máquina para ensaios de compressão de cimento PCE 100/20 - EMIC Cimento. Os cps de formato cilíndrico foram capeados na parte superior e inferior, de forma a gerar uma superfície lisa para o ensaio. Os cps cúbicos não necessitaram nenhum tratamento antes da ruptura. As FIG. 13-15 apresentam imagem do rompimento dos cps e a FIG. 16 apresenta um cp cilíndrico rompido.

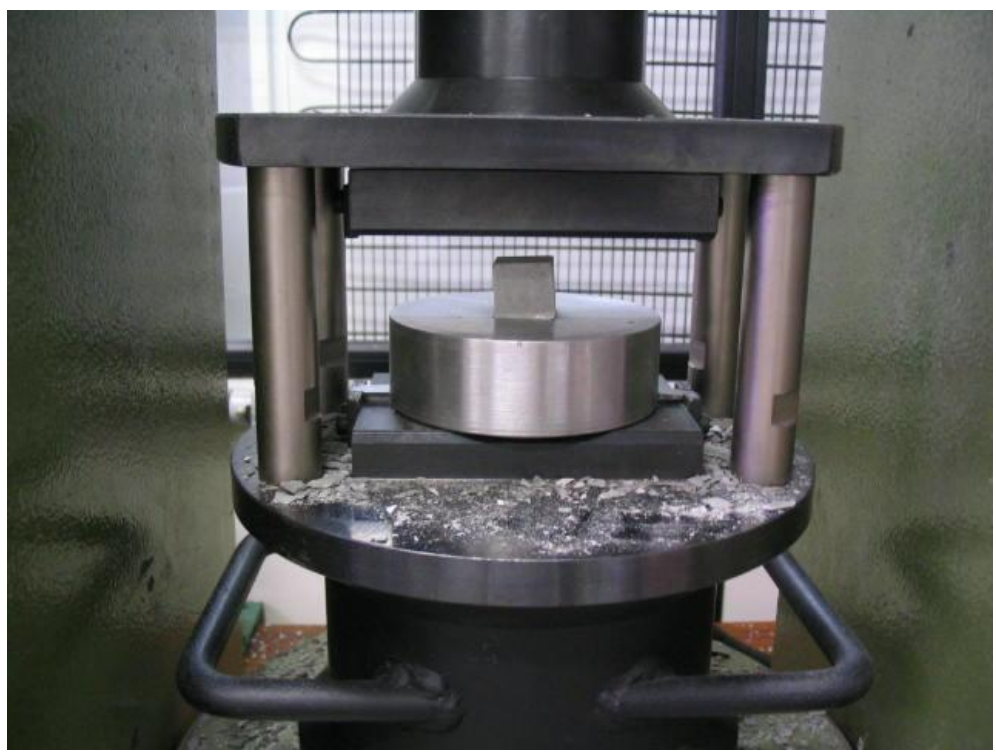

FIGURA 13 - Rompimento de corpo de prova cúbico 


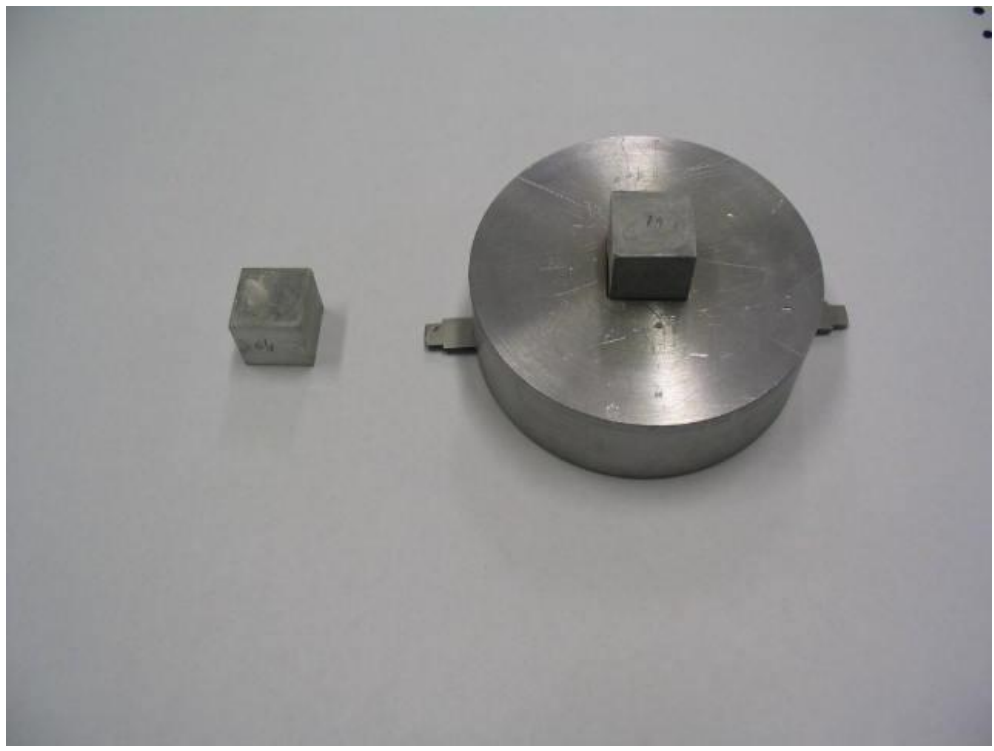

FIGURA 14 - Suporte para o rompimento dos corpos de prova cúbicos

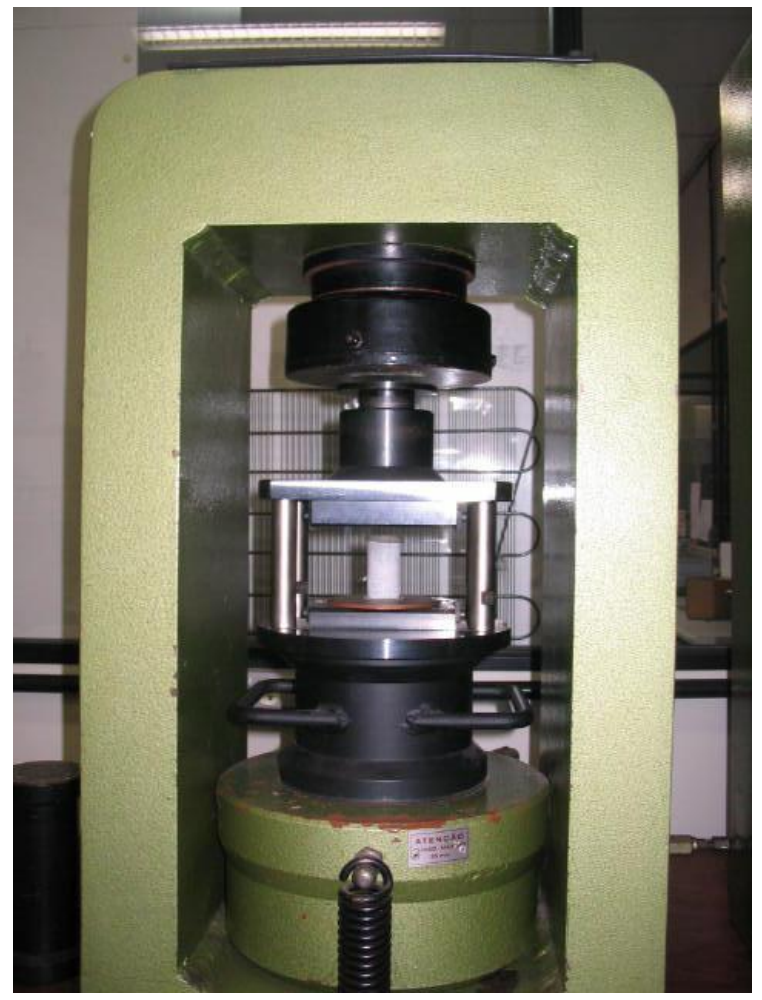

FIGURA 15 - Máquina de rompimento dos corpos de prova. 


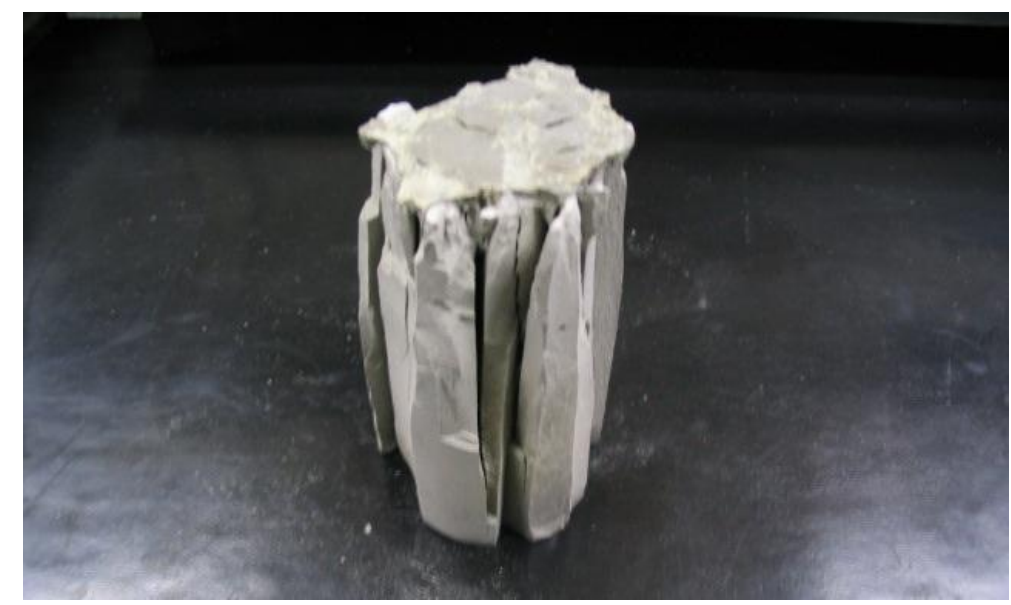

FIGURA 16 - Corpo de prova cilíndrico após o rompimento

O encolhimento e a variação de massa dos corpos de prova foram mensurados a partir da medida das massas e dos comprimentos (altura e diâmetro, nos cilíndricos e lados, nos cúbicos) (FIG. 17)

a) imediatamente após a cura;

b) imediatamente após a retirada de imersão/armazenamento à seco;

c) sete dias após a retirada da imersão e

d) imediatamente após a irradiação

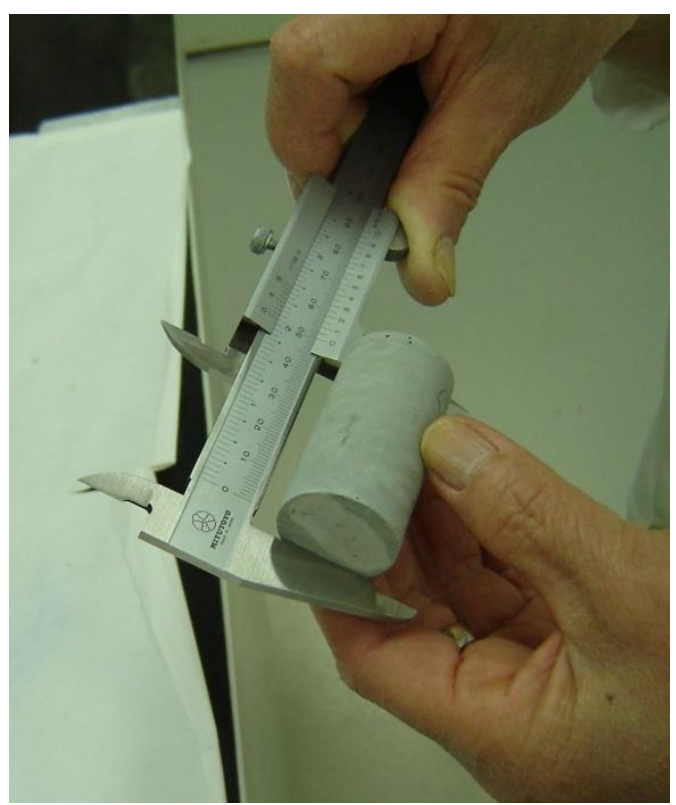

FIGURA 17 - Medida do comprimento de corpo de prova cilíndrico

A penetração e/ou lixiviação dos íons foi mensurada a partir da análise das concentrações restantes dos mesmos nas soluções de imersão. Alíquotas da solução de 
imersão dos corpos de prova cilíndricos foram colhidas e enviadas para análise no Centro de Química e Meio Ambiente (CQMA) do IPEN-CNEN/SP. As técnicas analíticas utilizadas foram: cromatografia de íons $\left(\mathrm{F}^{-}, \mathrm{Cl}^{-}, \mathrm{NO}_{2}{ }^{-}, \mathrm{NO}_{3}{ }^{-}, \mathrm{PO}_{4}{ }^{-2}\right.$ e $\left.\mathrm{SO}_{4}{ }^{-2}\right)$ e ICP-OES (Ca, $\mathrm{Na}, \mathrm{K}, \mathrm{Mg}, \mathrm{Al}, \mathrm{Fe}$ e $\mathrm{Si}$ ). Já a solução de imersão dos cps cúbicos foi analisada no Laboratório de Poços de Caldas (LAPOC-CNEN/MG). As técnicas utilizadas nessas análises foram: ICP-OES $(\mathrm{Ca}, \mathrm{Fe}, \mathrm{Mg}$ e $\mathrm{Si})$, potenciometria $(\mathrm{Cl}$ e $\mathrm{F})$, volumetria $\left(\mathrm{HCO}_{3}{ }^{-}\right)$, absorção atômica ( $\mathrm{Na}$ e $\mathrm{K})$ e espectrofotometria $\mathrm{UV}-\mathrm{V}$ is $\left(\mathrm{NO}_{3}{ }^{-}\right.$e $\left.\mathrm{SO}_{4}{ }^{-2}\right)$.

A composição mineralógica dos corpos de prova de pasta de cimento foi avaliada por meio de difração de raios $\mathrm{X}$ (DRX), análise termogravimétrica (TGA) e microscopia eletrônica de varredura (MEV). A difração de raios $\mathrm{x}$ foi realizada no Laboratório de Caracterização Tecnológica do Departamento de Engenharia de Minas e Petróleo da Escola Politécnica da Universidade de São Paulo. Nesta técnica, uma amostra dos cps é retirada e moída em almofariz de ágata, até que se obtenha um material em pó homogêneo. Essa amostra é então acondicionada em um suporte, formando uma superfície extremamente lisa. Ao ser colocado no equipamento, um feixe de raios x é incidido, em diferentes ângulos, sobre essa superfície, que refrata os raios em ângulos diferentes de acordo com a microestrutura do material. Dessa forma, é possível detectar a mineralogia dessa amostra. A análise foi realizada em equipamento X’Pert PRO, da marca PANalytical e a análise em software High Score Plus, da marca PANalytical. As condições analíticas utilizadas estão apresentadas na TAB. 6.

TABELA 6 - Condições de coleta dos difratogramas no ensaio por Difração de Raios X

Difratômetro
Posição inicial [ $\left.{ }^{\circ} 2 \mathrm{Th}.\right]$
Posição Final $\left[{ }^{\circ} 2 \mathrm{Th}.\right]$
Etapa de varredura [ ${ }^{\circ} 2 \mathrm{Th}$.]
Tempo de varredura por etapa [s]
Tipo de fenda de divergência
Tamanho da fenda de divergência $\left[{ }^{\circ}\right]$
Material anodo
Configurações do gerador
Raio goniômetro [mm]
Rotação

XPERT-PRO
5.0087
69.9827
0.0170
19.6850
Fixo
0.3350
$\mathrm{Cu}$
$35 \mathrm{~mA}, 40 \mathrm{kV}$
230.00
$2 \mathrm{~s}$

Para a análise de TGA, foram retiradas amostras dos cps, que foram então moídas em almofariz de ágata. Essa amostra moída foi submetida a aquecimento, de forma controlada, até cerca de $1000^{\circ} \mathrm{C}$. Durante o aquecimento, uma balança mede a massa da amostra e a perda de massa em determinadas temperaturas é relacionada à decomposição 
de minerais específicos. A análise de TGA foi obtida com equipamento TGA/SDTA851 e termobalança Mettler-Toledo, no Laboratório de Caracterização de Materiais do Centro Tecnológico da Marinha (CTMSP).

A análise de MEV foi realizada com o material precipitado na superfície dos cps após o período de imersão. Essa análise foi efetuada em um microscópio Phillips XL 30, alocado no Laboratório de Microscopia e Microanálise do Centro de Ciência e Tecnologia dos Materiais (CCTM), do IPEN-CNEN/SP. As amostras do precipitado foram previamente fixadas em suporte metálico para deposição de ouro. Foi utilizado analisador de energia por raios X dispersivos (EDAX), com o aumento de 1000 a 4000 vezes. Esta análise teve como objetivo caracterizar morfologicamente esse material precipitado na superfície dos cps.

A FIG. 18 apresenta um fluxograma da metodologia aplicada neste trabalho. 


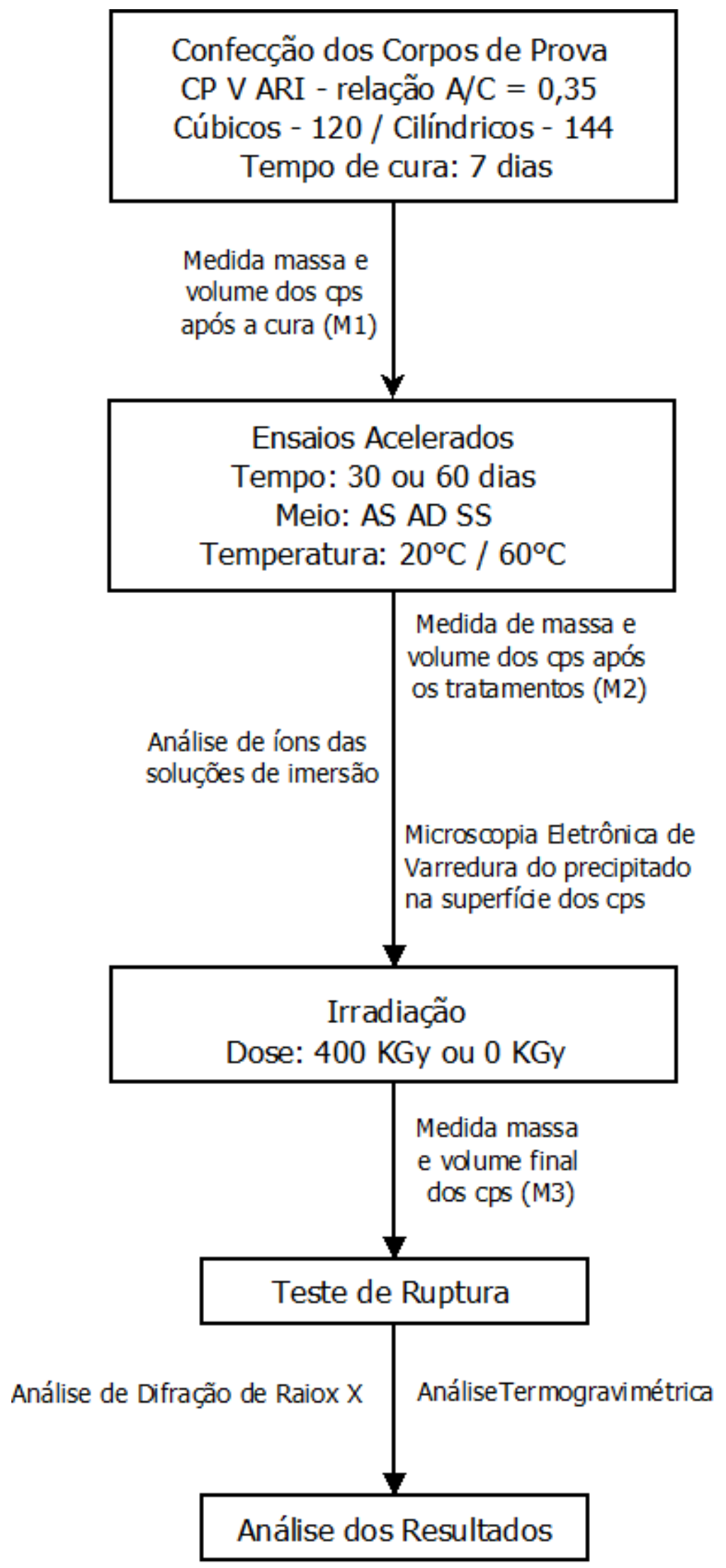

FIGURA 18 - Fluxograma da metodologia aplicada neste trabalho 


\section{RESULTADOS E DISCUSSÃO}

Os resultados dos experimentos multifatoriais utilizados para estimar os efeitos dos fatores individuais e sinergéticos sobre o comportamento do material foram analisados individualmente, comparando-se os tipos de exposição. Somente após essa primeira análise é que os resultados entre as técnicas foram comparados.

\subsection{Ensaios de resistência mecânica}

Os ensaios de resistência mecânica dos corpos de prova foram realizados por meio de sua compressão axial. Na TAB. 7 são apresentados os valores referentes à resistência mecânica dos cps cilíndricos, com valores máximos, médios, medianos, médias e de desvio padrão de cada lote. Os valores máximos, mínimos e medianos estão apresentados na forma de gráfico na FIG. 19.

Para avaliar os efeitos dos tratamentos na resistência mecânica, de forma individual ou sinergética, os valores obtidos foram separados por intervalos que vão de 815; 15-22; 22-29; 29-36; 36-43 e 43-51 (MPa) e, então, avaliada a porcentagem de cps em cada um desses intervalos, observando-se apenas um dos parâmetros analisados no ensaio.

As FIG 20-23 apresentam a frequência de cps com valor de resistência mecânica em cada faixa de porcentagem, entre os cps:

- $\quad$ submetidos à imersão (em AD e SS) por 30 dias ou por 60 dias armazenados a seco (0 Dias) (FIG. 20);

- $\quad$ armazenados a $20^{\circ} \mathrm{C}$ ou a $60^{\circ} \mathrm{C}$ (FIG. 21$)$;

- $\quad$ irradiados (400 KGy) ou não irradiados (0 KGy) (FIG. 22); e

- $\quad$ imersos em água destilada ou em solução salina (FIG. 23).

Houve uma grande variabilidade nos resultados de resistência mecânica dos cps submetidos aos mesmos tratamentos. Este comportamento pode ser explicado pela dimensão e geometria dos cps, que não foram adequadas para este propósito. Neville \& Brooks (2010) apontam, em seu livro texto, que não é usual e recomendado ensaios de resistência mecânica em corpos de prova com pasta de cimento devido à dificuldade em se obter resultados reprodutivos. 
TABELA 7 - Valores máximos, médios, medianos, médias e de desvio padrão de cada lote de resistência mecânica dos cps cilíndricos.

\begin{tabular}{|c|c|c|c|c|c|c|}
\hline \multirow{2}{*}{ Lotes } & \multicolumn{6}{|c|}{ Resistência Mecânica (MPa) } \\
\hline & Máximo & Mediana & Mínimo & Média & Desvio Padrão & $\% \mathrm{DP}$ \\
\hline A & 42 & 24 & 19 & 27 & 9 & $33 \%$ \\
\hline B & 48 & 30 & 13 & 31 & 11 & $36 \%$ \\
\hline $\mathrm{C}$ & 45 & 27 & 18 & 30 & 10 & $35 \%$ \\
\hline $\mathrm{D}$ & 37 & 26 & 20 & 26 & 6 & $23 \%$ \\
\hline E & 47 & 29 & 18 & 31 & 11 & $34 \%$ \\
\hline $\mathrm{F}$ & 49 & 24 & 17 & 28 & 11 & $41 \%$ \\
\hline G & 41 & 14 & 9 & 19 & 12 & $66 \%$ \\
\hline $\mathrm{H}$ & 17 & 15 & 11 & 14 & 2 & $16 \%$ \\
\hline I & 19 & 17 & 11 & 16 & 3 & $20 \%$ \\
\hline $\mathrm{J}$ & 23 & 18 & 14 & 18 & 3 & $18 \%$ \\
\hline $\mathrm{K}$ & 23 & 19 & 14 & 19 & 3 & $17 \%$ \\
\hline $\mathrm{L}$ & 38 & 23 & 16 & 25 & 8 & $33 \%$ \\
\hline $\mathrm{M}$ & 22 & 19 & 15 & 19 & 3 & $14 \%$ \\
\hline $\mathrm{N}$ & 34 & 22 & 15 & 23 & 7 & $31 \%$ \\
\hline $\mathrm{O}$ & 30 & 19 & 14 & 20 & 6 & $31 \%$ \\
\hline $\mathrm{P}$ & 21 & 19 & 18 & 19 & 1 & $5 \%$ \\
\hline Q & 51 & 25 & 15 & 30 & 15 & $50 \%$ \\
\hline $\mathrm{R}$ & 29 & 25 & 8 & 22 & 8 & $39 \%$ \\
\hline$S$ & 30 & 18 & 9 & 18 & 8 & $43 \%$ \\
\hline $\mathrm{T}$ & 35 & 20 & 13 & 21 & 9 & $41 \%$ \\
\hline $\mathrm{U}$ & 24 & 19 & 18 & 20 & 3 & $13 \%$ \\
\hline V & 24 & 18 & 15 & 19 & 4 & $20 \%$ \\
\hline W & 27 & 17 & 13 & 19 & 6 & $30 \%$ \\
\hline$X$ & 18 & 15 & 11 & 15 & 3 & $19 \%$ \\
\hline
\end{tabular}

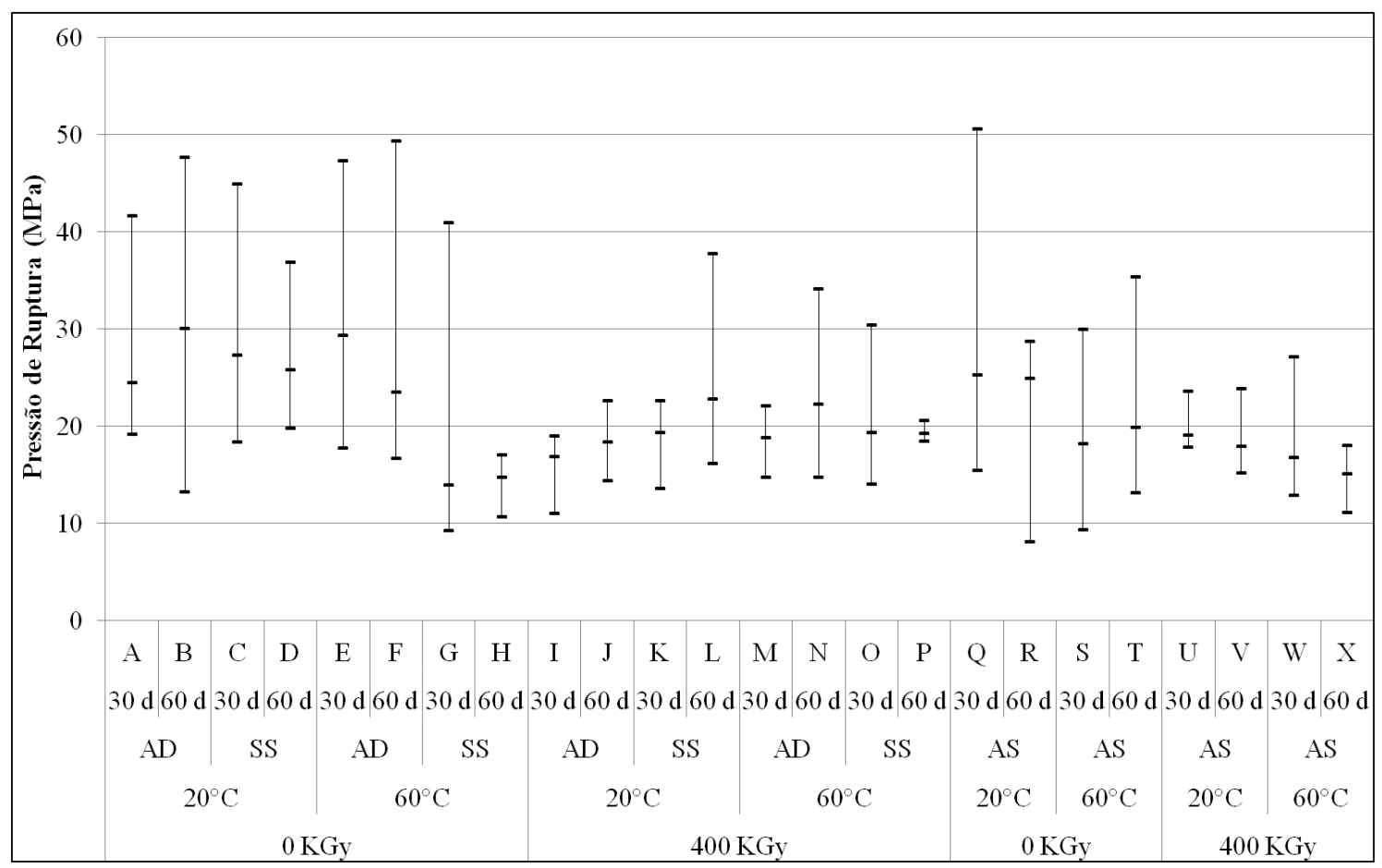

FIGURA 19 - Resistência mecânica máxima, mínima e mediana dos cps cilíndricos. 


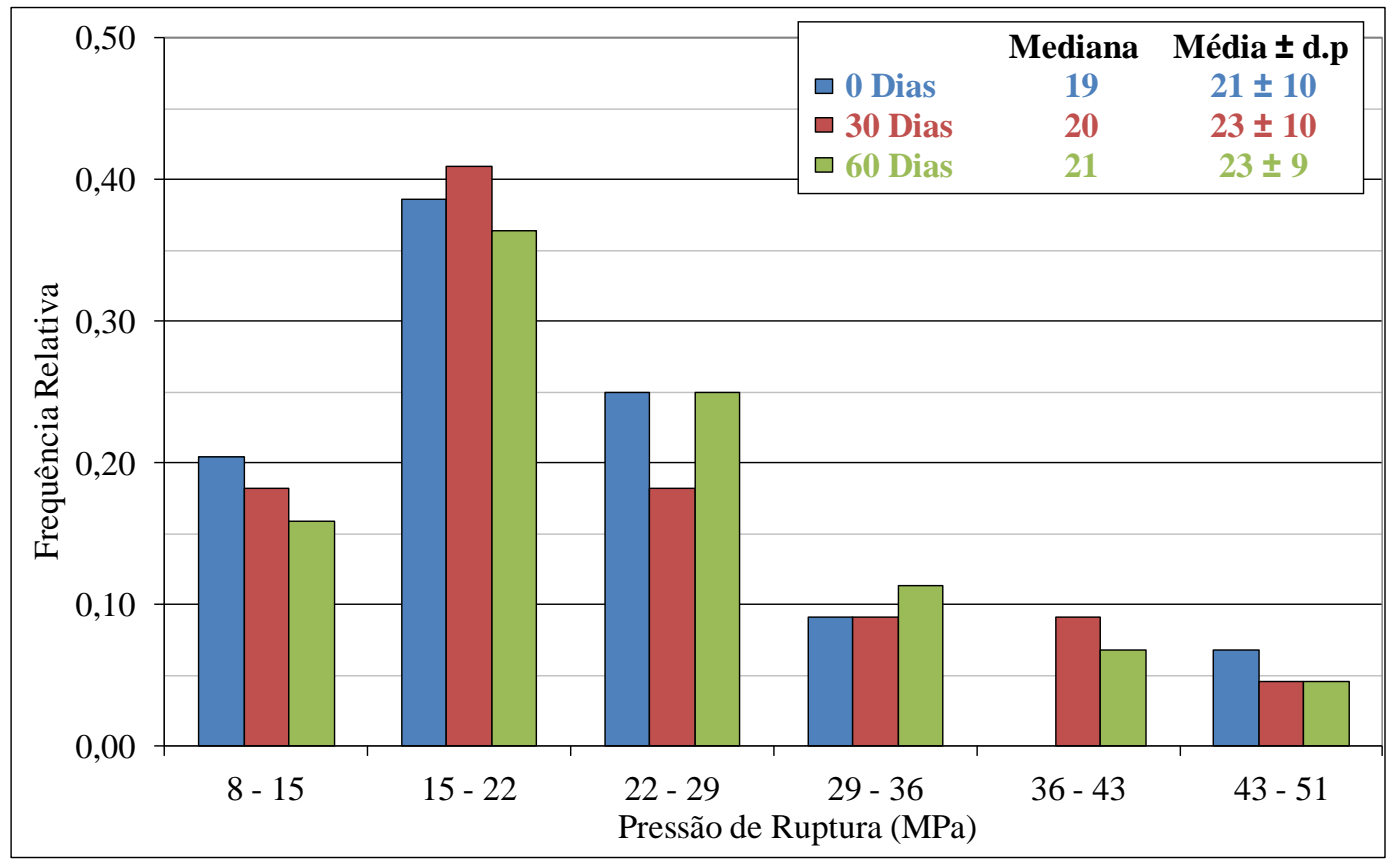

FIGURA 20 - Frequência relativa dos cps nos intervalos de pressão de ruptura em diferentes tempos de imersão

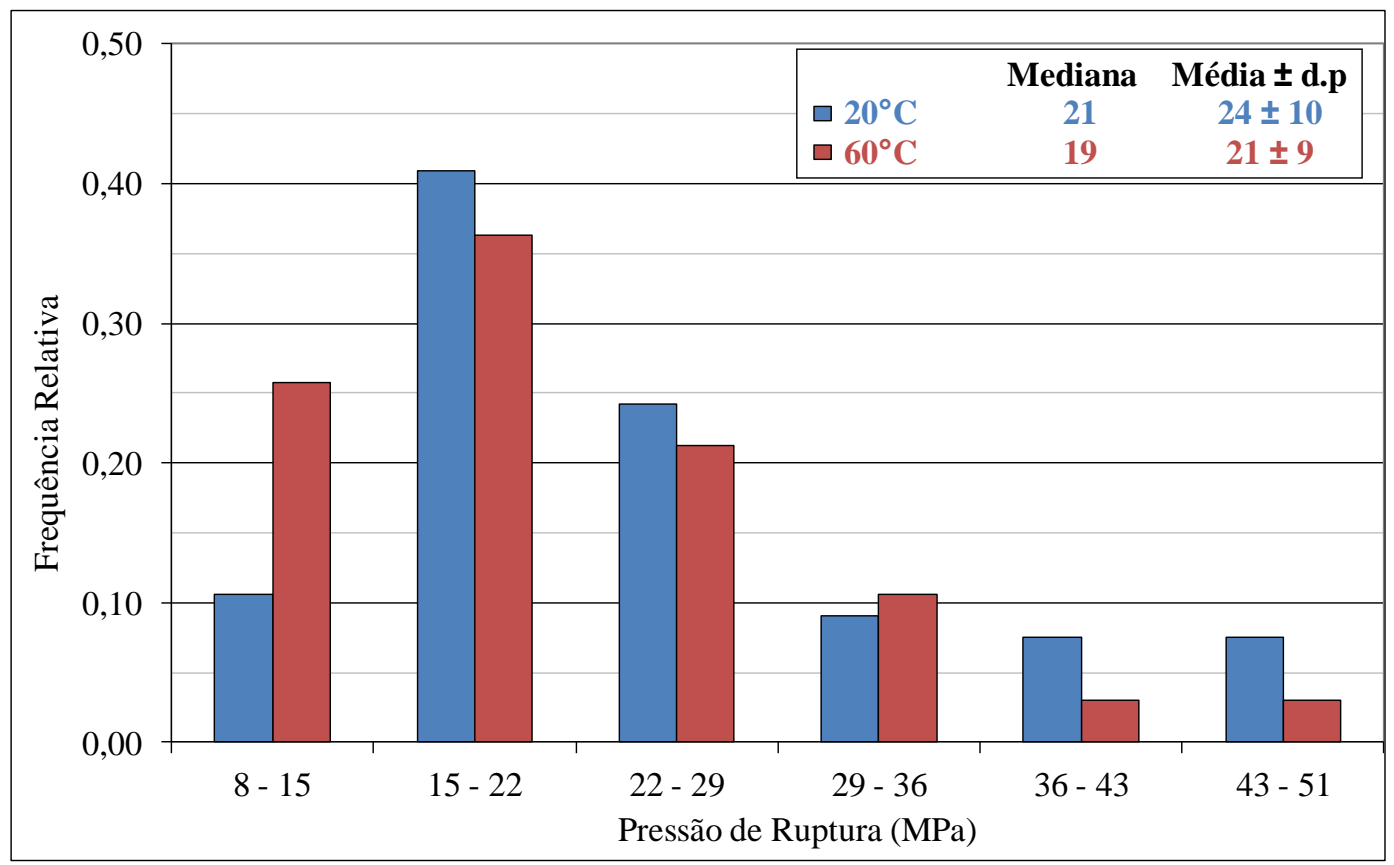

FIGURA 21 - Frequência relativa dos cps nos intervalos de pressão de ruptura em diferentes temperaturas 


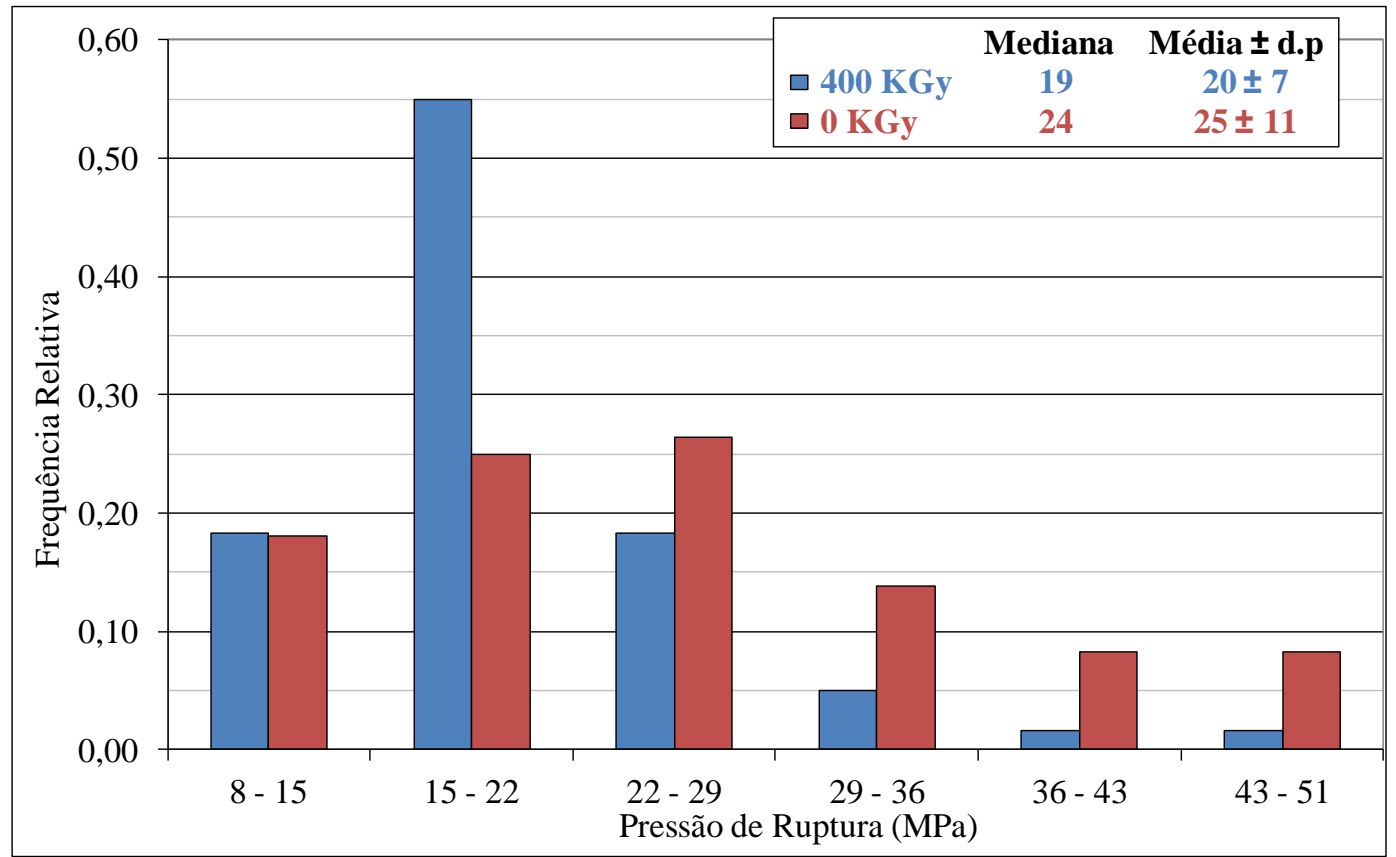

FIGURA 22 - Frequência relativa dos cps nos intervalos de pressão de ruptura em diferentes doses de irradiação

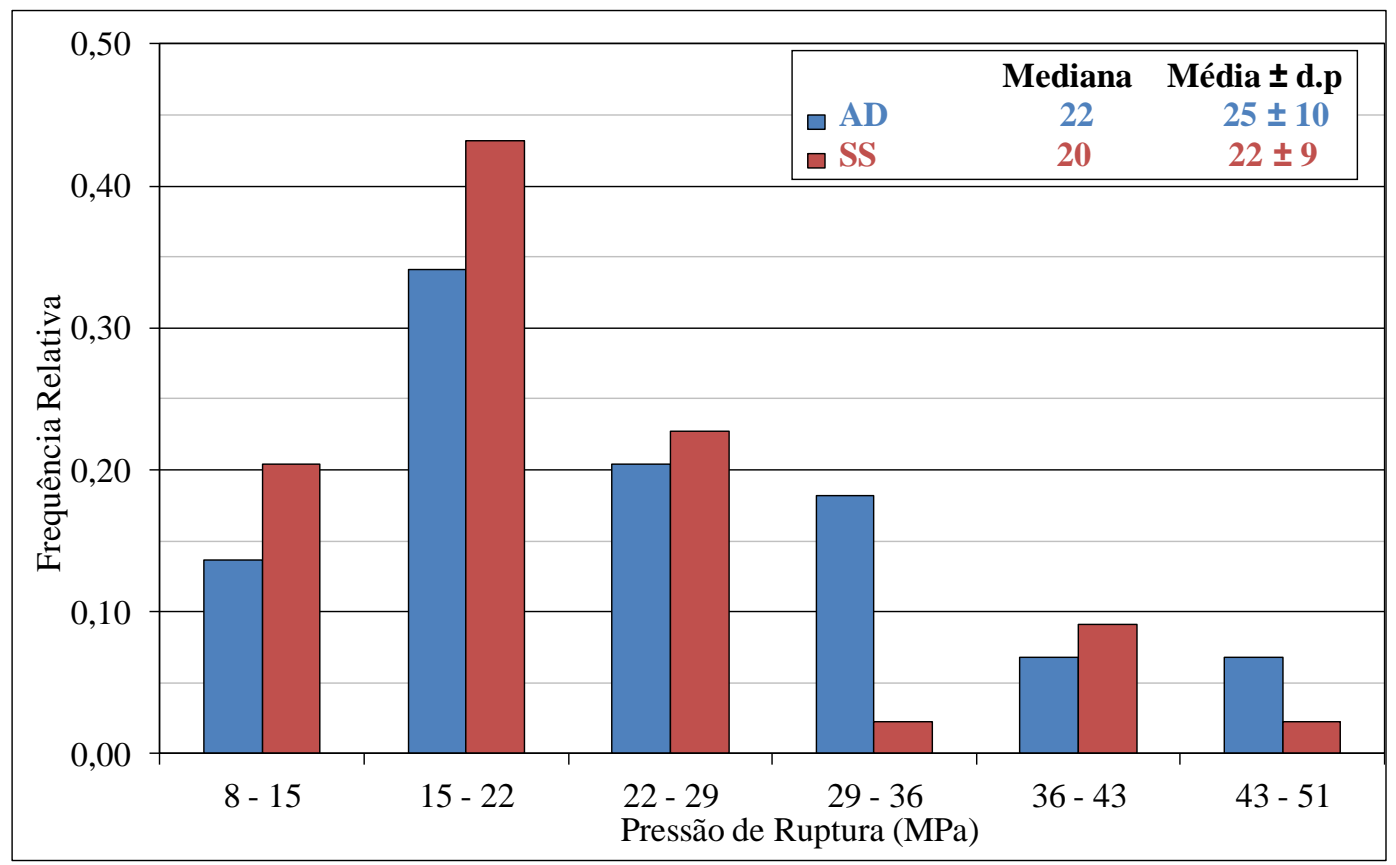

FIGURA 23 - Frequência relativa dos cps nos intervalos de pressão de ruptura em diferentes meios de imersão

Para contornar a variabilidade observada nos cps cilíndricos foram confeccionados cps de geometria cúbica. Nesse caso, a variabilidade observada (TAB. 8 e na FIG. 24) foi muito menor, estando dentro do esperado para esse ensaio de pasta de cimento (Bilesky, informação verbal). 
TABELA 8 - Valores máximos, médios, medianos, médias e de desvio padrão de cada lote de resistência mecânica dos cps cúbicos.

\begin{tabular}{cccccc}
\hline \multirow{2}{*}{ Lote } & Máximo & \multicolumn{3}{c}{ Resistência Mecânica (MPa) } & \\
& Mediana & Mínimo & Média & Desvio Padrão \\
\hline A & 133 & 119 & 98 & 116 & 15 \\
B & 128 & 118 & 107 & 118 & 9 \\
C & 110 & 98 & 78 & 98 & 13 \\
D & 131 & 120 & 101 & 119 & 12 \\
E & 150 & 126 & 101 & 123 & 19 \\
F & 152 & 123 & 102 & 123 & 21 \\
G & 131 & 123 & 91 & 118 & 15 \\
H & 141 & 109 & 76 & 108 & 25 \\
\hline I & 132 & 119 & 96 & 116 & 13 \\
J & 132 & 126 & 118 & 125 & 6 \\
K & 106 & 105 & 85 & 97 & 11 \\
L & 125 & 123 & 101 & 116 & 11 \\
M & 149 & 139 & 123 & 137 & 12 \\
N & 161 & 123 & 100 & 126 & 22 \\
O & 142 & 123 & 94 & 118 & 19 \\
P & 146 & 108 & 96 & 116 & 20 \\
\hline Q & 85 & 83 & 73 & 81 & 5 \\
R & 110 & 79 & 72 & 87 & 16 \\
S & 104 & 97 & 81 & 93 & 9 \\
T & 100 & 94 & 78 & 91 & 9 \\
\hline U & 96 & 84 & 80 & 87 & 7 \\
V & 104 & 84 & 78 & 88 & 12 \\
W & 111 & 91 & 67 & 89 & 17 \\
X & 109 & 89 & 82 & 92 & 10 \\
\hline
\end{tabular}

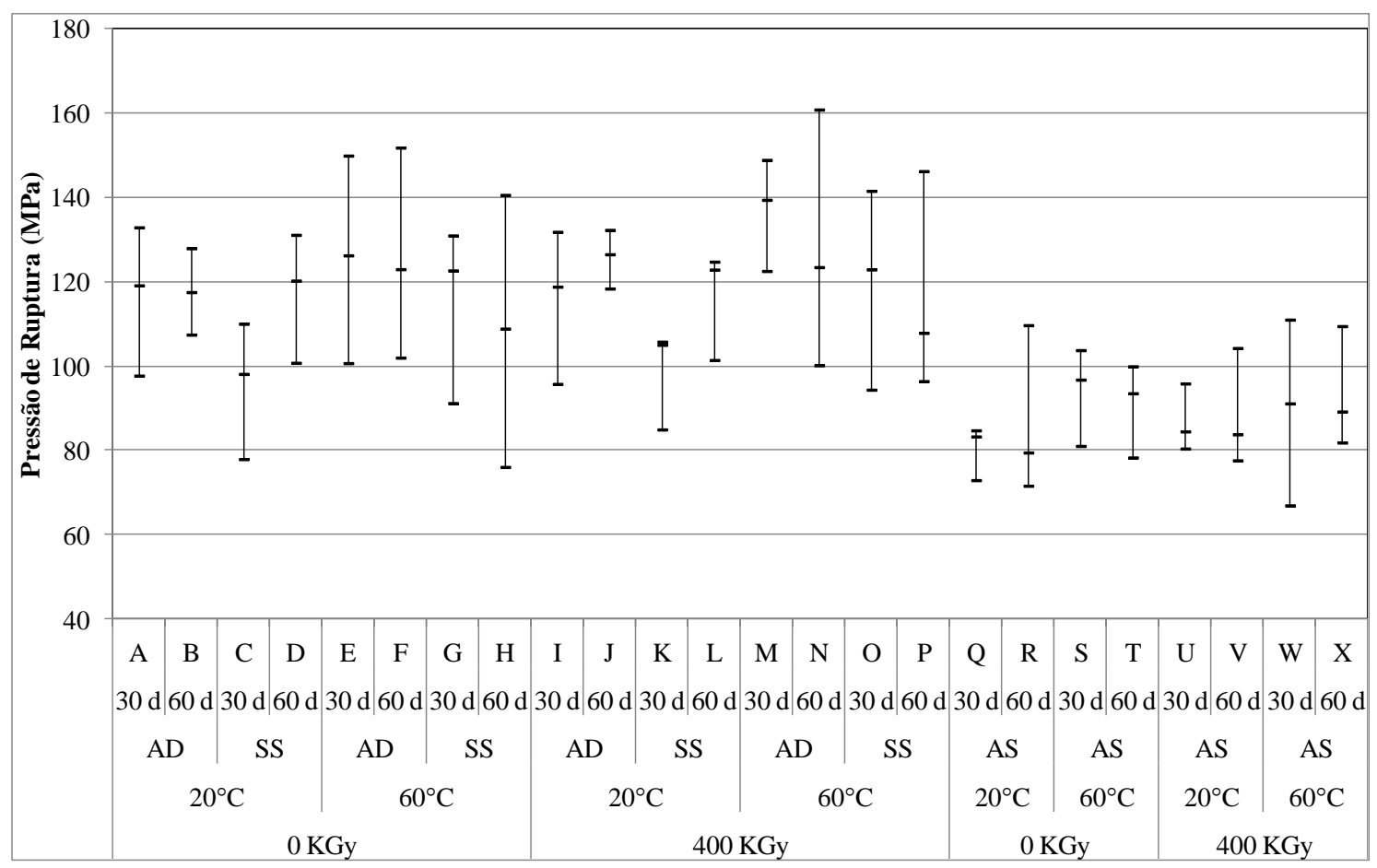

FIGURA 24 - Resistência mecânica máxima, mínima e mediana dos cps cúbicos. 
O critério de análise dos cps cúbicos foi o mesmo dos cilíndricos, no qual foram adotados intervalos de pressão de ruptura entre 66-82; 82-98; 98-114; 114-130; 130 146 e 146-162. Foi então avaliada a frequência de cps em cada um desses intervalos observando apenas um parâmetro analisado no ensaio.

As FIG. 25-28 apresentam a frequência de cps com valor de resistência mecânica em cada faixa de porcentagem, entre os cps que não foram submetidos à imersão (AS) ou ficaram em imersão (em AD ou SS) (FIG. 25), que foram armazenados a $20^{\circ} \mathrm{C}$ ou a $60^{\circ} \mathrm{C}$ (FIG. 26), que ficaram em tratamento por 30 ou 60 dias (FIG. 27); e que foram irradiados (400 KGy) ou não irradiados (0 KGy) (FIG. 28).

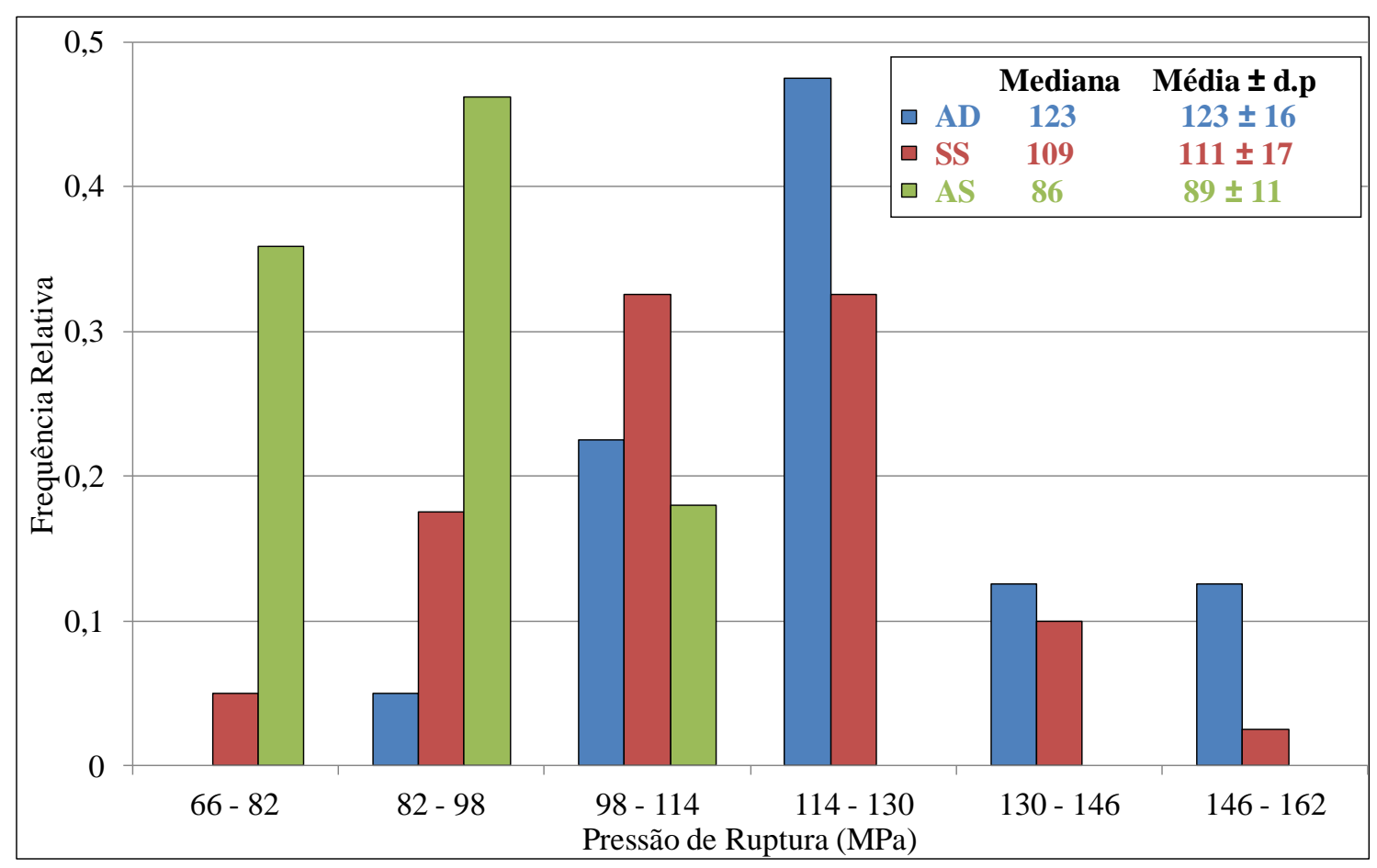

FIGURA 25 - Frequência relativa dos cps nos intervalos de pressão de ruptura em diferentes meios de imersão 


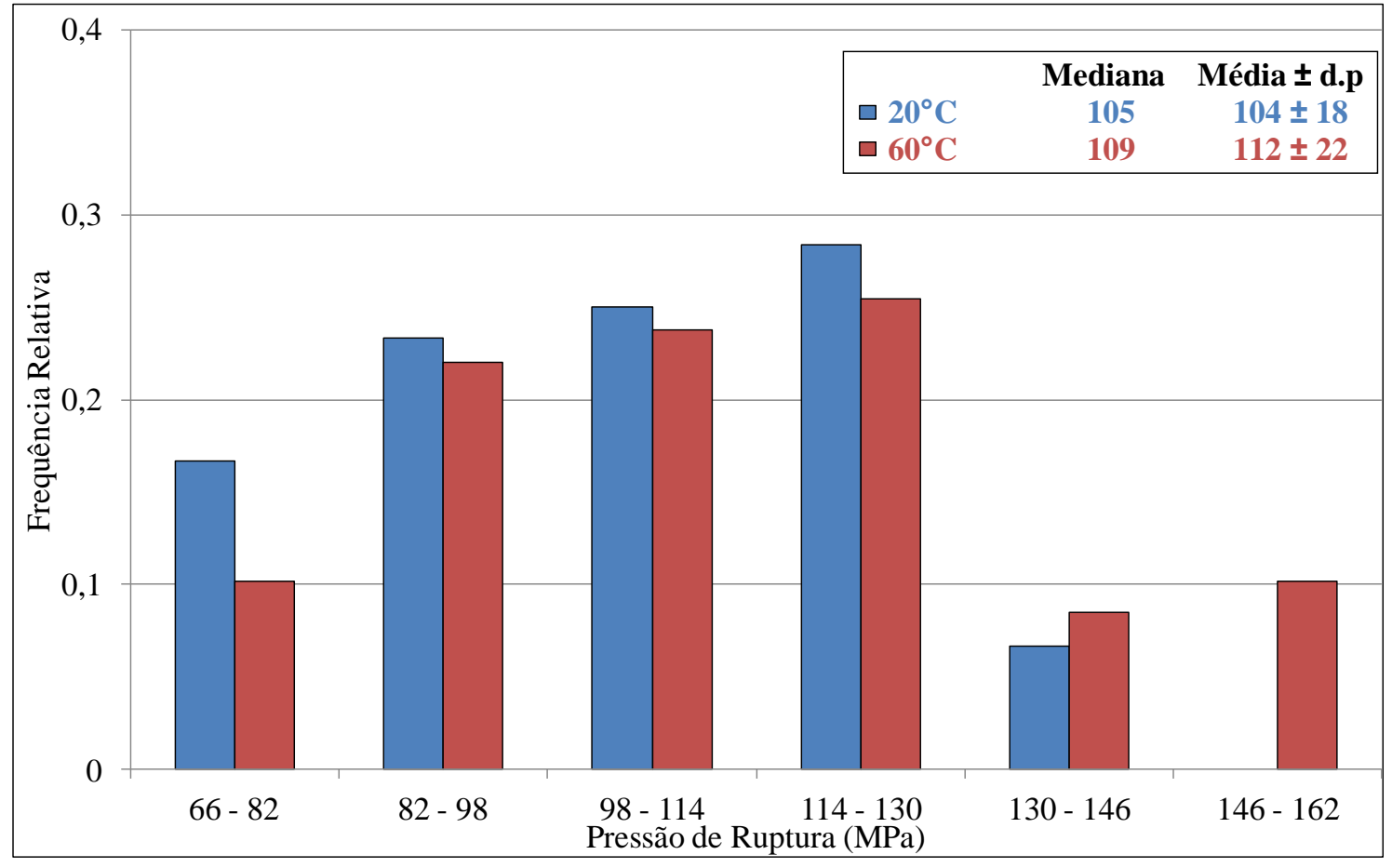

FIGURA 26 - Frequência relativa dos cps nos intervalos de pressão de ruptura em diferentes temperaturas

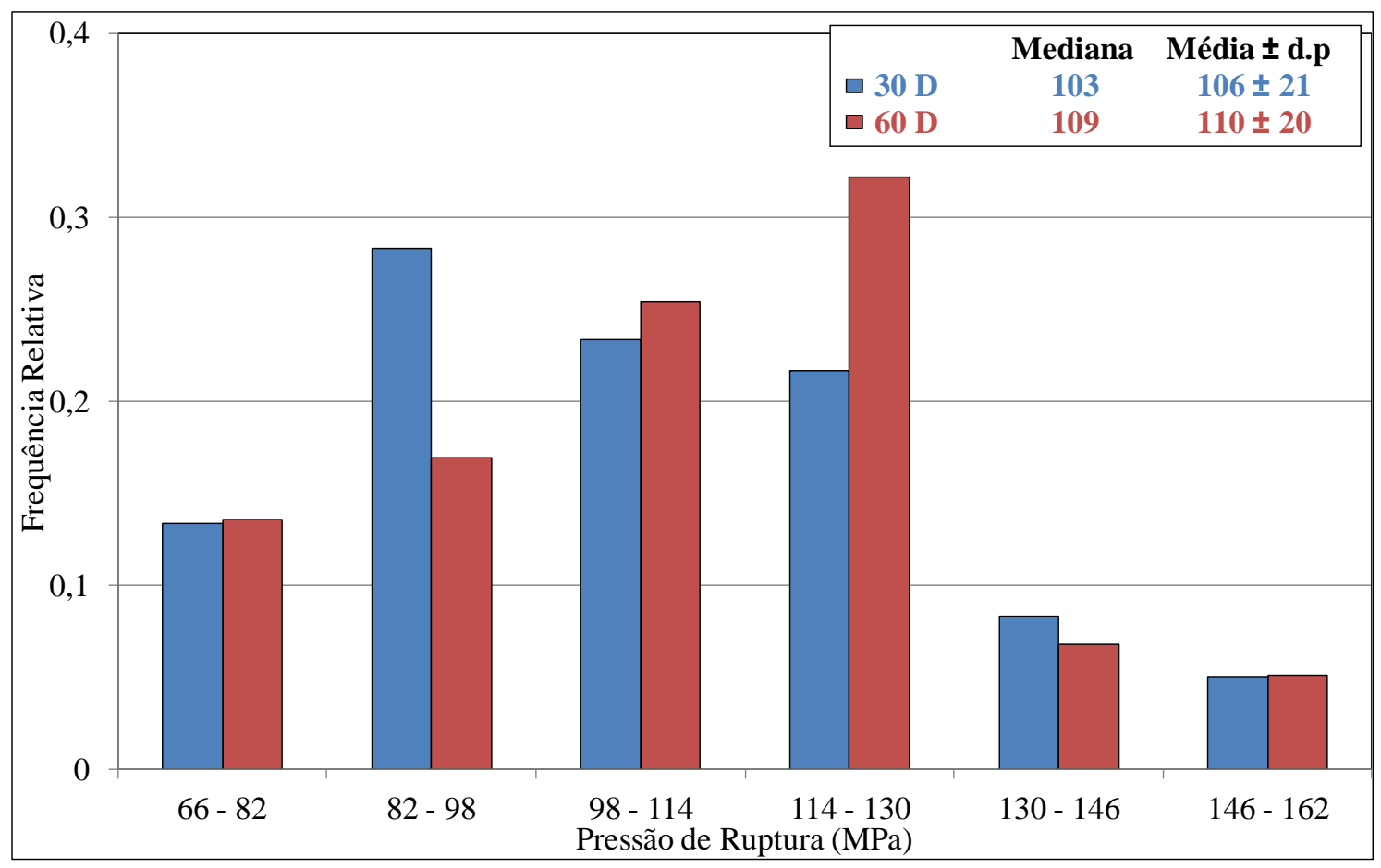

FIGURA 27 - Frequência relativa dos cps nos intervalos de pressão de ruptura em diferentes tempos de tratamento 


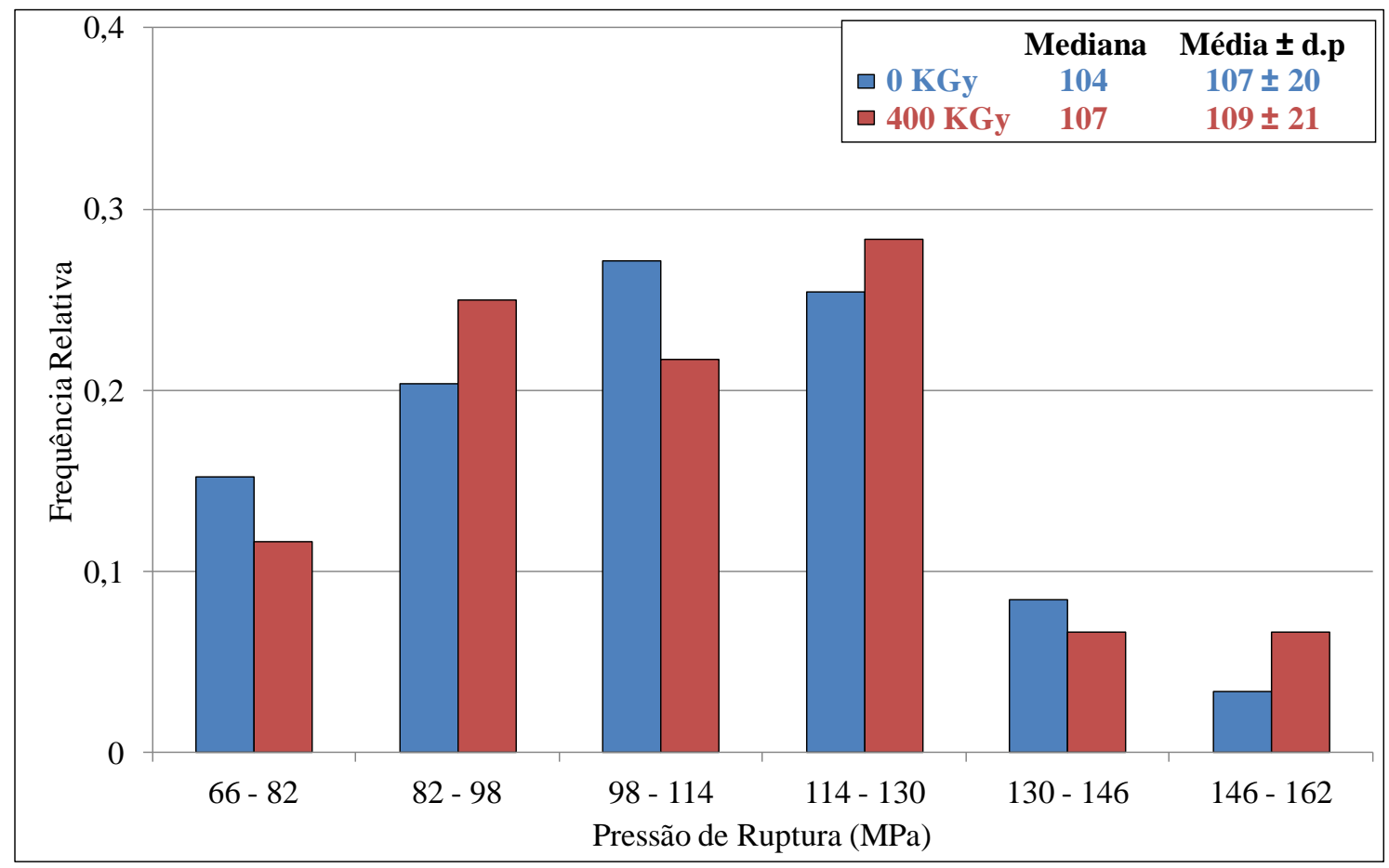

FIGURA 28 - Frequência relativa dos cps nos intervalos de pressão de ruptura em diferentes doses de irradiação

A influência de cada tratamento na resistência mecânica também foi avaliada por meio do teste t de Student, por meio da plataforma GraphPad's online QuickCalcs (GraphPad,2012). Nesse teste, os cps foram divididos em dois lotes, cada um com os cp's que foram submetidos a um mesmo tratamento, avaliando-os separadamente. A análise estatística fornece o p-valor, que indica se os resultados são estatisticamente diferentes (com nível de significância de 0,05) em diferentes graus:

1- não significantes, $\mathrm{p}$-valor $>0,0500$;

2- significantes, $0,0100<\mathrm{p}$-valor $<0,0500$;

3- muito significantes, $0,0001<\mathrm{p}$-valor $<0,0100$; e

4- extremamente significantes, p-valor $<0,0001$.

A análise dos resultados em níveis, observando a influência de um tratamento ou os efeito sinergéticos de 2 tratamentos na resistência mecânica é apresentada na TAB. 9. Os valores do grau de diferença estatística em negrito correspondem aos tratamentos que tiveram influência na resistência mecânica. 
TABELA 9 - Análise estatística (teste t) da resistência mecânica de cps submetidos a diferentes tratamentos

\begin{tabular}{|c|c|c|c|c|c|c|c|c|c|c|c|c|c|c|c|c|c|}
\hline \multicolumn{3}{|c|}{ Tratamentos } & \multicolumn{3}{|c|}{ Imersão } & \multicolumn{3}{|c|}{ Solução } & \multicolumn{3}{|c|}{ Temperatura $\left({ }^{\circ} \mathrm{C}\right)$} & \multicolumn{3}{|c|}{ Tempo (Dias) } & \multicolumn{3}{|c|}{ Irradiação (KGy) } \\
\hline $\mathrm{T}^{*}$ & $\begin{array}{c}\mathrm{RM} \\
(\mathrm{MPa})^{\dagger}\end{array}$ & $\mathrm{G}^{\S}$ & $\mathrm{T}^{*}$ & $\begin{array}{c}\mathrm{RM} \\
(\mathrm{MPa})^{\dagger}\end{array}$ & $\mathrm{G}^{\S}$ & $\mathrm{T}^{*}$ & $\begin{array}{c}\mathrm{RM} \\
(\mathrm{MPa})^{\dagger}\end{array}$ & $\mathrm{G}^{\S}$ & $\mathrm{T}^{*}$ & $\begin{array}{c}\mathrm{RM} \\
(\mathrm{MPa})^{\dagger}\end{array}$ & $\mathrm{G}^{\S}$ & $\mathrm{T}^{*}$ & $\begin{array}{c}\mathrm{RM} \\
(\mathrm{MPa})^{\dagger}\end{array}$ & $\mathrm{G}^{\S}$ & $\mathrm{T}^{*}$ & $\begin{array}{c}\mathrm{RM} \\
(\mathrm{MPa})^{\dagger}\end{array}$ & $\underset{\S}{\mathrm{G}}$ \\
\hline \multirow{2}{*}{$\mathrm{AD} / \mathrm{SS}$} & \multirow{2}{*}{$117 \pm 17$} & \multirow{4}{*}{4} & $\mathrm{AD} / \mathrm{SS}$ & & & $\mathrm{AD}$ & & & 20 & $113 \pm 14$ & & 30 & $115 \pm 18$ & & 0 & $115 \pm 17$ & \\
\hline & & & AS & & & $\mathrm{SS}$ & & & 60 & $121 \pm 19$ & 2 & 60 & $119 \pm 16$ & 1 & 400 & $119 \pm 18$ & 1 \\
\hline \multirow{2}{*}{ AS } & \multirow{2}{*}{$89 \pm 11$} & & $\mathrm{AD} / \mathrm{SS}$ & & & $\mathrm{AD}$ & & & 20 & $86 \pm 10$ & & 30 & $88 \pm 11$ & & 0 & $88 \pm 11$ & \\
\hline & & & AS & & & SS & & & 60 & $91 \pm 11$ & 1 & 60 & $90 \pm 11$ & 1 & 400 & $89 \pm 11$ & 1 \\
\hline \multirow{2}{*}{$\mathrm{AD}$} & \multirow{2}{*}{$123 \pm 16$} & \multirow{4}{*}{3} & $\mathrm{AD} / \mathrm{SS}$ & & & $\mathrm{AD}$ & & & 20 & $119 \pm 11$ & 1 & 30 & $123 \pm 17$ & & 0 & $120 \pm 16$ & \\
\hline & & & AS & & & SS & & & 60 & $127 \pm 18$ & 1 & 60 & $123 \pm 15$ & 1 & 400 & $126 \pm 15$ & 1 \\
\hline \multirow{2}{*}{ SS } & \multirow{2}{*}{$111 \pm 17$} & & $\mathrm{AD} / \mathrm{SS}$ & & & $\mathrm{AD}$ & & & 20 & $108 \pm 15$ & 1 & 30 & $108 \pm 17$ & & 0 & $111 \pm 18$ & 1 \\
\hline & & & AS & & & SS & & & 60 & $115 \pm 19$ & 1 & 60 & $115 \pm 17$ & 1 & 400 & $112 \pm 17$ & 1 \\
\hline \multirow{2}{*}{$20^{\circ} \mathrm{C}$} & \multirow{2}{*}{$104 \pm 18$} & \multirow{4}{*}{2} & $\mathrm{AD} / \mathrm{SS}$ & $113 \pm 14$ & 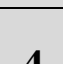 & $\mathrm{AD}$ & $119 \pm 11$ & $?$ & 20 & & & 30 & $99 \pm 17$ & 2 & 0 & $103 \pm 19$ & 1 \\
\hline & & & AS & $86 \pm 10$ & 4 & $\mathrm{SS}$ & $108 \pm 15$ & 2 & 60 & & & 60 & $109 \pm 19$ & 2 & 400 & $105 \pm 18$ & 1 \\
\hline \multirow{2}{*}{$60^{\circ} \mathrm{C}$} & \multirow{2}{*}{$112 \pm 22$} & & $\mathrm{AD} / \mathrm{SS}$ & $121 \pm 19$ & 4 & $\mathrm{AD}$ & $127 \pm 18$ & ? & 20 & & & 30 & $113 \pm 22$ & 1 & 0 & $110 \pm 21$ & 1 \\
\hline & & & $\mathrm{AS}$ & $91 \pm 11$ & 4 & $\mathrm{SS}$ & $115 \pm 19$ & 2 & 60 & & & 60 & $110 \pm 22$ & 1 & 400 & $113 \pm 24$ & 1 \\
\hline \multirow{2}{*}{$30 \mathrm{D}$} & \multirow{2}{*}{$106 \pm 21$} & \multirow{4}{*}{1} & $\mathrm{AD} / \mathrm{SS}$ & $115 \pm 18$ & 1 & $\mathrm{AD}$ & $123 \pm 17$ & 3 & 20 & $99 \pm 17$ & & 30 & & & 0 & $105 \pm 20$ & \\
\hline & & & $\mathrm{AS}$ & $88 \pm 11$ & 4 & $\mathrm{SS}$ & $108 \pm 17$ & 5 & 60 & $113 \pm 22$ & 3 & 60 & & & 400 & $107 \pm 22$ & 1 \\
\hline \multirow{2}{*}{$60 \mathrm{D}$} & \multirow{2}{*}{$110 \pm 20$} & & $\mathrm{AD} / \mathrm{SS}$ & $119 \pm 16$ & 4 & $\mathrm{AD}$ & $123 \pm 15$ & 1 & 20 & $109 \pm 19$ & 1 & 30 & & & 0 & $108 \pm 21$ & \\
\hline & & & AS & $90 \pm 11$ & & SS & $115 \pm 17$ & 1 & 60 & $110 \pm 22$ & 1 & 60 & & & 400 & $111 \pm 20$ & 1 \\
\hline \multirow{2}{*}{$0 \mathrm{KGy}$} & \multirow{2}{*}{$107 \pm 20$} & & $\mathrm{AD} / \mathrm{SS}$ & $115 \pm 17$ & 4 & $\mathrm{AD}$ & $120 \pm 16$ & 1 & 20 & $103 \pm 19$ & 1 & 30 & $105 \pm 20$ & 1 & 0 & & \\
\hline & & 1 & $\mathrm{AS}$ & $88 \pm 11$ & 4 & SS & $111 \pm 18$ & 1 & 60 & $110 \pm 21$ & 1 & 60 & $108 \pm 21$ & 1 & 400 & & \\
\hline $400 \mathrm{KG}$ & $100+21$ & 1 & $\mathrm{AD} / \mathrm{SS}$ & $119 \pm 18$ & 4 & $\mathrm{AD}$ & $126 \pm 15$ & 3 & 20 & $105 \pm 18$ & 1 & 30 & $107 \pm 22$ & 1 & 0 & & \\
\hline $400 \mathrm{KGy}$ & $109 \pm 21$ & & AS & $89 \pm 11$ & 4 & $\mathrm{SS}$ & $112 \pm 17$ & 3 & 60 & $113 \pm 24$ & 1 & 60 & $111 \pm 20$ & 1 & 400 & & \\
\hline
\end{tabular}

* - T = tratamento; $\quad \dagger$ R.M. = média \pm desvio padrão da resistência mecânica dos cps submetidos aos tratamentos indicados; $\S-\mathrm{G}=$ Teste $\mathrm{t}$ de Student, onde o grau de diferença estatística é: 1 -não significante; 2 - significante; 3 - muito significante; e 4 extremamente significante. 
Pela análise dos gráficos das FIG. 25-28 e da TAB. 9, observa-se que a imersão dos cps pode ser considerada um fator de influência na resistência mecânica dos mesmos. Esperava-se que a imersão fosse prejudicial à resistência mecânica, principalmente nos cps que ficaram imersos em solução salina, contendo íons agressivos à pasta de cimento, que tendem à acelerar sua degradação. Ao mesmo tempo, a temperatura mais alta também tende a aumentar a taxa de degradação, afetando sua durabilidade. No entanto, observou-se que os cps armazenados a seco possuem resistência mecânica inferior aos demais. Esse resultado sugere que os cps não estavam devidamente hidratados antes do início dos ensaios acelerados e a imersão dos mesmos possibilitou que eles continuassem a se hidratar, adquirindo resistência maior. Os cps que ficaram em imersão em água destilada possuem maior resistência do que aqueles que ficaram em imersão em solução salina. $\mathrm{O}$ ataque de substâncias agressivas presentes na solução salina tende a diminuir a resistência da pasta de cimento e, consequentemente, sua durabilidade.

A temperatura de imersão também foi capaz de alterar a resistência mecânica dos cps. Nesse caso, os cps que ficaram em altas temperaturas apresentaram resistência mecânica maior do que aqueles que ficaram em temperaturas mais baixas, ao contrário do esperado.

\subsection{Variação de massa dos corpos de prova}

A influência de cada tratamento na massa dos cps foi avaliada a partir da variação de sua massa em relação à massa inicial dos cps, aferida um dia após serem retirados do processo de cura. Um dia após serem removidos da imersão ou do armazenamento a seco (antes da irradiação) e um dia antes do ensaio de resistência à compressão (após a irradiação), a massa de todos os cps cúbicos foi mensurada. As massas foram nomeadas "M1" para aquelas obtidas após o processo de cura dos cps, "M2" para as obtidas antes da irradiação e "M3" para as obtidas após a irradiação. A massa "M3" dos cps cilíndricos que não foram submetidos à irradiação não foi mensurada.

A variação das massas dos cps cilíndricos e cúbicos está apresentada nas FIG. 29 e 30, respectivamente. Cada coluna do gráfico representa o ganho ou perda de massa em relação à massa inicial "M1". As colunas em vermelho indicam a variação após a remoção dos tratamentos (M2), enquanto as em azul indicam a variação após a irradiação (M3). 

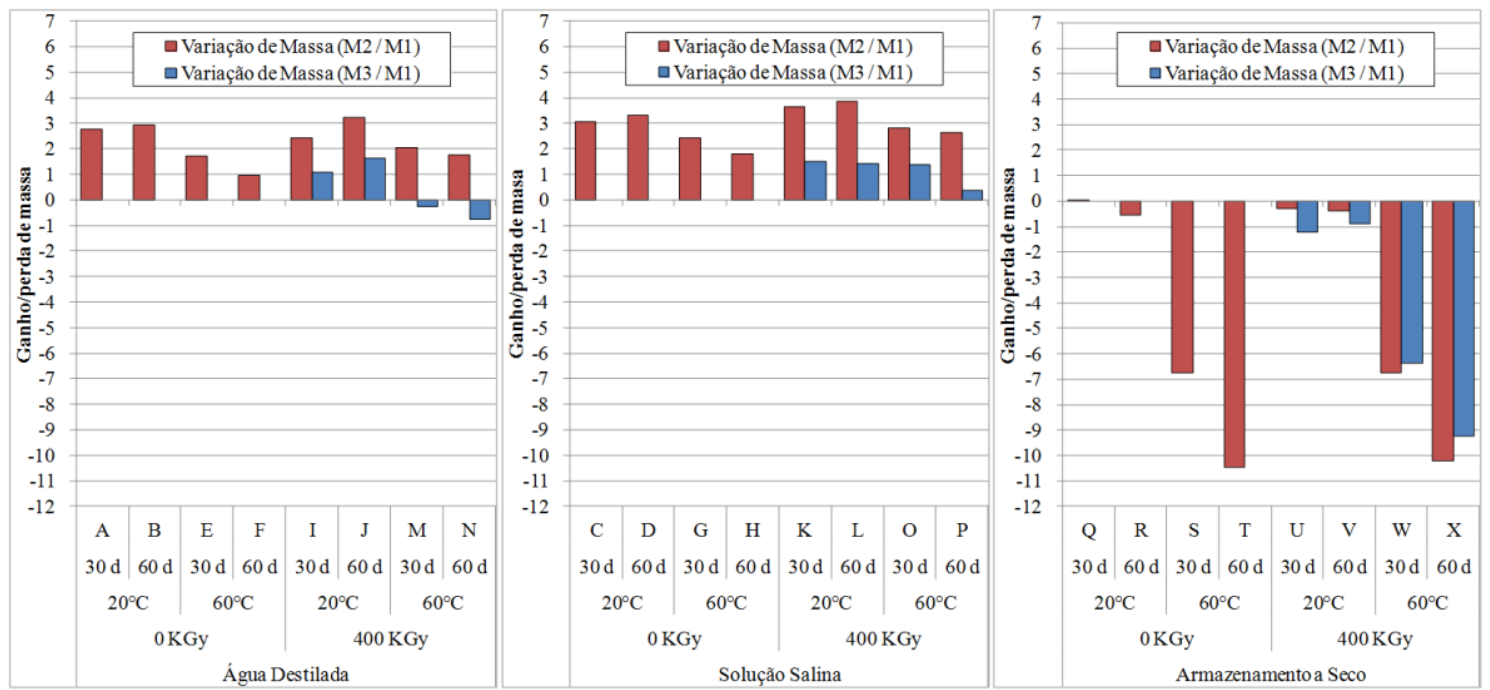

FIGURA 29 - Variação de massa dos cps cilíndricos antes e após a irradiação.
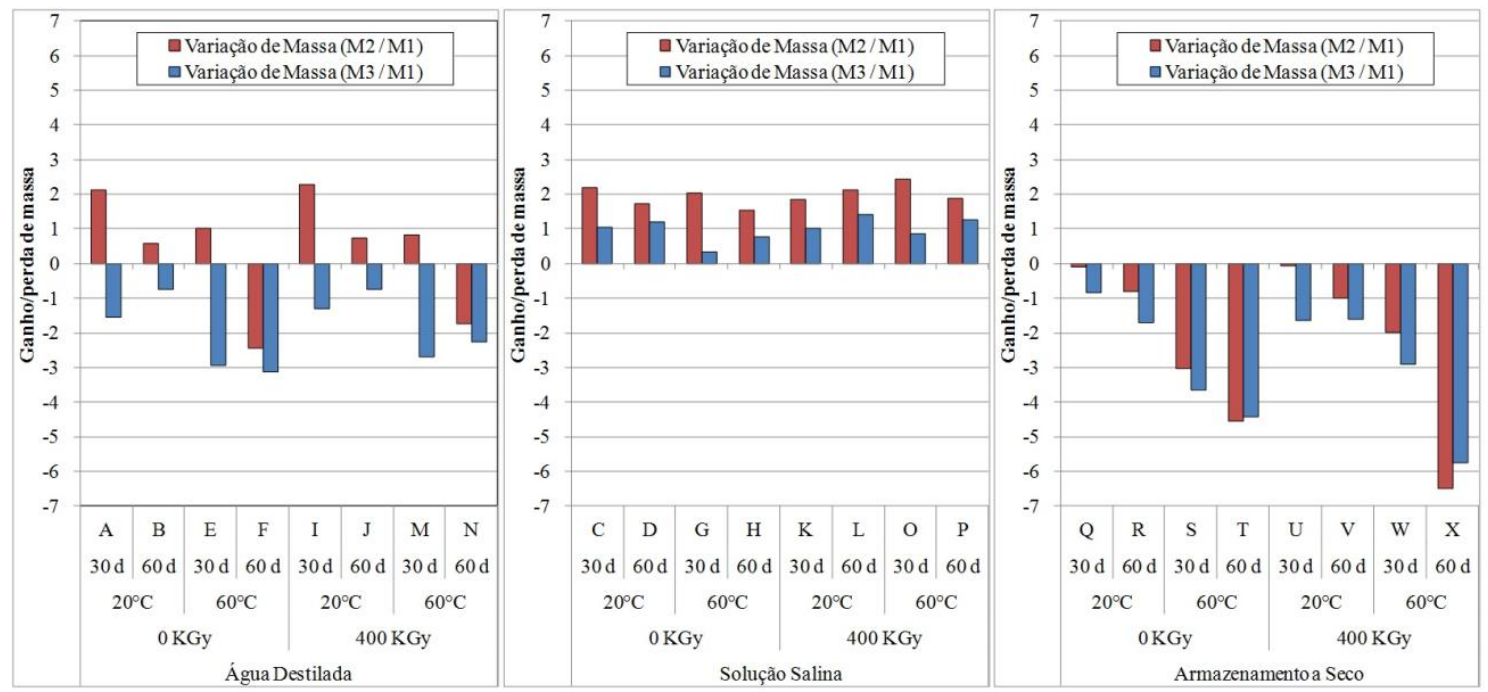

FIGURA 30 - Variação de massa dos cps cúbicos antes e após a irradiação.

Os cps cilíndricos e cúbicos apresentaram comportamento similar na variação de massa após cada etapa. Os cps que ficaram armazenados a seco em temperatura ambiente não apresentaram grande variação durante o armazenamento, enquanto aqueles que ficaram em temperatura elevada apresentaram grande perda de massa. Os cps que ficaram imersos (tanto em AD quanto em SS) apresentaram ganho de massa após o tratamento, exceto os cúbicos imersos em água destilada, por 60 dias a $60^{\circ} \mathrm{C}$, que apresentaram perda de massa.

Observou-se também que M2 foi maior do que M1 nos cps imersos em água destilada, devido à absorção de água nos poros do cimento. No entanto, M3 foi menor do que M1 (para cps irradiados ou não), provavelmente devido à perda da água absorvida e 
outros compostos hidratados lixiviados da pasta. De acordo com Lécolier et al (2007) e Galíndez e Molinero (2010), em contato com água, os compostos hidratados da pasta de cimento podem ser dissolvidos e lixiviados, aumentando sua permeabilidade e porosidade, tornando a pasta mais susceptível à penetração de água, que poderia alcançar as barreiras internas do repositório e causar a falha do sistema.

Todos os cps imersos em SS apresentaram ganho de massa, provavelmente causado pela penetração e reação de algumas espécies. Berner (1992), Collepardi (2003), El-Hachem et al (2012) e Matschei and Glasser (2010) afirmaram que espécies químicas dissolvidas na solução salina podem reagir com os compostos hidratados da pasta de cimento e causar fissuramento e fragmentação da mesma. A penetração de grandes quantidade de cloreto e sulfato podem causar esses fenômenos. Por outro lado, a reação de bicarbonato e cálcio pode produzir calcita, que causa o bloqueio dos poros e reduz a permeabilidade da pasta.

\subsection{Análise de íons em solução}

As soluções, em que os cps cilíndricos e cúbicos ficaram em imersão, foram analisadas para determinação dos íons presentes. As FIG. 31-34 apresentam os gráficos de concentração dos íons na solução de imersão.

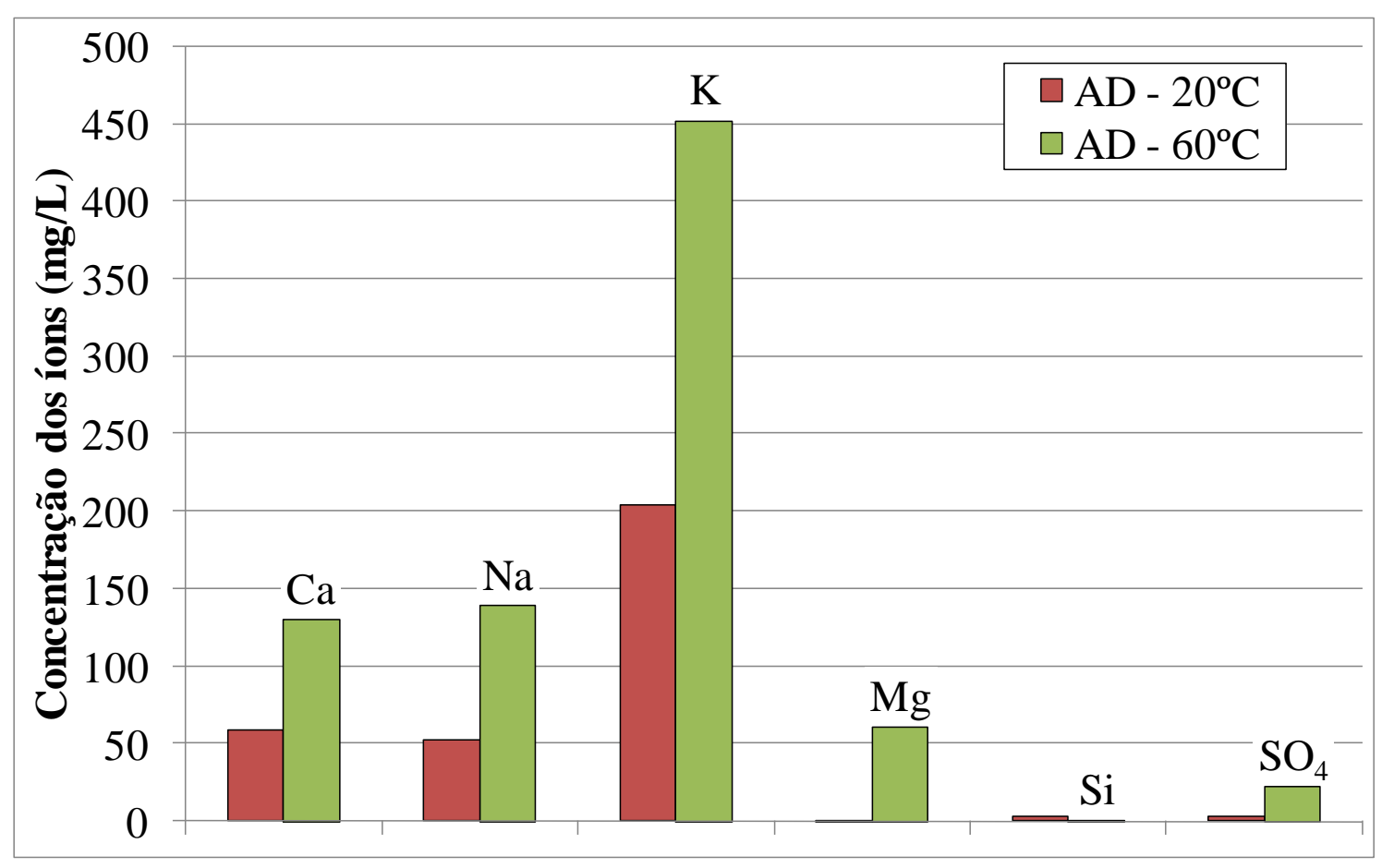

FIGURA 31 - Concentração das espécies na água destilada após a imersão dos cps cilíndricos 


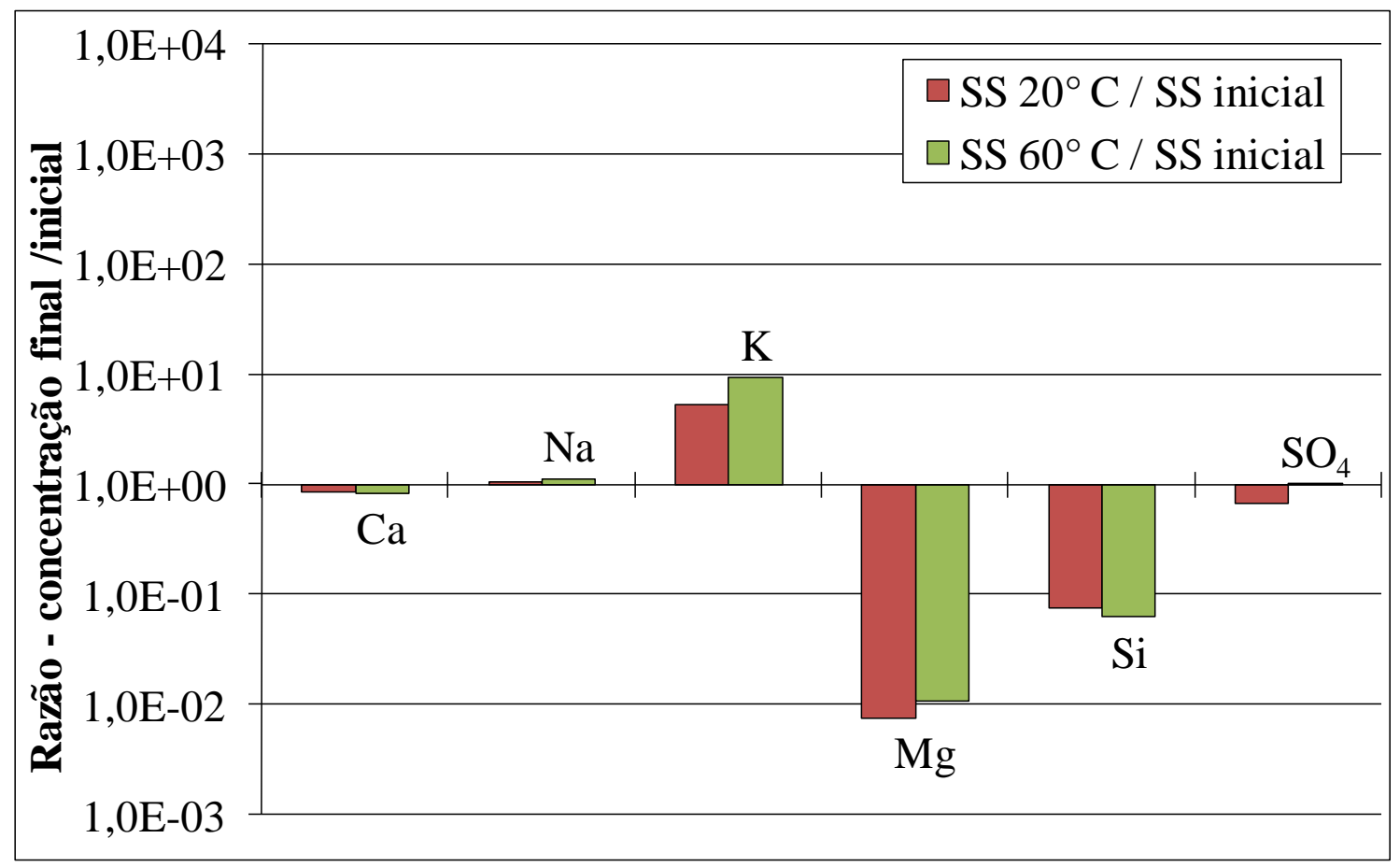

FIGURA 32 - Razão entre as concentrações finais em relação à inicial das espécies nas soluções salinas após a imersão dos cps cilíndricos

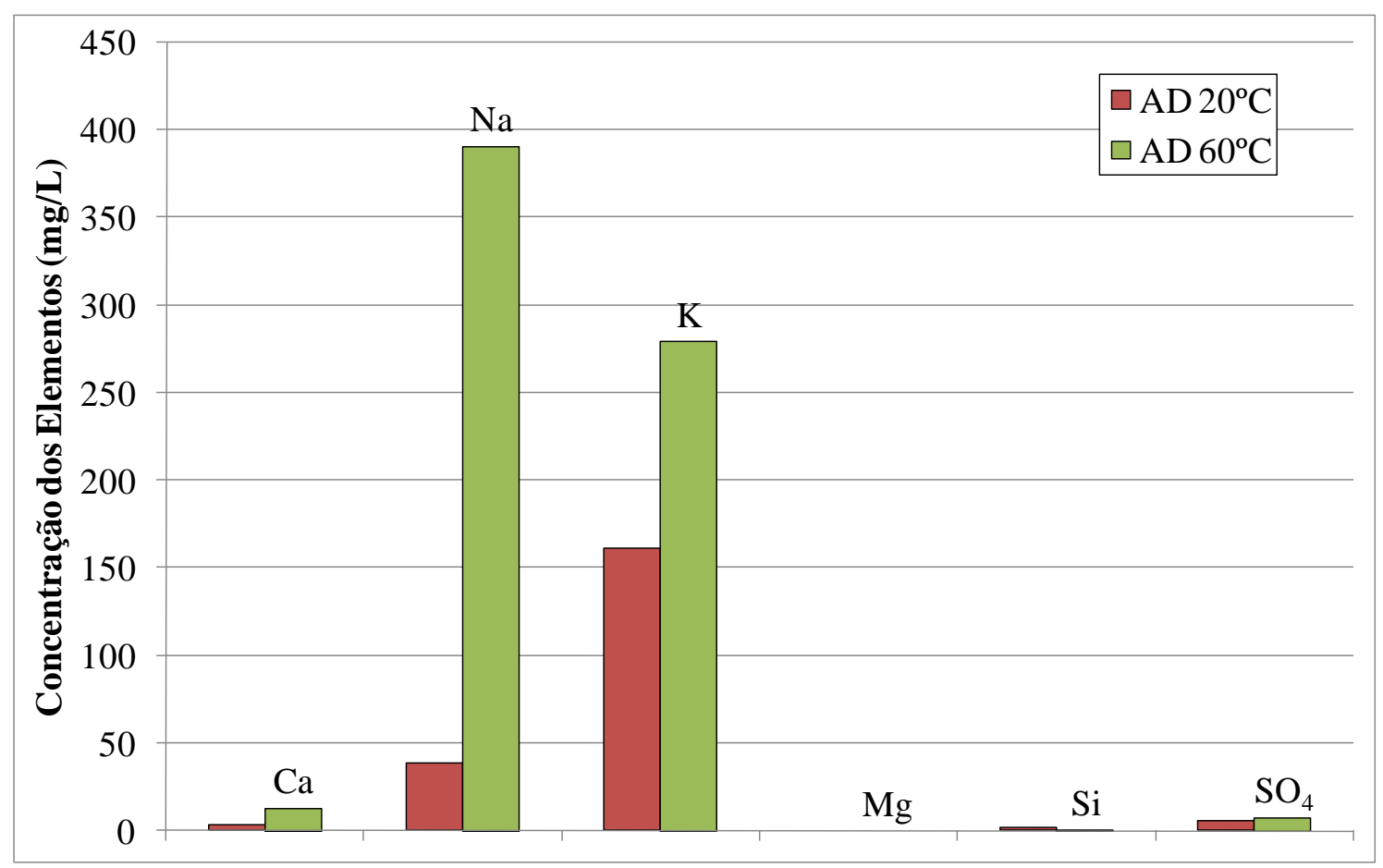

FIGURA 33 - Concentração das espécies na água destilada após a imersão dos cps cúbicos 


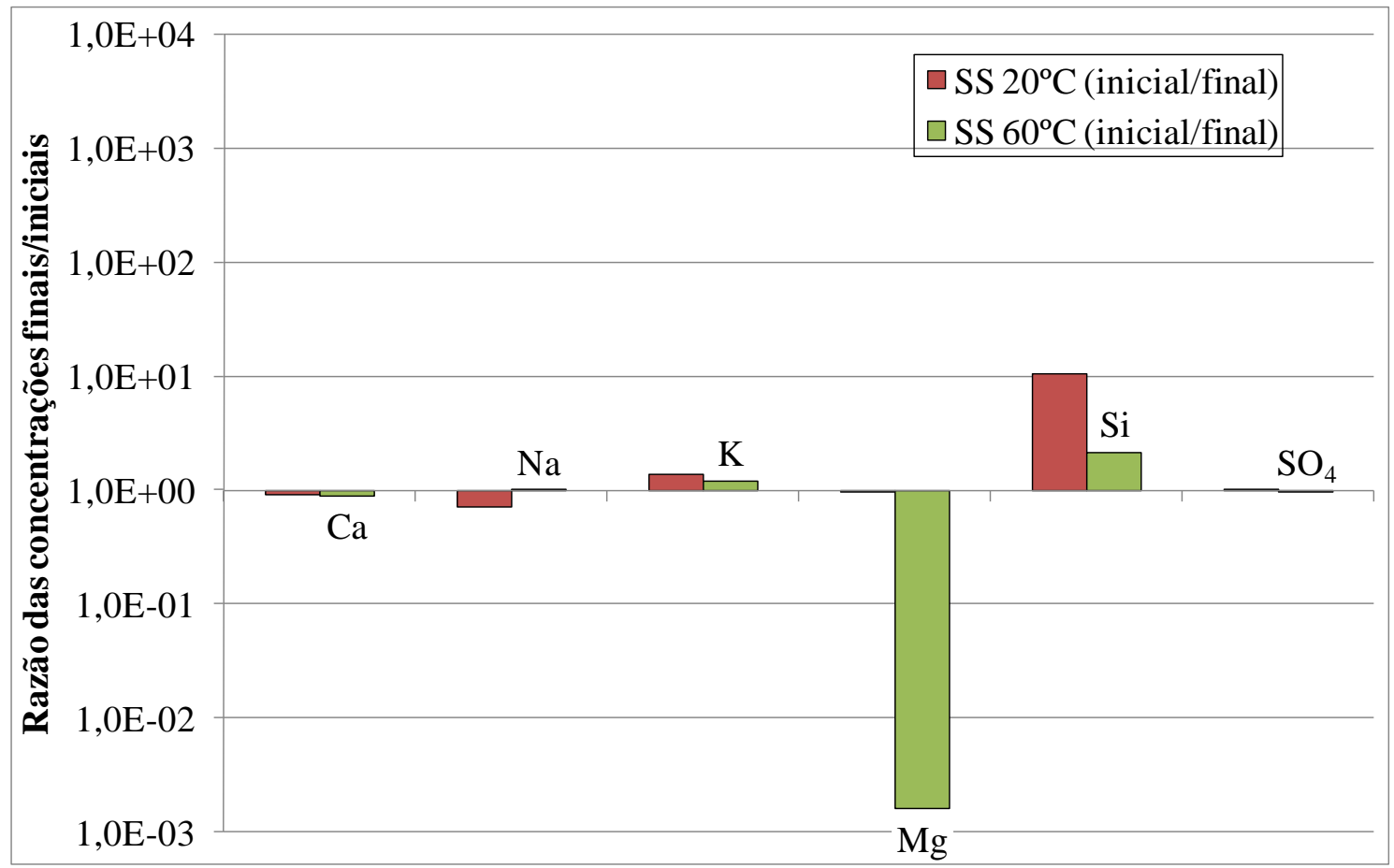

FIGURA 34 - Razão entre as concentrações finais em relação à inicial das espécies nas soluções salinas após a imersão dos cps cúbicos

A FIG. 31 apresenta o gráfico de concentrações dos íons presentes na solução de imersão dos cps cilíndricos que ficaram imersos em água destilada a $20^{\circ} \mathrm{C}$ ou a $60^{\circ} \mathrm{C}$ e a FIG. 32 as diferenças entre as concentrações iniciais e finais de cada íon na solução após a imersão dos cps cilíndricos em solução salina. As FIG. 33-34 apresentam os gráficos para as concentrações na solução de imersão dos cps cúbicos.

Não foi observada variação considerável nas concentrações de $\mathrm{Al}, \mathrm{Fe}, \mathrm{NO}_{3}{ }^{-}$, $\mathrm{NO}_{2}^{-}, \mathrm{PO}_{4}^{2-}, \mathrm{HCO}_{3}, \mathrm{Br}^{-}, \mathrm{Cl}^{-}$e $\mathrm{F}^{-}$, tanto para cps cúbicos como para os cilíndricos. As concentrações de $\mathrm{Ca}^{2+}, \mathrm{Na}^{+}, \mathrm{K}^{+}$e $\mathrm{Mg}^{2+}$ apresentaram aumento substancial com o aumento da temperatura. Esse comportamento pode ser explicado pela diferença de solubilidade dos compostos desses íons nessas condições.

O cálcio está presente em quase todos os compostos da pasta de cimento hidratado e, como esperado, observou-se que esse composto é lixiviado da pasta de cimento para a solução quando imerso em água destilada, embora em proporções pequenas. Na imersão em solução salina, no entanto, observou-se que a concentração desse íon diminuiu na solução, indicando que houve a penetração desse íon no cp. Apesar da absorção de cálcio parecer pequena, isso ocorre devido à alta quantidade adicionada na solução inicial de imersão. De fato o cálcio é o material que mais penetra na pasta de cimento em concentração absoluta, cerca de 250 a 300 g/L. A diminuição de cálcio na 
solução salina pode ser resultante da absorção do mesmo no gel de C-S-H, aumentando a proporção cálcio/sílica, ou da reação do mesmo com bicarbonato, que ocorre nos poros da pasta e causa o bloqueio da rede de poros, diminuindo sua permeabilidade

A concentração de silício não sofreu alteração na água destilada, porém diminuiu na solução salina. No entanto, como sua concentração inicial foi baixa, essa diminuição resumiu-se a cerca de $5 \mathrm{~g} / \mathrm{L}$, muito menor do que a do cálcio.

$\mathrm{O}$ aumento na concentração dos álcalis na solução $\left(\mathrm{K}^{+} \mathrm{e} \mathrm{Na}{ }^{+}\right)$sugere que eles são lixiviados da pasta de cimento. Sua liberação libera sítios ativos do C-S-H para a entrada de $\mathrm{Ca}^{2+}$ e $\mathrm{Mg}^{2+}$, o que pode explicar a entrada desses dois íons para a pasta de cimento, quando imersa em solução salina. De fato, foi observada a penetração de $\mathrm{Mg}^{2+}$ para a pasta de cimento em todas as amostras.

O íon sulfato penetra na pasta de cimento em maiores proporções na solução que ficou a $20^{\circ} \mathrm{C}$. A penetração de sulfato em grandes quantidades pode resultar na formação de etringita secundária, causando fissuras no cimento já endurecido e prejudicando seu desempenho. Nesse caso, essa reação dificilmente ocorreria, pois a penetração de sulfato foi muito baixa, no tempo estabelecido neste trabalho.

\subsection{Análise por difração de raios $X$}

As amostras retiradas dos cps rompidos e analisadas por difração de raios $\mathrm{x}$ estão identificadas na TAB. 10. As amostras foram selecionadas de forma a abranger todos os tratamentos realizados durante o ensaio acelerado. Além disso, foram retiradas amostras da superfície e do centro das amostras com o intuito de detectar possíveis diferenças na profundidade das amostras.

A difração de raios $\mathrm{X}$ permite analisar a mineralogia das amostras. Para análise das amostras, foi utilizado o software PANalytical X'Pert High Score Plus e base de dados do ICDD (International Center for Diffraction Data) para análise mineralógica. Com as características de cada amostra, a partir de uma análise por agrupamento (cluster analysis), é possível agrupá-las de acordo com suas semelhanças mineralógicas.

A análise por agrupamento é uma ferramenta que, considerando algoritmos e critérios matemáticos, ordenam uma coleção de amostras quaisquer em grupos de semelhanças e dissimilaridades, de maneira que amostras pertencentes ao mesmo grupo possuem similaridade máxima, enquanto amostras pertencentes a grupos diferentes possuem similaridades mínimas. Essa técnica não necessita de conhecimento prévio das amostras (ANTONIASSI, 2010). 
O dendrograma apresentado na FIG. 35 representa esse agrupamento, que permite observar o grau das mudanças induzidas pelos tratamentos nas amostras.

TABELA 10 - Identificação das amostras enviadas para análise por difração de raios X

\begin{tabular}{|c|c|c|c|c|c|}
\hline $\begin{array}{l}\mathrm{N}^{\circ} \text { da } \\
\text { Amostra }\end{array}$ & Meio & Temperatura & $\begin{array}{l}\text { Tempo de } \\
\text { Imersão }\end{array}$ & Irradiação & $\begin{array}{c}\text { Local de } \\
\text { Amostragem }\end{array}$ \\
\hline 1 & SS & $60^{\circ} \mathrm{C}$ & 30 dias & 0 KGy & $\begin{array}{c}\text { Centro } \\
\text { Superfície }\end{array}$ \\
\hline $\begin{array}{l}3 \\
4 \\
\end{array}$ & SS & $60^{\circ} \mathrm{C}$ & 60 dias & 0 KGy & $\begin{array}{c}\text { Centro } \\
\text { Superfície }\end{array}$ \\
\hline $\begin{array}{l}5 \\
6\end{array}$ & AS & $20^{\circ} \mathrm{C}$ & 60 dias & 0 KGy & $\begin{array}{l}\text { Centro } \\
\text { Superfície }\end{array}$ \\
\hline $\begin{array}{l}7 \\
8\end{array}$ & AS & $20^{\circ} \mathrm{C}$ & 60 dias & $0 \mathrm{KGy}$ & $\begin{array}{l}\text { Centro } \\
\text { Superfície }\end{array}$ \\
\hline $\begin{array}{l}9 \\
10\end{array}$ & AS & $60^{\circ} \mathrm{C}$ & 30 dias & 0 KGy & $\begin{array}{l}\text { Centro } \\
\text { Superfície }\end{array}$ \\
\hline $\begin{array}{l}11 \\
12\end{array}$ & AS & $60^{\circ} \mathrm{C}$ & 60 dias & $0 \mathrm{KGy}$ & $\begin{array}{l}\text { Centro } \\
\text { Superfície }\end{array}$ \\
\hline $\begin{array}{l}13 \\
14\end{array}$ & $\mathrm{AD}$ & $20^{\circ} \mathrm{C}$ & 30 dias & $0 \mathrm{KGy}$ & $\begin{array}{c}\text { Centro } \\
\text { Superfície }\end{array}$ \\
\hline $\begin{array}{l}15 \\
16\end{array}$ & $\mathrm{AD}$ & $20^{\circ} \mathrm{C}$ & 60 dias & 0 KGy & $\begin{array}{l}\text { Centro } \\
\text { Superfície }\end{array}$ \\
\hline $\begin{array}{l}17 \\
18\end{array}$ & SS & $20^{\circ} \mathrm{C}$ & 30 dias & 0 KGy & $\begin{array}{c}\text { Centro } \\
\text { Superfície }\end{array}$ \\
\hline $\begin{array}{l}19 \\
20\end{array}$ & SS & $20^{\circ} \mathrm{C}$ & 60 dias & 0 KGy & $\begin{array}{c}\text { Centro } \\
\text { Superfície }\end{array}$ \\
\hline $\begin{array}{l}21 \\
22 \\
\end{array}$ & $\mathrm{AD}$ & $60^{\circ} \mathrm{C}$ & 30 dias & 0 KGy & $\begin{array}{c}\text { Centro } \\
\text { Superfície }\end{array}$ \\
\hline $\begin{array}{l}23 \\
24\end{array}$ & $\mathrm{AD}$ & $60^{\circ} \mathrm{C}$ & 60 dias & 0 KGy & $\begin{array}{c}\text { Centro } \\
\text { Superfície }\end{array}$ \\
\hline $\begin{array}{l}25 \\
26\end{array}$ & $\mathrm{AD}$ & $20^{\circ} \mathrm{C}$ & 30 dias & 400 KGy & $\begin{array}{l}\text { Centro } \\
\text { Superfície }\end{array}$ \\
\hline $\begin{array}{l}27 \\
28\end{array}$ & $\mathrm{AD}$ & $20^{\circ} \mathrm{C}$ & 60 dias & $400 \mathrm{KGy}$ & $\begin{array}{c}\text { Centro } \\
\text { Superfície }\end{array}$ \\
\hline $\begin{array}{l}29 \\
30\end{array}$ & SS & $20^{\circ} \mathrm{C}$ & 30 dias & $400 \mathrm{KGy}$ & $\begin{array}{c}\text { Centro } \\
\text { Superfície }\end{array}$ \\
\hline $\begin{array}{l}31 \\
32 \\
33\end{array}$ & SS & $20^{\circ} \mathrm{C}$ & 60 dias & 400 KGy & $\begin{array}{l}\text { Centro } \\
\text { Superfície } \\
\text { Centro }\end{array}$ \\
\hline $\begin{array}{l}34 \\
35\end{array}$ & $\mathrm{AD}$ & $60^{\circ} \mathrm{C}$ & 30 dias & $400 \mathrm{KGy}$ & $\begin{array}{c}\text { Centro } \\
\text { Superfície }\end{array}$ \\
\hline 36 & $\mathrm{AS}$ & $20^{\circ} \mathrm{C}$ & 60 dias & $400 \mathrm{KGy}$ & Centro \\
\hline $\begin{array}{l}37 \\
38\end{array}$ & $\mathrm{AD}$ & $60^{\circ} \mathrm{C}$ & 60 dias & $400 \mathrm{KGy}$ & $\begin{array}{c}\text { Centro } \\
\text { Superfície }\end{array}$ \\
\hline $\begin{array}{l}39 \\
40\end{array}$ & SS & $60^{\circ} \mathrm{C}$ & 30 dias & 400 KGy & $\begin{array}{c}\text { Centro } \\
\text { Superfície }\end{array}$ \\
\hline $\begin{array}{l}41 \\
42\end{array}$ & SS & $60^{\circ} \mathrm{C}$ & 60 dias & $400 \mathrm{KGy}$ & $\begin{array}{c}\text { Centro } \\
\text { Superfície }\end{array}$ \\
\hline $\begin{array}{l}43 \\
44\end{array}$ & AS & $20^{\circ} \mathrm{C}$ & 60 dias & 400 KGy & $\begin{array}{l}\text { Centro } \\
\text { Superfície }\end{array}$ \\
\hline $\begin{array}{l}45 \\
46\end{array}$ & AS & $20^{\circ} \mathrm{C}$ & 60 dias & 400 KGy & $\begin{array}{l}\text { Centro } \\
\text { Superfície }\end{array}$ \\
\hline $\begin{array}{l}47 \\
48\end{array}$ & AS & $60^{\circ} \mathrm{C}$ & 30 dias & 400 KGy & $\begin{array}{c}\text { Centro } \\
\text { Superfície }\end{array}$ \\
\hline 49 & AS & $60^{\circ} \mathrm{C}$ & 60 dias & $400 \mathrm{KGy}$ & Centro \\
\hline
\end{tabular}




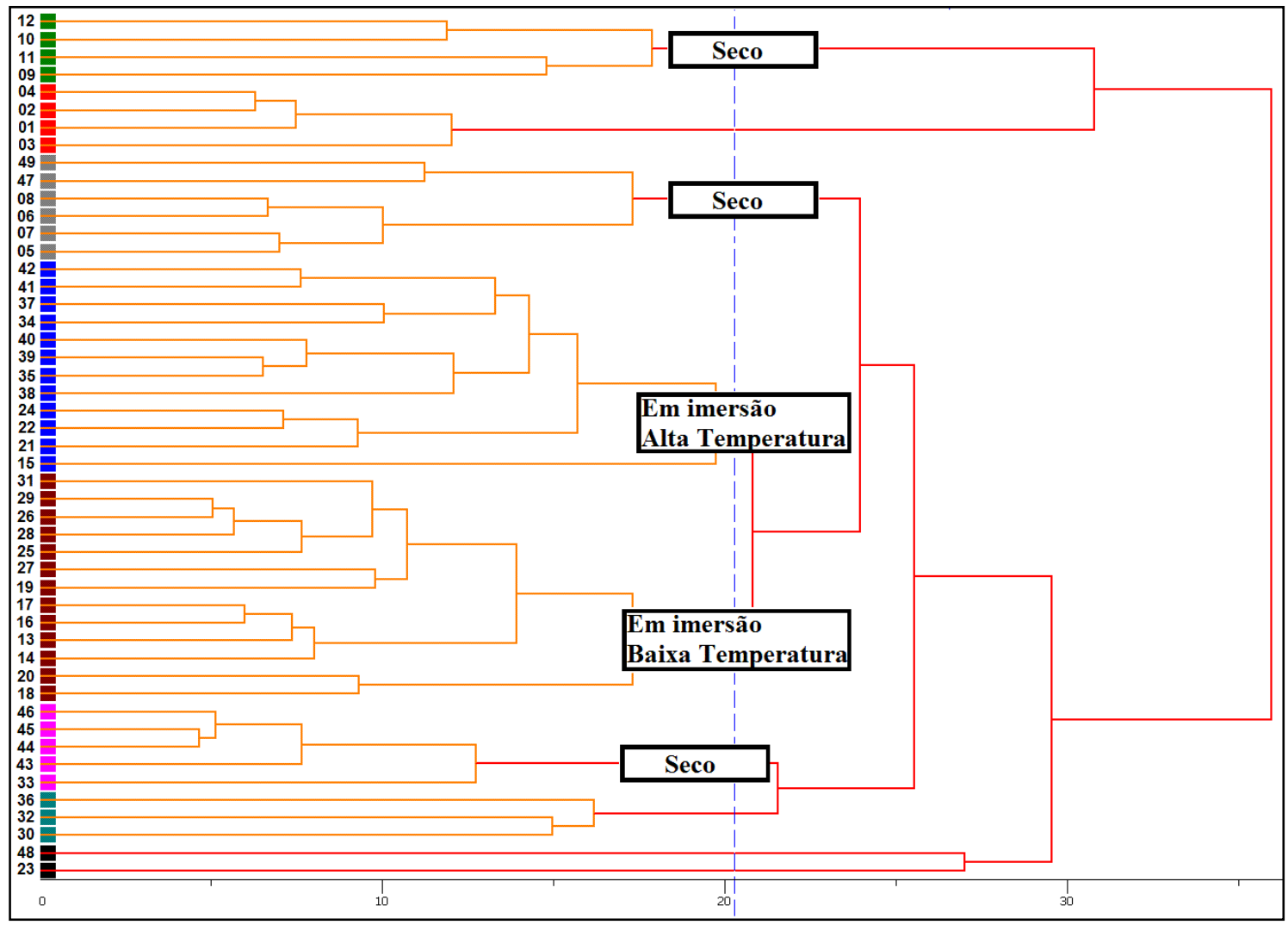

FIGURA 35 - Agrupamento das amostras por semelhanças mineralógicas, obtidas pela análise de cluster de DRX

O difratograma completo de doze amostras selecionadas está apresentado na FIG. 36. Pelos difratogramas, é possível diferenciar e comparar as amostras de cps expostos a tratamentos diferentes. A FIG. 37 apresenta uma aproximação entre os ângulos $7^{\circ}$ e $26^{\circ} 2 \theta$. As alturas dos picos é proporcional a concentração das espécies em cada amostra e os principais picos identificados correspondem a um composto mineral específico, como segue: 1. Pico principal da etringita; 2. Pico de etringita; 3 . Pico principal da portlandita $\left[\mathrm{Ca}(\mathrm{OH})_{2}\right] ; 4$. Pico da etringita e da calcita $\left(\mathrm{CaCO}_{3}\right) ; 5$. Pico principal da calcita $\left(\mathrm{CaCO}_{3}\right)$; e 6.Pico principal da alita; 


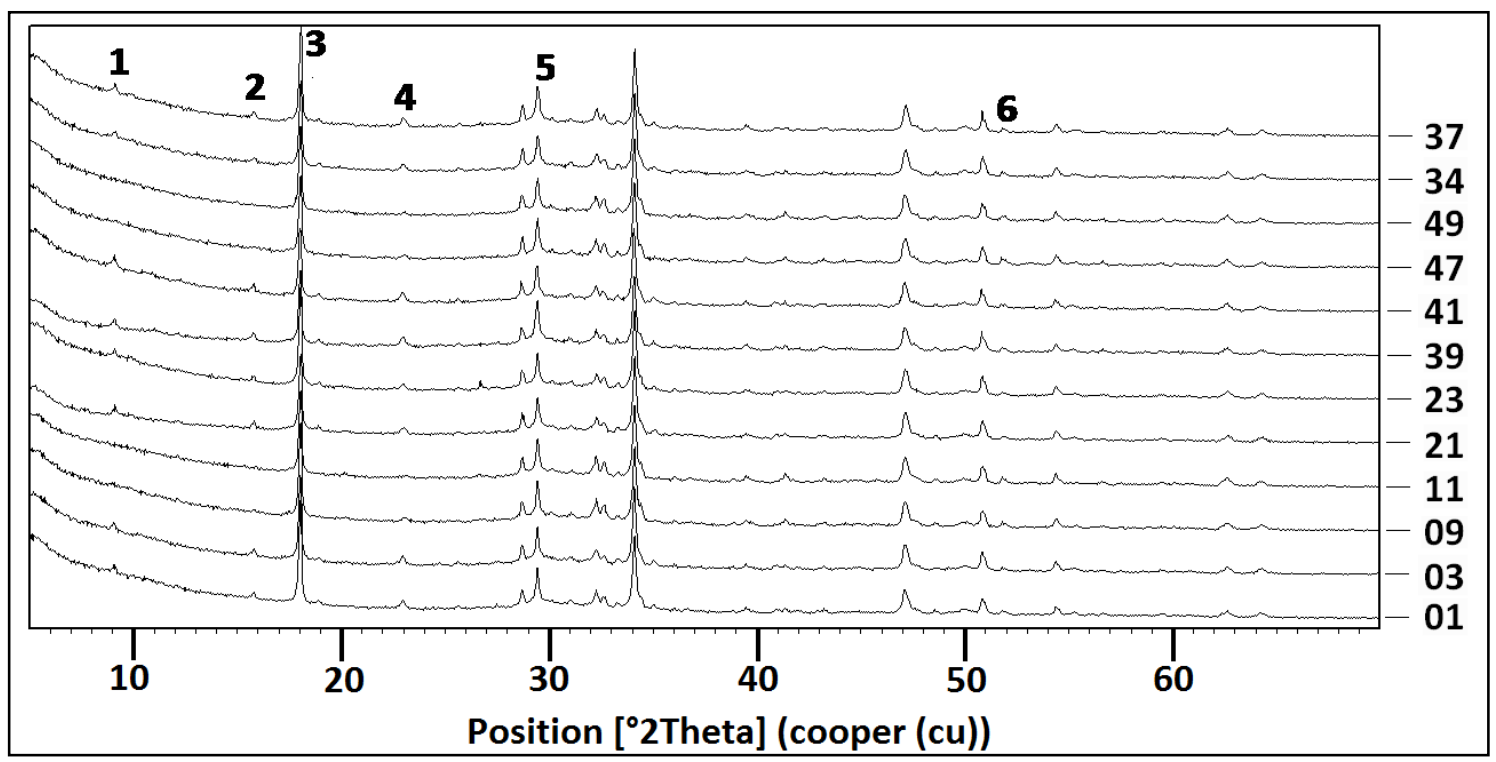

FIGURA 36 - Difratograma de doze amostras de pasta de cimento.

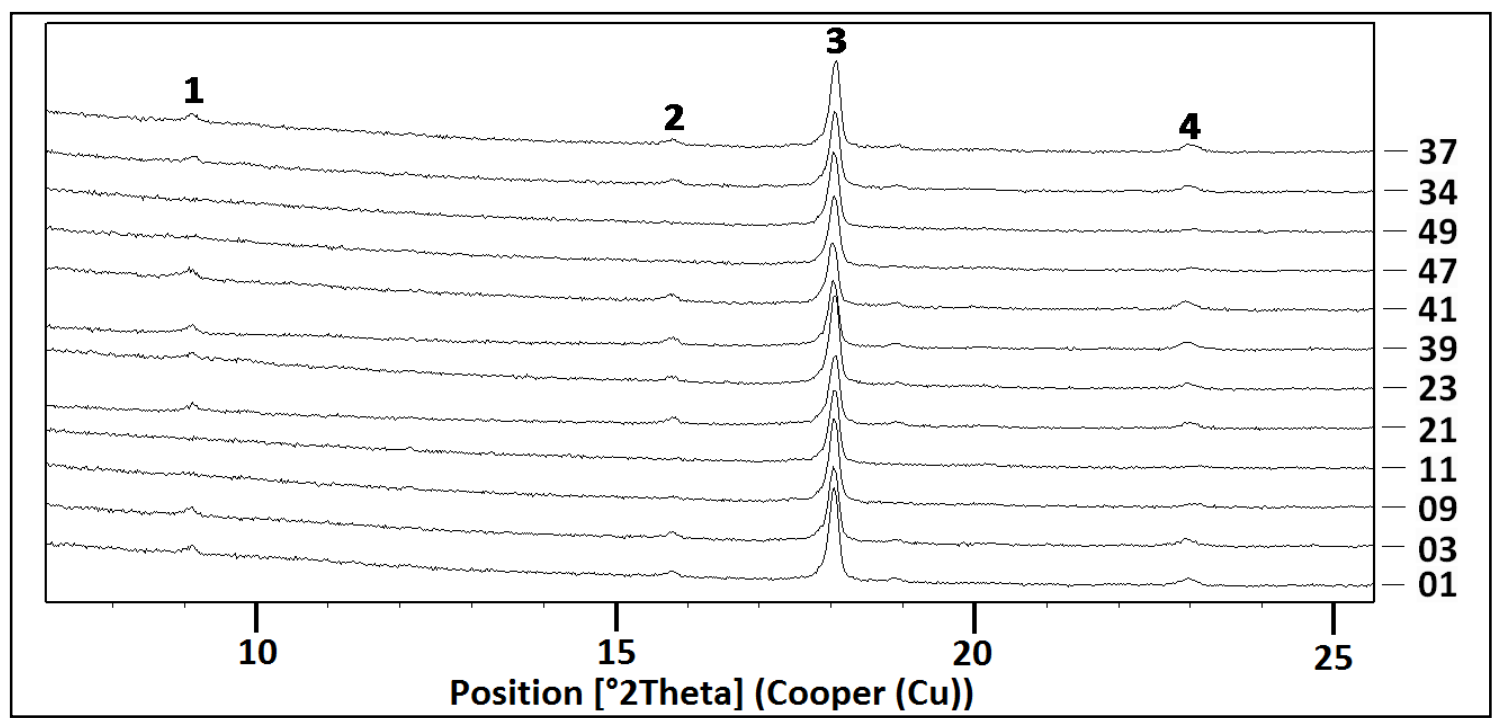

FIGURA 37 - Aproximação do difratograma das doze amostras.

Ainda por meio do software PANalytical X’Pert High Score Plus, foi possível realizar uma análise semiquantitativa dos compostos minerais presentes na amostra. Essa análise é feita pela intensidade dos picos correspondentes a cada composto. Foram realizadas análises semiquantitativas de algumas amostras, que melhor representam cada agrupamento apresentado no dendrograma da FIG. 35. O gráfico com a análise de quatro delas está apresentado na FIG. 38. 


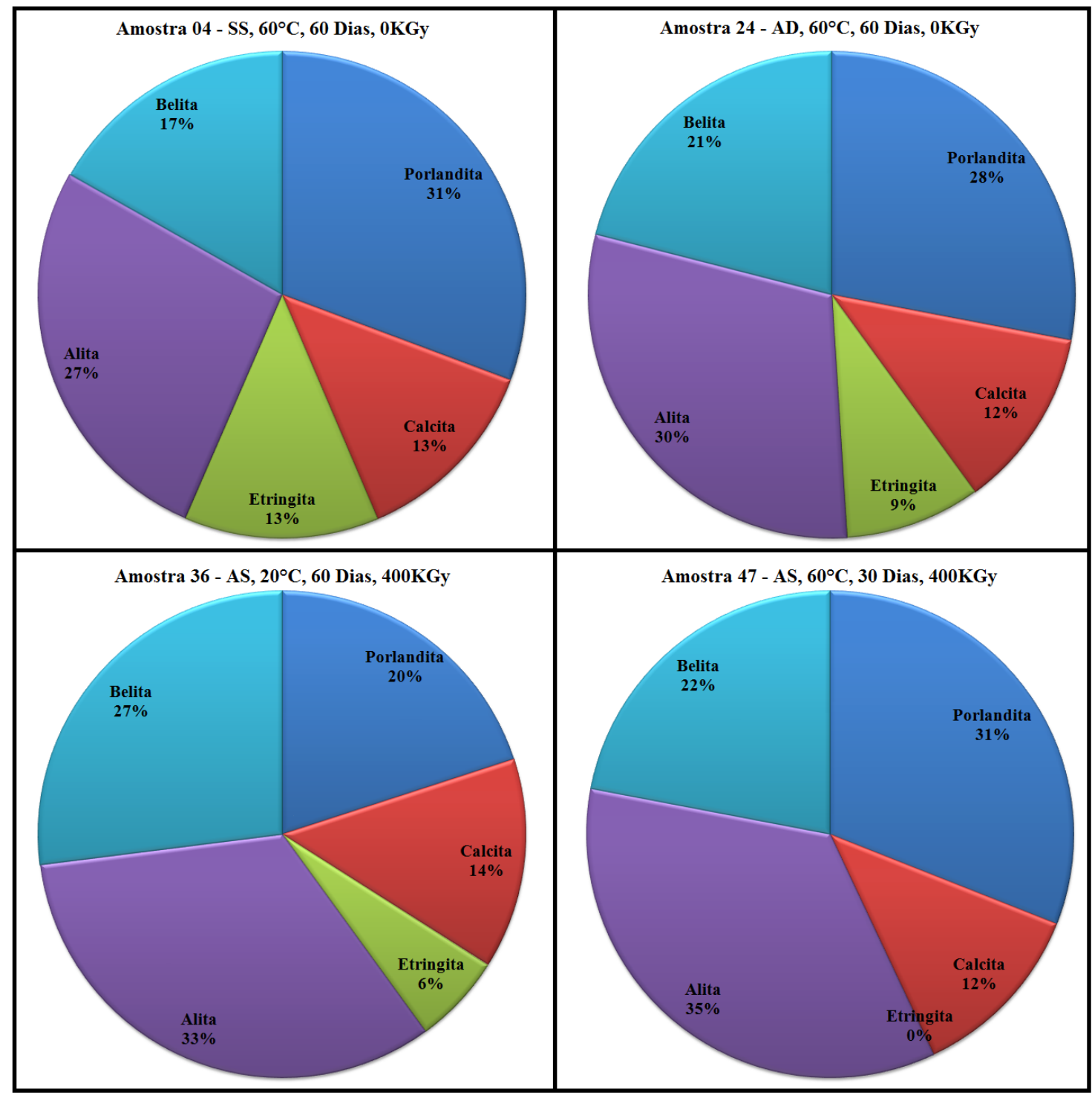

FIGURA 38 - Análise semiquantitativa de quatro amostras.

Pela análise por agrupamento, apresentada na FIG. 35, observa-se que a difração de raios $\mathrm{X}$ é capaz de diferenciar e separar as amostras imersas daquelas que ficaram armazenadas à seco. Além disso, as amostras imersas podem ser agrupadas entre aquelas armazenadas a $60^{\circ} \mathrm{C}$ e $20^{\circ} \mathrm{C}$. Dessa forma, é possível afirmar que os tratamentos citados alteram a mineralogia da pasta de cimento.

Analisando as FIG. 36-37, observa-se que as amostras armazenadas a seco em alta temperatura $\left(60^{\circ} \mathrm{C}\right)$ não apresentaram os picos característicos da etringita, ou seja, ela está ausente em sua composição mineralógica. A análise semiquantitativa confirmou a ausência nessas amostras. Observou-se também que os cps armazenados a seco apresentaram maior quantidade de alita e belita, compostos característicos do cimento anidro, sugerindo que a hidratação foi prejudicada nessas condições de ensaio. Por outro 
lado, os cps que ficaram sob imersão apresentaram maior grau de hidratação e menor quantidade desses produtos.

\subsection{Análise por microscopia eletrônica de varredura (MEV)}

A análise de microscopia eletrônica de varredura (MEV) foi realizada para analisar o material precipitado formado na superfície dos cps que ficaram em imersão. Na imagem obtida pela MEV (FIG. 39), verificaram-se alguns grãos e algumas agulhas. Na FIG. 40 é apresentada a análise de elementos químicos presentes na agulha e nos grãos da mesma amostra.

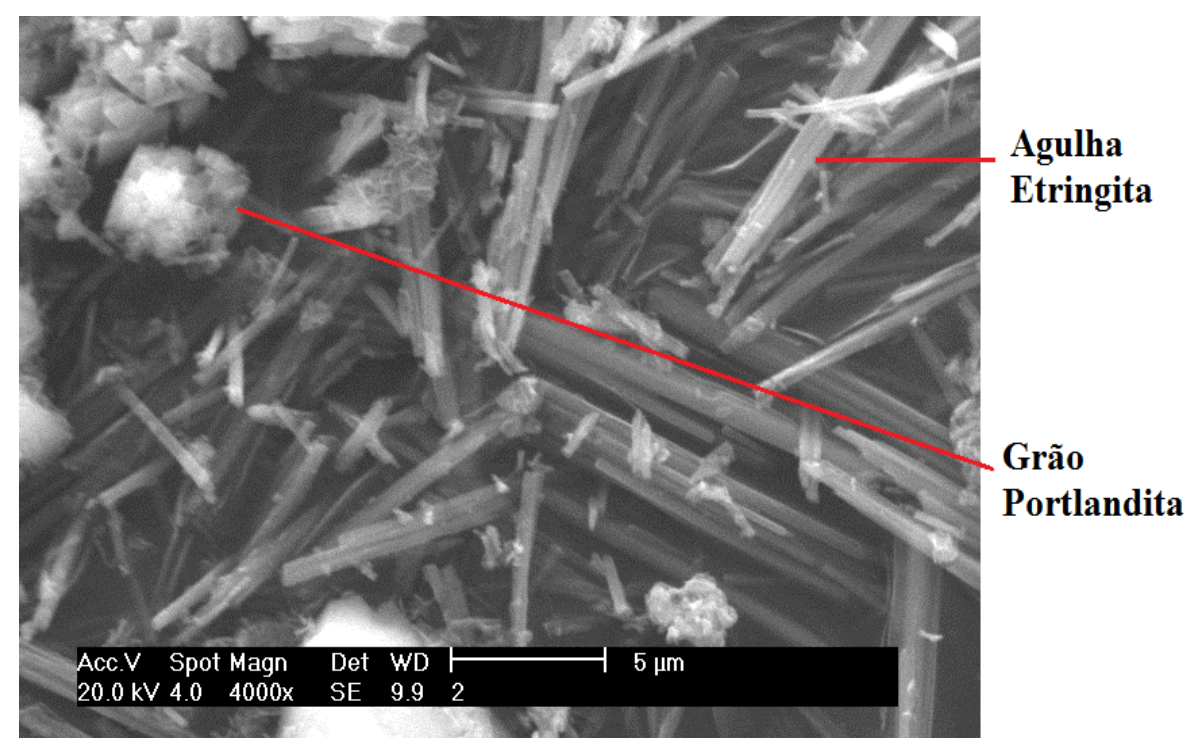

FIGURA 39 - Imagem obtida pela MEV do material precipitado na superfície dos cps.

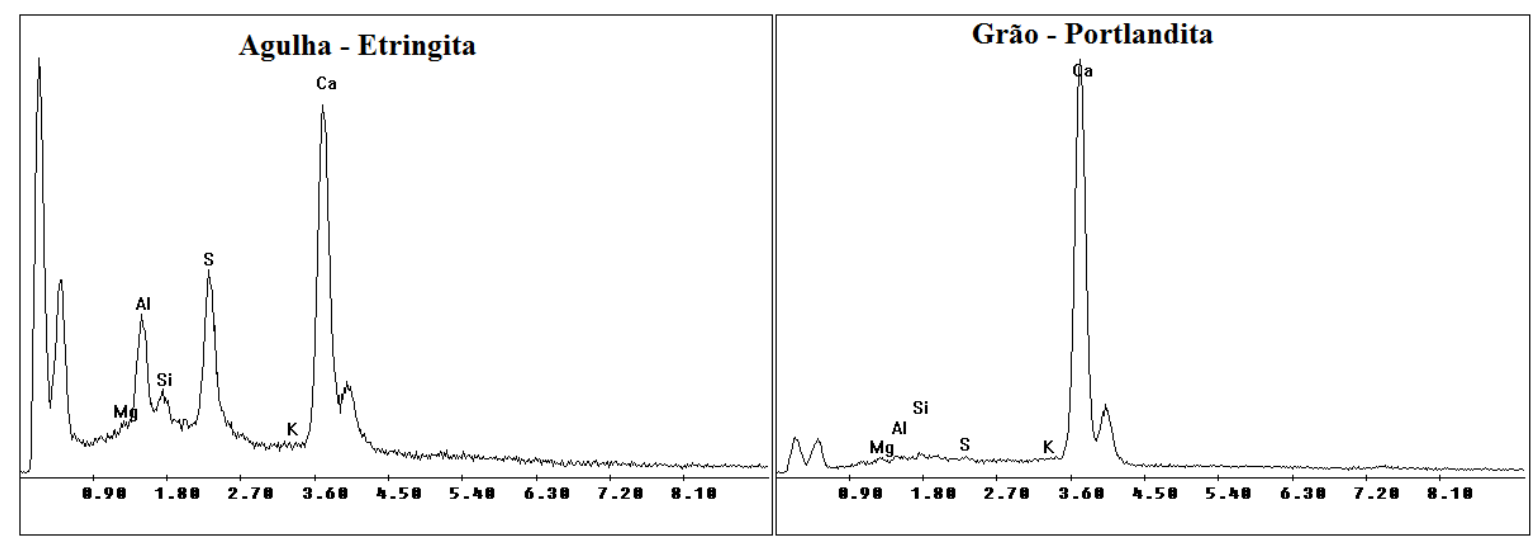

FIGURA 40 - Elementos presentes no grão e na agulha do material precipitado.

As agulhas foram identificadas como cristais de etringita, composto que tem como base os elementos cálcio, alumínio e enxofre. A etringita, formada durante a 
hidratação do cimento pela reação dos compostos presentes no clínquer do cimento com sulfato, é um composto expansivo e sua formação ainda nessa fase é benéfica à pasta de cimento, uma vez que ela preenche os vazios deixados durante a hidratação, aumentando sua resistência. Em idades avançadas, pode haver formação de etringita no material endurecido, causando rachaduras e fissuras.

Nos grãos, verifica-se a presença de cálcio e a ausência de qualquer outro elemento, sendo provável que sejam cristais de portlandita, ou hidróxido de cálcio $\left[\mathrm{Ca}(\mathrm{OH})_{2}\right]$. A formação de Portlandita também é uma etapa própria do processo de hidratação do cimento.

\subsection{Análise Termogravimétrica (TGA)}

Após o rompimento dos cps, foram retiradas amostras para análise de termogravimetria (TGA) no Centro Tecnológico da Marinha (CTM-SP). A identificação das amostras e a perda de massa de cada uma em razão da temperatura estão indicadas na TAB. 11. Todas ficaram em tratamento por 30 dias A FIG. 41 apresenta a análise por TGA da amostra número 6.

TABELA 11 - Identificação das amostras enviadas para TGA e perda de massa de cada uma nos intervalos de temperatura selecionados.

\begin{tabular}{|c|c|c|c|c|c|c|c|c|c|}
\hline \multirow{2}{*}{$\begin{array}{l}\mathrm{N}^{\circ} \\
\text { Amostra }\end{array}$} & \multirow[b]{2}{*}{ Meio } & \multirow[b]{2}{*}{ Temperatura } & \multirow{2}{*}{$\begin{array}{c}\text { Tempo de } \\
\text { imersão }\end{array}$} & \multirow[b]{2}{*}{ Irradiação } & \multicolumn{5}{|c|}{ Perda de massa (\%) } \\
\hline & & & & & $\begin{array}{l}25 \mathrm{a} \\
60^{\circ} \mathrm{C}\end{array}$ & $\begin{array}{l}60 \mathrm{a} \\
290^{\circ} \mathrm{C}\end{array}$ & $\begin{array}{l}290 \mathrm{a} \\
485^{\circ} \mathrm{C}\end{array}$ & $\begin{array}{l}485 \mathrm{a} \\
1000^{\circ} \mathrm{C}\end{array}$ & $\begin{array}{l}\text { Resíduo a } \\
1000^{\circ} \mathrm{C}\end{array}$ \\
\hline 1 & AS & $20^{\circ} \mathrm{C}$ & $30 \mathrm{D}$ & Não & 4,5 & 10,8 & 5,0 & 4,9 & 74,5 \\
\hline 2 & AS & $20^{\circ} \mathrm{C}$ & $30 \mathrm{D}$ & Sim & 4,4 & 11,0 & 4,8 & 5,1 & 74,6 \\
\hline 3 & AS & $60^{\circ} \mathrm{C}$ & $30 \mathrm{D}$ & Não & 3,2 & 8,6 & 5,1 & 4,1 & 79,0 \\
\hline 4 & AS & $60^{\circ} \mathrm{C}$ & $30 \mathrm{D}$ & Sim & 3,1 & 9,0 & 5,5 & 7,5 & 74,9 \\
\hline 5 & SS & $20^{\circ} \mathrm{C}$ & $30 \mathrm{D}$ & Não & 4,4 & 11,9 & 4,9 & 6,2 & 72,7 \\
\hline 6 & $\mathrm{AD}$ & $20^{\circ} \mathrm{C}$ & $30 \mathrm{D}$ & Não & 3,7 & 11,5 & 5,0 & 6,4 & 73,3 \\
\hline
\end{tabular}




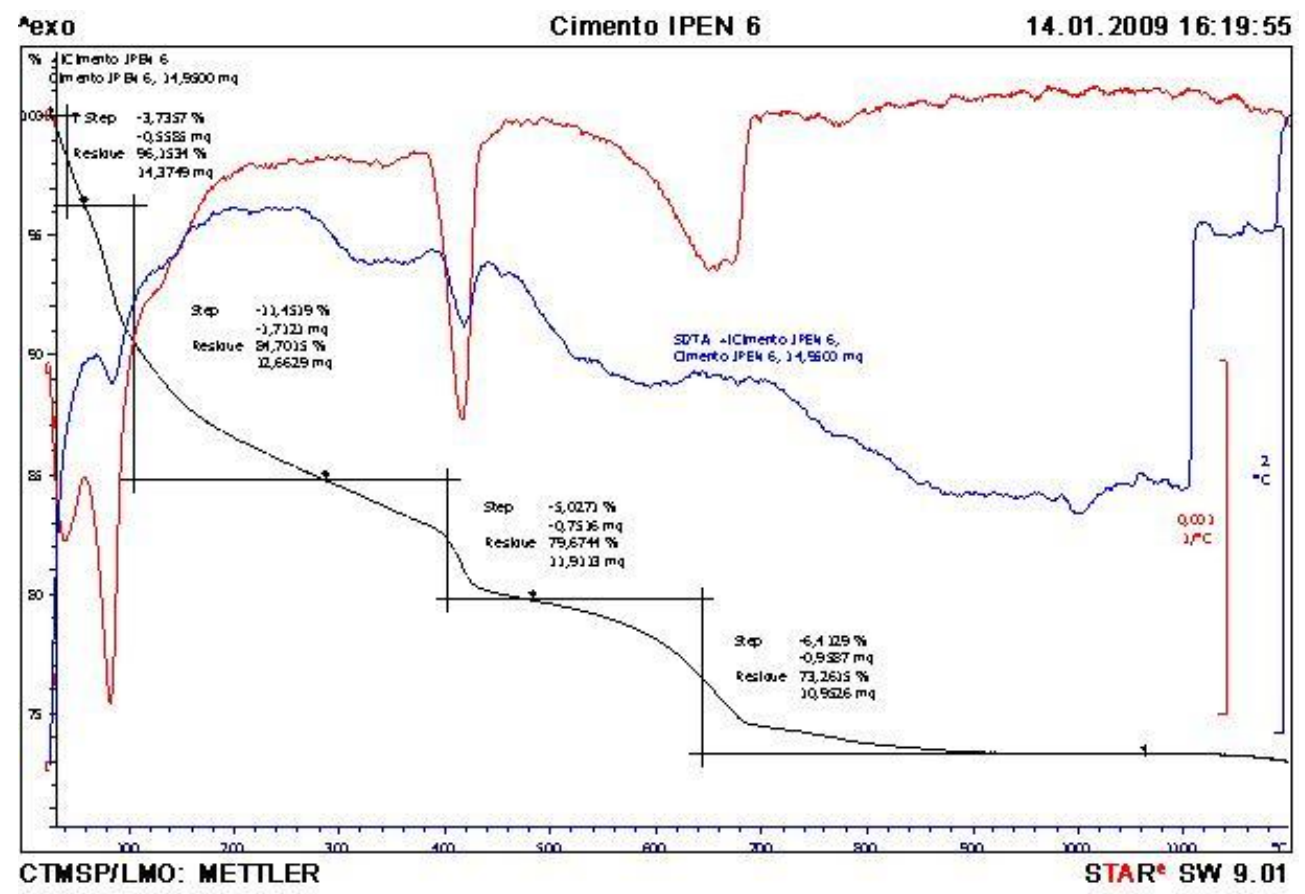

FIGURA 41 - Curva de TGA detalhada da amostra 6

$\mathrm{Na}$ TAB. 11, observou-se que os cps que ficaram armazenados a seco em alta temperatura apresentaram perda de massa entre $25-60^{\circ} \mathrm{C}$ e $60-290^{\circ} \mathrm{C}$ inferior as demais amostras. Nessas temperaturas, ocorre a perda de água livre da pasta de cimento e a perda de água de alguns compostos, como etringita. De acordo com Arlacon-Ruiz et al (2005), amostras que apresentam menor perda de massa indicam a falta de água livre na pasta e a ausência de etringita em sua microestrutura.

\subsection{Análise comparativa dos efeitos induzidos}

Os resultados obtidos neste trabalho permitiram algumas observações importantes sobre o comportamento da pasta de cimento após a exposição dos corpos de prova a cada tratamento. Algumas considerações sobre a influência dos tratamentos na hidratação e na mineralogia da pasta de cimento estão apresentadas neste tópico, observando cada parâmetro de exposição.

\subsubsection{Efeitos da imersão e do armazenamento à seco}

De acordo com a literatura, a resistência mecânica de cps submetidos à ação de espécies químicas agressivas, como sulfato e cloreto, deveria ser menor do que a resistência de cps armazenados a seco. No entanto, foi observado que a resistência mecânica dos cps cúbicos que ficaram em imersão (tanto em $\mathrm{AD}$ como em SS) foi maior 
do que a resistência daqueles armazenados a seco. Esse comportamento pode ser explicado pelo tempo de imersão dos cps. Lee et al (2005), em trabalho que observava a resistência de corpos de prova mantidos sob imersão e sob ataque de espécies químicas, comprovaram que cps mantidos em imersão por 28 dias, durante o processo de cura, apresentam resistência mecânica maior do que cps mantidos em cura por apenas 7 dias. Neste mesmo trabalho, após 90 dias de imersão, observou-se que a resistência mecânica diminui. Este comportamento foi atribuído à formação de etringita, que em idades iniciais de hidratação preenche os poros da pasta de cimento e aumenta sua resistência. Já a formação da etringita em idades avançadas de hidratação (etringita secundária) forma fissuras na pasta de cimento, diminuindo sua resistência. Esse comportamento foi comprovado por Torii et al (1994) e Al-Amoudi (1998). De fato, cps mantidos em imersão em solução salina apresentaram menor resistência do que cps imersos em água destilada. Outra possível causa para essa diminuição na resistência mecânica é a penetração de magnésio na pasta de cimento. Bénard et al (2008) atribui esse comportamento à presença de algumas espécies químicas na solução, que afeta o processo de hidratação por contaminação, adsorção ou precipitação dessas espécies.

A hidratação do cimento começa imediatamente após a adição de água. Neste trabalho, o cimento utilizado (CP V ARI) sofre hidratação rápida e seu tempo de pega é muito curto. Embora essa característica seja importante no conceito do repositório, o endurecimento rápido dos corpos de prova nos ensaios acelerados pode dificultar a hidratação completa dos grãos anidros do cimento. Após a cura, a hidratação do cimento não foi completa nos cps e esse processo reinicia quando eles são imersos, levando a aumento no grau de hidratação e, consequentemente, na resistência mecânica. Aziz et al (2005) observaram este comportamento em seu trabalho que investigou a relação entre o processo de hidratação e a durabilidade de corpos de prova, e concluíram que a resistência mecânica é maior em cps que foram mantidos por maior tempo em hidratação. Assim, os resultados da análise semiquantitativa na DRX confirmaram que os cps mantidos em imersão apresentaram menor quantidade de compostos do cimento anidro em sua composição do que aqueles mantidos à seco.

As alterações químicas na pasta de cimento induzidas pelo ataque de espécies químicas agressivas na solução de imersão foi avaliada por algumas técnicas analíticas. ICP-OES e cromatografia de íons mostraram as mudanças na concentração de cátions e ânions nas soluções de imersão em diferentes condições experimentais. Foi observada a lixiviação de $\mathrm{Na}^{+}$e $\mathrm{K}^{+}$da pasta de cimento para a solução e a penetração, na pasta, de $\mathrm{Ca}^{2+}$ 


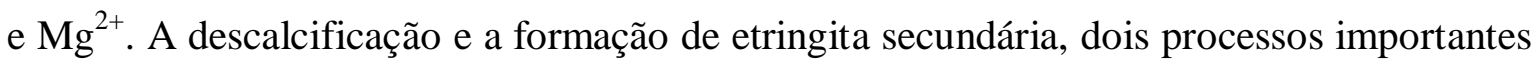
que levam a degradação da pasta de cimento, não foram notadas, uma vez que não foi possível observar, em quantidades significativas, lixiviação do íon $\mathrm{Ca}^{2+}$ nem a penetração do íon $\mathrm{SO}_{4}{ }^{2-}$ na pasta de cimento. Os fatores de imersão (concentração dos íons, tempo de exposição, temperatura etc) não foram capazes de induzir trocas dos íons citados entre a pasta de cimento e a solução. Marumo (1997) investigou a penetração de sulfato em corpos de prova de argamassas e pasta de cimento imersos em soluções com concentrações de $0,005 \mathrm{M}$ (equivalente à concentração utilizada neste trabalho) e $0,5 \mathrm{M}$ e não observou a penetração de quantidades significativas desse íon em suas amostras que ficaram imersas em baixa concentração, enquanto aquelas que ficaram em solução com altos níveis de sulfato apresentaram maior penetração e, consequentemente, maior degradação.

A análise por agrupamento na difração de raios $\mathrm{X}$ foi capaz de identificar as diferenças mineralógicas causadas pela exposição dos cps aos ambientes agressivos. Com exceção da etringita, essas alterações foram, no entanto, muito pequenas e não foi possível observá-las nos difratogramas. A análise de MEV permitiu observar compostos cristalinos formados na hidratação da pasta de cimento e produtos de reação com os íons dissolvidos na solução de imersão. Cristais de etringita foram claramente observados pela MEV e confirmados nos difratogramas na DRX.

A ausência de etringita nos cps que ficaram armazenados a seco em alta temperatura pode ser explicada pela decomposição desse composto. Embora a temperatura de decomposição da etringita seja por volta de $110-120^{\circ} \mathrm{C}$, ela pode se decompor para metaetringita, um composto amorfo, em ambientes com temperatura acima de $50^{\circ} \mathrm{C}$ e na ausência de água (Meller et al, 2009; Zhou and Glasser, 2001; Zhou et al, 2003).

Os corpos de prova que ficaram armazenados a seco apresentaram, ainda, uma perda de massa significativa, principalmente aqueles que ficaram em alta temperatura. Esse comportamento é esperado, uma vez que a perda de água é um processo natural nos cps quando armazenados a seco, enquanto aqueles que ficaram em imersão apresentam ganho de água e, portanto, de massa. A análise de TGA confirmou que os cps armazenados a seco continham menor quantidade de água nos poros.

\subsubsection{Efeitos da temperatura}

Embora se saiba que o aumento da temperatura causa danos à pasta de cimento em longo prazo, durante seu processo de cura esse aumento pode ser benéfico para a sua resistência (Ballester et al, 2009; Soroka, 1993). Neste trabalho, a temperatura provou ser 
um fator significante, alterando a resistência mecânica dos cps. Uma vez que o processo de hidratação é resultado de interações químicas entre os compostos presentes no cimento e a água, o aumento da temperatura pode acelerar a cinética da reação, resultando numa melhor hidratação e maior resistência mecânica.

Uma vez que a imersão dos cps pode ser considerada como uma continuidade ao processo de hidratação, como dito anteriormente, o aumento da temperatura causa um aumento na resistência mecânica dos cps de $113 \mathrm{MPa}$ (para os cps mantidos à $20^{\circ} \mathrm{C}$ ) para $121 \mathrm{MPa}$ ( para os cps mantidos à $60^{\circ} \mathrm{C}$ ).

A única alteração mineralógica associada à temperatura ocorreu nos cps armazenados a seco a $60^{\circ} \mathrm{C}$, que não apresentaram etringita em sua composição (ver seção 5.7.1).

\subsubsection{Efeitos da irradiação}

A presença de campo de radiação no ambiente do repositório pode levar à radiólise da água dos poros da pasta de cimento, dependendo do tipo de radiação, da dose no ambiente e da composição química da água dos poros. Os radicais formados durante o processo de radiólise pode reagir com compostos presentes na pasta de cimento e prejudicar a durabilidade do repositório.

No entanto, não foi possível observar a influência da irradiação na composição mineralógica dos cps neste trabalho quando analisadas individualmente ou sob possíveis efeitos sinergéticos com os demais tratamentos. A dose de irradiação adotada neste trabalho não foi capaz de induzir quaisquer alterações na pasta de cimento.

\subsubsection{Efeitos do tempo de exposição}

Os cps expostos por 30 ou 60 dias apresentaram diferenças apenas na variação de massa. A principal diferença ocorreu naqueles que ficaram armazenados a seco por 60 dias, que apresentaram perda de massa maior do que aqueles armazenados por apenas 30 dias. A perda de massa dos cps imersos em água destilada, por 60 dias a $60{ }^{\circ} \mathrm{C}$ pode ser atribuída à descalcificação, que é induzido pelo aumento da temperatura em idades mais avançadas.

O tempo de exposição, no entanto, não alterou a resistência mecânica dos cps, assim como sua mineralogia. Possivelmente o tempo de exposição indicado neste trabalho foi muito curto para apresentar alguma influência. 


\section{CONCLUSÕES}

A durabilidade da pasta de cimento foi investigada por meio de ensaios acelerados para se estabelecer o tempo de vida útil deste material em ambiente de repositório profundo tipo borehole. As informações obtidas permitiram avaliar e medir os efeitos dos fatores de degradação na pasta de cimento. Foi possível concluir que:

1. A imersão dos cps, tanto em AD como em SS, promoveu melhor hidratação e maior resistência mecânica aos mesmos. Em comparação com os cps imersos em AD, cps imersos em SS apresentaram resistência mecânica menor, indicando que espécies químicas agressivas presentes na SS degradaram a pasta de cimento. No entanto, as concentrações dos íons na solução de imersão (em SS), embora realistas, foram baixas para induzir danos mais sérios à pasta de cimento e a imersão teve papel mais importante ao melhorar a hidratação, o que aumentou a resistência mecânica da pasta;

2. A hidratação dos cps que ficaram armazenados a seco foi incompleta, comprovando a importância da imersão do processo de hidratação. Além disso, a alta temperatura no armazenamento a seco promoveu maior evaporação da água livre presente nos poros da pasta e levou ao processo de decomposição da etringita para metaetringita;

3. A temperatura mais alta no ensaio acelerou a cinética da hidratação e promoveu melhor hidratação e resistência mecânica maior;

4. A irradiação, nas doses aplicadas, não alterou a mineralogia dos cps;

5. O tempo de ensaio não influenciou a mineralogia da pasta de cimento e os resultados de resistência mecânica.

Foi observado que os parâmetros selecionados para este trabalho conseguiram induzir mudanças na mineralogia da pasta de cimento. Apesar disso, esses parâmetros não produziram danos nos corpos de prova e não alteraram de forma significativa sua resistência mecânica. A hidratação dos corpos de prova foi um importante fator, pois ela não se completou durante o processo de cura e continuou após a imersão dos cps, causando dificuldades na avaliação dos resultados. Essa hidratação prolongada se mostrou mais importante na resistência mecânica dos cps do que os danos causados pela imersão. Um período maior de imersão e/ou armazenamento e uma maior dose de irradiação devem ser aplicados para induzir alterações na mineralogia da pasta de cimento para se estabelecer a relação entre a intensidade da exposição e a durabilidade da pasta de cimento. Apesar dos 
avanços no tema obtidos neste trabalho, para garantir a segurança e a durabilidade do repositório serão necessários outros trabalhos para extrapolar os resultados em curto prazo obtidos em laboratório para as condições reais no repositório durante o tempo de vida útil do mesmo. 


\section{SUGESTÃO PARA TRABALHOS FUTUROS}

Para garantir segurança do repositório serão necessários outros ensaios acelerados. O processo de confecção dos corpos de prova deve ser melhorado, garantindo que sua cura seja completa antes do início do ensaio acelerado. $O$ uso de superplastificantes é o mais indicado nesse caso, pois não alteram a microestrutura do material (como no caso da adição de materiais suplementares) e permitem maior trabalhabilidade para a pasta. Dentre os parâmetros utilizados nos ensaios, o tempo de exposição deve ser prolongado, com corpos de prova expostos a seis meses ou um ano. A dose de irradiação deve ser maior do que a adotada nesse trabalho, com o intuito de prever os processos relacionados à radiólise e outras reações químicas que ocorrem no cimento. Para tal, se torna necessária a confecção de mais corpos de prova. 


\section{REFERÊNCIAS BIBLIOGRÁFICAS}

ABNT, ASSOCIAÇÃO BRASILEIRA DE NORMAS TÉCNICAS. Cimento Portland Composto - Especificação. Rio de Janeiro: ABNT, 1991a. (ABNT NBR 11578).

ABNT, ASSOCIAÇÃO BRASILEIRA DE NORMAS TÉCNICAS. Cimento Portland Comum - Especificação. Rio de Janeiro: ABNT, 1991b. (ABNT NBR 5732).

ABNT, ASSOCIAÇÃO BRASILEIRA DE NORMAS TÉCNICAS. Cimento Portland de Alta Resistência Inicial. Rio de Janeiro: ABNT, 1991c. (ABNT NBR 5733).

ABNT, ASSOCIAÇÃO BRASILEIRA DE NORMAS TÉCNICAS. Cimento Portland de Alto-Forno - Especificação. Rio de Janeiro: ABNT, 1991d. (ABNT NBR 5735).

ABNT, ASSOCIAÇÃO BRASILEIRA DE NORMAS TÉCNICAS. Cimento Portland Pozolânico - Especificação. Rio de Janeiro: ABNT, 1991e. (ABNT NBR 5736).

ABNT, ASSOCIAÇÃO BRASILEIRA DE NORMAS TÉCNICAS. Cimento Portland Resistente a Sulfatos - Especificação. Rio de Janeiro: ABNT, 1992. (ABNT NBR 5737).

ABNT, ASSOCIAÇÃO BRASILEIRA DE NORMAS TÉCNICAS. Cimento Portland de Baixo Calor de Hidratação - Especificação. Rio de Janeiro: ABNT, 1994. (ABNT NBR 13116).

ABNT, ASSOCIAÇÃO BRASILEIRA DE NORMAS TÉCNICAS. Cimento Portland - Determinação da resistência à compressão. Rio de Janeiro: ABNT, 1996. (ABNT NBR 7215)

ABNT, ASSOCIAÇÃO BRASILEIRA DE NORMAS TÉCNICAS. Concreto Procedimento para moldagem e cura de corpos-de-prova. Rio de Janeiro: ABNT, 2003 (ABNT NBR 5738).

ADAMOPOULOU, E.; PIPILIKAKI, P.; KATSIOTIS, M.S.; CHANIOTAKIS, M.; KATSIOTI, M. How sulfates and increased temperature affect delayed ettringite formation (DEF) in white cement mortars. Construction and Building Materials, v. 25, p. 3583-3590, 2011.

AL-AMOUDI, O.S.B. Sulfate attack and reinforcement corrosion in plain and blended cements exposed to sulfate environments. Building and Environment. v. 33, p. 53-61, 1998.

ALARCON-RUIZ, L.; PLATRET, G.; MASSIEU, E.; EHRLACHER, A. The use of thermal analysis in assessing the effect of temperature on a cement paste. Cement and Concrete Research. v. 35, p. 609-613, 2005. 
ANGUS, M. J.; CRUMPTOM, C.; MCHUGH, G.; MORETON, A. D.; ROBERTS, P. T.; Management and disposal of Disused Sealed Radioactive Sources in the European Union. United Kingdom: Safeguard International Ltd, 2000.

ANTONIASSI, J.L. a Difração de raios X com o método de Rietveld aplicada a bauxitas de Porto Trombetas, PA. Dissertaçao (Mestrado) - Escola Politécnica da Universidade de São Paulo, São Paulo, 2010.

ARCOS, D.; BRUNO, J.; KARNLAND, O. Geochemical model of the granitebentonite-groundwater interaction at Äspö HRL (LOT experiment). Applied Clay Science, v. 23, n 1-4, p. 219-228, 2003 (Clay Microstructure. Proceedings of a Workshop held in Lund, Sweden, 15-17 October 2002).

ASTM, American Society for Testing and Materials. Standard practice for developing accelerated tests to aid prediction of the service life of building components and materials. 1996 (ASTM E 632)

ASTM, AMERICAN SOCIETY FOR TESTING AND MATERIALS. Standard Specification for Blended Cement. 2009 (ASTM C595-09).

ASTM, AMERICAN SOCIETY FOR TESTING AND MATERIALS. Standard Specification for Portland Cement. 1986 (ASTM C150-86).

AZIZ, M.A.E., ALEEM, S.A.E.; HEIKAL, M.; DIDAMONY, H.E. Hydration and durability of sulphate-resisting and slag cement blends in Caron's Lake water. Cement and Concrete Research, v. 35, p. 1592-1600, 2005.

BALLESTER, P.; HIDALGO, A.; MÁRMOL, I.; MORALES, J.; SÁNCHEZ, L. Effect of brief heat-curing on microstructure and mechanical properties in fresh cement based mortars. Cement and Concrete Research. v. 39, p. 573-579, 2009.

BATTAGIN, A.F. Cimento Portland. In: ISAIA, G.C. Concreto - Ciência e Tecnologia.1 ed, São Paulo, IBRACON, 2011.

BÉNARD, P.; GARRAULT, S.; NONAT, A.; CAU-DIT-COUMES, C. Influence of orthophosphate ions on the dissolution of tricalcium silicate. Cement and Concrete Research. v. 38, p. 1137-1141, 2008.

BERNER, U.R. Evolution of pore water chemistry during degradation of cement in a radioactive waste repository environment. Waste Management, v. 12, p. 201-219, 1992.

BILESKY, P. P. Informação verbal.

BOUNIOL, P. The influence of iron on water radiolysis in cement-based materials. Journal of Nuclear Materials, v. 403, p. 167-183, 2010.

BOUNIOL, P; BJERGBAKKE, E. A comprehensive model to describe radiolytic processes in cement medium, Journal of Nuclear Materials, v. 372, p. 1 - 15, 2008. 
BULLARD, J.W.; JENNINGS, H.M.; LIVINGSTON, R.A.; NONAT, A.; SCHERER, G.W.; SCHWEITZER, J.S.; SCRIVENER, K.L.; THOMAS, J.J. Mechanisms of cement hydration. Cement and Concrete Research., v. 41 p. 1208-1223, 2011.

BUZZI, O.; BOULON, M.; HERVÉ, M.; SU, K. Leaching of rock-concrete interfaces. Rock Mechanics and Rock Engineering, v. 41 p. 445-466, 2008.

CALVO; J.L.G.; HIDALGO, A.; ALONSO, C.; LUCO L.F. Development of low-pH cementitious materials for HLRW repositories. Resistance against ground waters aggression. Cement and Concrete Research, v. 40, p. 1290-1297, 2010.

CEN, European Committee for standardization . Composition, specification and conformity criteria for common cements, Bruxells, 2000 (EN 197-1).

CENTURIONE, S. L. Influência das características das matérias-primas no processo de sinterização do clínquer Portland. Dissertação (Mestrado) - Universidade de São Paulo, USP, 1993

CNEN - COMISSÃO NACIONAL DE ENERGIA NUCLEAR. CNEN-NN-3.01 Diretrizes Básicas de Proteção, 2011.

CNEN - COMISSÃO NACIONAL DE ENERGIA NUCLEAR. CNEN-NE-6.05 Gerência de Rejeitos Radioativos em Instalações Radiativas, 1985.

CODINA, M.; CAU-DIT-COUMES, C.; LE BESCOP, P.; VERDIER, J.; OLLIVIER, J.P. Design and characterization of low-heat and low-alkalinity cements. Cement and Concrete Research, v. 38, p. 437-448, 2008

ÇOLAK, A.; ÇOSGUN, T.; BAKIRCI, A.E. Effects of environmental factors on the adhesion and durability characteristics of epoxy-bonded concrete prisms. Construction and Building Materials, v. 23, p. 758-767, 2009.

COLLEPARDI, M. A State-of-the-Art Review on Delayed Ettringite Attack on Concrete. Cement \& Concrete Composities, v. 25 p. 401-407, 2003.

COURTIER, R.H. The Assessment of ASR-Affected Structures. Cement \& Concrete Composities, v. 12 p.191-201, 1990.

DAYAL, R. Disposal options for disused radioactive sources. In: WASTE MANAGEMENT 04 CONFERENCE, Feb 29-Mar 04, 2004, Tucson, Az. Proceedings... Disponível em: < www.wms.org> Acesso em 15 abril 2012

DEBY, F.; CARCASSÈS, M.; SELLIER, A. Probabilistic approach for durability design of reinforced concrete in marine environment. Cement and Concrete Research, v. 39, p. 466-471, 2009.

DRACE, Z.; OJOVAN, M.I. The Behaviours of Cementitious Materials in Long Term Storage and Disposal: An Overview of Results of the IAEA Coordinated Research Project. Material Research Society, v. 1193, p. 663-672, 2009, MRS Proceedings 
DUNANT, C.F.; SCRIVENER, K.L.Effects of aggregate size on alkali-silica-reaction induced expansion. Cement and Concrete Research., 2012, doi:10.1016/j.cemconres.2012.02.012.

El-HACHEM, R.; ROZIERE, E.; GRONDIN, F.; LOUKILI, A. New procedure to investigate external sulphate attack on cementitious materials. Cement and Concrete Composities, v. 34, p. 357-364, 2012.

FERREIRA, E.G.A; GOBBO, L.; MARUMO, J.T.; VICENTE,R. XRD analysis of cement paste samples exposed to the simulated environment of a deep repository. In: WASTE MANAGEMENT 2012 CONFERENCE, Feb 26-Mar 01, 2012, Phoenix, Az. Proceedings...

GALÍNDEZ, J.M.; MOLINERO, J. Assessment of the long-term stability of cementitious barriers of radioactive waste repositories by using digital-image-based microstructure generation and reactive transport modeling. Cement and Concrete Research, v. 40, p. 1278-1289, 2010.

GRAPHPAD QUICKCALCS: calculadora online para cientistas. Análise de teste t de Student. GraphPad Software Disponível em:

http://www.graphpad.com/quickcalcs/ttest1/ Acessado em jul. 2012

GRIMM, J.P. Excess and unwanted radioactive sealed source disposition by the U.S. Department of Energy offsite source recovery program. In: WASTE MANAGEMENT 04 CONFERENCE, Feb 29-Mar 04, 2004, Tucson, Az. Proceedings... Disponível em: < www.wms.org> Acesso em 15 abril 2012

HIROMOTO, G.; DELLAMANO, J.C.; MARUMO, J.T.; ENDO, L.S.; VICENTE, R.; HIRAYAMA, T. Introdução à gerência de rejeitos radioativos. Instituto de Pesquisas Energéticas e Nucleares -Departamento de Rejeitos Radioativos, São Paulo, 1999.

IAEA - International Atomic Energy Agency. Behaviors of Cementitous Materials in Long Term Storage and Disposal - Coordinated Research Project. IAEA. (unpublished draft). 2006

KATSIOTI, M.; PATSIKAS, N.; PIPILIKAKI, P.; KATSIOTIS, N.; MIKEDI, K.; CHANIOTAKIS, M. Delayed ettringite formation (DEF) in mortars of white cement. Construction and Building Materials, v. 25, p. 900-905, 2011.

LÉCOLIER, E.; RIVEREAU, A.; LE SAOÛT, G.; AUDIBERT-HAYET, A. Durability of Hardened Portland Cement Paste used for Oilwell Cementing. Oil \& Gas Science and Technology, v. 62, p. 335-345, 2007.

LEE, J.J.; ARNOLD, B.W.; SWIFT, P.N.; HADGU, T. A Prototype Performance Assessment Model for Generic Deep Borehole Repository for High-Level Nuclear Waste. In: WASTE MANAGEMENT 2012 CONFERENCE, Feb 26-Mar 01, 2012, Phoenix, Az. Proceedings...

LEE, S.T.; MOON, H.Y.; SWAMY, R.N. Sulfate attack and role of silica fume in resisting strength loss. Cement \& Concrete Composities, v. 27, p. 65-76, 2005. 
LEINZ, V. Geologia Geral. 1 ed, Companhia Editora Nacional, São Paulo, 1998.

LOTHENBACH, B.; BARY, B.; LE BESCOP, P.; SCHMIDT, T.; LETERRIER, N. Sulfate ingress in Portland cement. Cement and Concrete Research, v. 40, p. 12111225,2010

MARUMO, J.T. Difusão de cloreto e ataque por sulfatos em pastas e argamassas de cimento Portland. Dissertação (Mestrado) - Instituto de Pesquisas Energéticas e Nucleares, São Paulo, 1997.

\section{MARUMO, J.T. Informação verbal.}

MATSCHEI, T.; GLASSER, F.P.; Temperature dependence, 0 to $40{ }^{\circ} \mathrm{C}$, of the mineralogy of Portland cement paste in the presence of calcium carbonate. Cement and Concrete Research, v. 40, p. 763-777, 2010.

McFEE, J.N.; LANGSTED, J.M.; YOUNG, M.E.; DAY, J.E. Evaluation of Terrorist Interest in Radioactive Waste. In: WASTE MANAGEMENT 06 CONFERENCE, Feb 26-Mar 02, 2006, Tucson, Az. Proceedings... Disponível em: < www.wms.org> Acesso em 15 abril 2012

MEHTA, P.K., MONTEIRO, P.J.M. Concreto: Microestrutura, Propriedades e Materiais, 1 ed., Ibracon, São Paulo, 2008.

MELLER, N.; KYRITSIS, K.; HALL, C. The hydrothermal decomposition of calcium monosulfoaluminate 14-hydrate to katoite hydrogarnet and $\beta$-anhydrite: An in-situ synchrotron X-ray diffraction study. Journal of Solid State Chemistry. v. 182, p. 2743-2747, 2009

MISSANA, T.; ALONSO, U.; TURRERO, M.J. Generation and stability of bentonite colloids at the bentonite/granite interface of a deep geological radioactive waste repository. Journal of Contaminant Hydrology, v. 61, n 1-4, p. 17-31, 2003.

MONTANHEIRO, T.J., Proposta de pré - qualificação pozolânica de materiais geológicos : Difratometria de raios- $\mathrm{x}$ como método alternativo, Revista do Instituto Geológico, v. 24, p. 1-9, 2003.

MULTON, S.; CYR, M.; SELLIER, A.; DIEDERICH, P.; PETIT, L.; Effects of aggregate size and alkali content on ASR expansion. Cement and Concrete Research., v. 40 p. $508-516,2010$.

NEVILLE, A.M.; BROOKS, J.J. Concrete Technology, 2 ed., Prentice Hall, Malaysia, 2010.

OJOVAN, M.I.; DMITRIEV, S.A.; SOBOLEV, L.A. Long-term safe storage and disposal of spent sealed radioactive sources in borehole type repositories. In: WASTE MANAGEMENT 03 CONFERENCE, Feb 23-27, 2003, Tucson, Az. Proceedings... Disponível em: < www.wms.org> Acesso em 15 abril 2012

OROZCO, J.; BALDI, A.; MARTÍN, P.L.; BRATOV, A.; JIMÉNEZ, C. Monitoring of bentonite pore water with a probe based on solid-state microsensors. Analytica

Chimica Acta, v. 579, n. 1, p.95-101, 2006. 
PHILIPOSE, K.E. 500 year concrete for a radioactive waste repository. WASTE MANAGEMENT 88 CONFERENCE, Feb 28 - Mar -03, 1988, Tucson, Az.

Proceedings... Disponível em: < www.wms.org> Acesso em 15 abril 2012

QUENNOZ, A.; GALUCCI, E.; SCRIVENER, K.L. Calcium silicate - calcium aluminate interactions and their influence on cement early hydration. In: XIII ICCC INTERNATIONAL CONGRESS ON THE CHEMISTRY OF CEMENT, Jul 03 - 08, 2011, Madri. Proceedings...

REIS, L.C.A.; HEILBRON FILHO, F.L.; Reutilization and conditioning of spent sealed sources from nuclear gauges. In: WASTE MANAGEMENT 00 CONFERENCE, Feb 27 - Mar -02, 2000, Tucson, Az. Proceedings... Disponível em: $<$ www.wms.org> Acesso em 15 abril 2012

ROMIJN, E. Groundwater quality and contamination. Em: ZAPOROZEC, A. Groundwater contamination inventory - A methodological Guide. UNESCO, 2002. p. 17-21. Disponível em <http://www.bvsde.paho.org/bvsacd/cd29/inventory/cap2-4.pdf>

SCRIVENER, K.L.; FULLMANN, T.; GALLUCCI, E.; WALENTA, G.; BERMEJO E. Quantitative study of Portland cement hydration by X-ray diffraction/Rietveld analysis and independent methods. Cement and Concrete Research, v. 34, p.15411547, 2004.

SCRIVENER, K.L.; KIRKPATRICK, R.J. Innovation in use and research on cementitious material. Cement and Concrete Research., v. 38 p. 128-136, 2008.

SCRIVENER, K.L.; NONAT, A. Hydration of cementitious materials, present and future. Cement and Concrete Research, v. 41, p. 651-665, 2011.

SKALNY, J.; MARCHAND, J.; ODLER, I. Sulfate Attack on Concrete, 1 ed., E \& FN Spon, London, 2002.

SOROKA, I. Concrete in Hot Environments, 1 ed., E \& FN Spon, London, 1993.

TAYLOR, H.F.W.; FAMY, C.; SCRIVENER, K.L. Delayed ettringite formation. Cement and Concrete Research, v. 31, p. 683-693, 2001

TOLEDO, M. C. M. Publicação eletrônica (mensagem pessoal). Mensagem recebida por<rvicente@ipen.br>.

TORII, K.; TANIGUCHI. K.; KAWAMURA, M. Sulfate resisance of high fly ash content concrete. Cement and Concrete Research. v. 25, p. 759-768, 1995.

US-EPA: UNITED STATES ENVIRONMENTAL PROTECTION AGENCY: Cementing Requirements for Class I Injection Wells. 1988

VAN BREUGEL, K. Modelling of cement-based systems - the alchemy of cement chemistry. Cement and Concrete Research., v. 34 p. 1661-1668, 2004. 
VICENTE, R. Disposal of disused sealed Radiation Sources in Borehole. In: WASTE MANAGEMENT 07 CONFERENCE, Feb 25 - Mar -01, 2007a, Tucson, Az. Proceedings... Disponível em: < www.wms.org> Acesso em 15 abril 2012

VICENTE, R. Gestão de fontes radioativas seladas descartadas. 2002. Tese (Doutorado) - Instituto de Pesquisas Energéticas e Nucleares, São Paulo.

VICENTE, R. Qualitative Performance Assessment of a Borehole Disposal System. In: WASTE MANAGEMENT 07 CONFERENCE, Feb 25 - Mar -01, 2007b, Tucson, Az. Proceedings... Disponível em: < www.wms.org> Acesso em 15 abril 2012

VICENTE, R.; MATUMO, J. T.; MIYAMOTO, H.; HIGA, L. H.; GOBBO, L.; TOLEDO, M. C. M.; ISIKI, V. L. K.; FERREIRA, E. G. A. Progress Report Assessment of the durability of cementitious materials in repository environment. Mai, 2008.

VICENTE, R.; SORDI, G.M.; HIROMOTO, G. Management of spent sealed radiation sources. Health Physics, v. 86, p. 497-504, 2004.

VICHOT, A.; OLLIVIER, J.P. La durabilité des bétons. In:

NONAT, A. L'hydratation des ciments. 2 ed., Paris, Presses de l'école nationale des Ponts et Chaussées, 2008.

XIE, S.Y.; SHAO, J.F.; BURLION, N. Experimental study of mechanical behaviour of cement paste under compressive stress and chemical degradation. Cement and Concrete Research, v. 38, p. 1416-1423, 2008.

XU, Y.; WONG, Y.L.; POON, C.S.; ANSON, M. Influence of PFA on cracking of concrete and cement paste after exposure to high temperatures. Cement and Concrete Research, v. 33, p. 2009-2013, 2003

ZHOU Q.; GLASSER, F.P. Thermal stability and decomposition mechanisms of ettringite at $<120^{\circ}$ C. Cement and Concrete Research. v. 31, p. 1333-1339, 2001.

ZHOU Q.; LACHOWSKI, E.E.; GLASSER, F.P.;. Metaettringite, a decomposition product of ettringite. Cement and Concrete Research. v. 34, p. 703-710, 2003. 